UNIVERSIDADE DE BRASÍLIA

FACULDADE DE TECNOLOGIA

DEPARTAMENTO DE ENGENHARIA CIVIL E AMBIENTAL

\title{
REATOR BIOLÓGICO COM MEMBRANA (MBR) APLICADO AO TRATAMENTO DE ESGOTOS GERADOS POR UNIDADES RESIDENCIAIS UNIFAMILIARES
}

ANNE RELVAS PEREIRA

ORIENTADOR: MARCO ANTONIO ALMEIDA DE SOUZA

DISSERTAÇÃO DE MESTRADO EM TECNOLOGIA AMBIENTAL E RECURSOS HÍDRICOS

PUBLICAÇÃO: PTARH.DM - 190/16

BRASÍLIA/DF: SETEMBRO - 2016 
UNIVERSIDADE DE BRASÍLIA

FACULDADE DE TECNOLOGIA

DEPARTAMENTO DE ENGENHARIA CIVIL E AMBIENTAL

REATOR BIOLÓGICO COM MEMBRANA (MBR) APLICADO AO

TRATAMENTO DE ESGOTOS GERADOS POR UNIDADES

RESIDENCIAIS UNIFAMILIARES

ANNE RELVAS PEREIRA

DISSERTAÇÃO SUBMETIDA AO DEPARTAMENTO DE ENGENHARIA CIVIL E AMBIENTAL DA FACULDADE DE TECNOLOGIA DA UNIVERSIDADE DE BRASÍLIA COMO PARTE DOS REQUISITOS NECESSÁRIOS PARA A OBTENÇÃO DO GRAU DE MESTRE EM TECNOLOGIA AMBIENTAL E RECURSOS HÍDRICOS.

APROVADA POR:

Prof. Marco Antonio Almeida de Souza, Ph.D (ENC-UnB) (Orientador)

Prof ${ }^{\text {a }}$ Conceição de Maria Alves, Ph.D (ENC-UnB)

(Examinador Interno)

Prof. Welitom Ttatom Pereira da Silva, Dr (DESA-UFMT) (Examinador Externo)

BRASÍLIA/DF, 29 DE SETEMBRO DE 2016 


\section{FICHA CATALOGRÁFICA}

\begin{tabular}{|l} 
PEREIRA, ANNE RELVAS \\
Reator biológico com membrana (MBR) aplicado ao tratamento de esgotos gerados por \\
unidades residenciais unifamiliares. [Distrito Federal] 2016. xvi, 113p., 210x297 \\
mm (ENC/FT/UnB, Mestre, Tecnologia Ambiental e Recursos Hídricos, 2016). \\
Dissertação de Mestrado - Universidade de Brasília. Faculdade de Tecnologia. \\
Departamento de Engenharia Civil e Ambiental. \\
$\begin{array}{ll}\text { 1.Reator biológico com membrana } & \text { 2.Tratamento de esgoto unifamiliar } \\
\text { 3.Análise de decisão multicritério e multiobjetivo } & \text { 4. Avaliação tecnológica } \\
\text { I. ENC/FT/UnB } & \text { II. Título (série) }\end{array}$
\end{tabular}

\section{REFERÊNCIA BIBLIOGRÁFICA}

PEREIRA, A. R. (2016). Reator biológico com membrana (MBR) aplicado ao tratamento de esgotos gerados por unidades residenciais unifamiliares. Dissertação de Mestrado em Tecnologia Ambiental e Recursos Hídricos, Publicação PTARH.DM - 190/2016, Departamento de Engenharia Civil e Ambiental, Universidade de Brasília, Brasília, DF, $164 p$.

\section{CESSÃO DE DIREITOS}

AUTOR: Anne Relvas Pereira.

TÍTULO: Reator biológico com membrana (MBR) aplicado ao tratamento de esgotos gerados por unidades residenciais unifamiliares.

GRAU: Mestre ANO: 2016

É concedida à Universidade de Brasília permissão para reproduzir cópias desta dissertação de mestrado e para emprestar ou vender tais cópias somente para propósitos acadêmicos e científicos. $\mathrm{O}$ autor reserva outros direitos de publicação e nenhuma parte desta dissertação de mestrado pode ser reproduzida sem autorização por escrito do autor.

Anne Relvas Pereira

Campus Universitário Darcy Ribeiro Universidade de Brasília - UnB, SG-12 - Térreo

CEP: 70.910-900, Brasília - DF, Brasil 
Dedico este trabalho a toda minha família, principalmente aos meus pais, Álvaro Pereira e Maria José S. Relvas Pereira, maiores exemplos de vida, pelo amor e dedicação. Minha profunda admiração. Por trilhar os caminhos ensinados por vocês, cheguei até aqui. 
"Todos podemos colaborar, como instrumentos de Deus, no cuidado da criação, cada um a partir da sua cultura, experiência, iniciativas e capacidades"

(Papa Francisco, Laudato si, 2015:14) 


\section{AGRADECIMENTOS}

Em todo percurso desta jornada sempre nos deparamos com pessoas que nos fortificam com auxílio, incentivo e amizade. Não poderia deixar de expressar minha gratidão.

Agradeço primeiramente a Deus, por sempre me amparar e estar presente em todos os momentos de desafios, conquistas e alegrias.

Aos meus pais, Álvaro Pereira e Maria José, simplesmente por tudo. Pelo apoio e pela certeza de que este dia chegaria, seus ensinamentos e valores transmitidos são a minha maior força.

Aos meus irmãos Antonieta, Aline, Álvaro, Alexandro e Adilson por completarem minha vida e por dedicarem apoio, confiança e amizade mesmo longe.

À família que me acolheu em minha chegada à Brasília com toda atenção, carinho e cuidado, Conceição, Airton, Arthur, Gabriel e Gilson.

Ao meu orientador, Professor Marco Antonio Almeida de Souza, pela acolhida, orientação no trabalho, paciência, apoio e incentivo. Seus ensinamentos foram fundamentais e serão guardados com muita estima. Por ser uma pessoa admirável e se mostrar um excelente profissional e por auxiliar nas decisões.

Aos professores Yovanka, Oscar, Lenora, Ricardo, Ariuska, Conceição, Dirceu e Sérgio Koide pelos ensinamentos no decorrer desta caminhada. Aos funcionários Adelias, Érica e Daniela.

Aos amigos que sempre estavam por perto dando forças e que levarei para a vida, Adriane Dias, Andreia de Almeida, Thallyta Manuela, Nielde Prado, Daniel Valencia, Gilliard Nunes, Patrícia Bonolo, Renei Rocha, Norma Mendes e Marília Almeida. Obrigada por todos os momentos compartilhados e por estarem presente nos momentos mais difíceis. 
Aos amigos que mesmo com a distância sempre me apoiaram e tiveram presentes, Laura Júlia, Tallyne Peres, Joseney Malta, Klenna Lívia, Heloíse Medeiros e Marcelo Dayron.

Á todos que contribuíram no delinear desse caminho com sua amizade e companheirismo, em especial aos meus amigos do Emaús, pelas orações e incentivos, Manu, Priscila, Amanda, Samantha, Luma, Malu, Eduardo, Dani, Pedro, Vânia, Marcelo e Vavá.

Aos colegas do PTARH e da UnB pelos momentos compartilhados.

Ao Conselho Nacional de Desenvolvimento científico e Tecnológico - CNPq e a Fundação de Amparo à Pesquisa do Amazonas - FAPEAM pela ajuda financeira por meio de bolsa de estudos, indispensável para que eu pudesse me dedicar ao projeto.

A todos que ajudaram, de qualquer forma, mas não foram citados aqui. Muito Obrigada! 


\section{RESUMO}

A escolha da tecnologia apropriada para o tratamento de esgoto doméstico tem sido uma preocupação crescente devido ao interesse em proporcionar um efluente de melhor qualidade, tanto para manutenção da qualidade ambiental como para produzir água para reúso. O objetivo desta pesquisa foi o de avaliar a aplicabilidade do processo de Reator Biológico com Membrana (MBR) a sistemas provenientes de unidades residenciais unifamiliares de esgotos no Brasil e as condições em que esse processo seria recomendado. Por isso, propôs-se um sistema MBR adaptado às condições existentes nos sistemas de esgotos sanitários provenientes de unidades residenciais unifamiliares. Em seguida, para avaliar o sistema MBR proposto, foi desenvolvida uma metodologia simplificada de avaliação tecnológica de processos de tratamento de esgotos unifamiliares com uma abordagem de análise de decisão multiobjetivo e multicritério, por meio da utilização dos métodos ELECTRE III e TOPSIS. Essa metodologia foi utilizada para realizar a avaliação tecnológica dos seguintes processos e operações unitárias: (A1) Tanque séptico; (A2) Tanque séptico seguido de filtro anaeróbio; (A3) Tanque séptico seguido de Wetlands; (A4) UASB seguido por biofiltro aerado submerso; (A5) Reator UASB acompanhado por lodo ativado convencional; e (A6) Tanque séptico acompanhado por reator biológico com membrana. Esses processos foram avaliados em três cenários brasileiros: (1) Nível do lençol freático baixo e com alta permeabilidade e com risco epidemiológico e ambiental pequeno; (2) Nível do lençol freático alto e/ou com capacidade de infiltração baixa com risco epidemiológico e ambiental grande; e (3) Realização de reúso direto não potável da água em área urbana e rural. Foram estabelecidos dez critérios, subdividindo-os em quatro dimensões da Tecnologia: técnica, econômica, ambiental e social. Uma das conclusões do emprego da metodologia de análise tecnológica foi que, embora a tecnologia MBR ainda seja muito cara devido a sua complexidade e por ainda estar em fase de desenvolvimento no Brasil, ela se mostrou adequada para ser instalada em locais que sofrem com a escassez hídrica e necessitam de utilizar o efluente tratado de esgoto sanitário. Evidenciou-se que os altos custos de implantação e manutenção da tecnologia MBR influenciaram na análise tecnológica realizada. Porém, quando se tratou da possibilidade de se realizar o reúso de água, a análise demonstrou que somente o sistema MBR tem condições de atender aos critérios exigidos pelas normas e legislação vigentes. 


\section{ABSTRACT}

The choice of appropriate technology for the treatment of sewage has been a growing concern due to the interest in providing a better quality effluent, both for environmental quality maintenance as to produce water for reuse. The objective of this research was to evaluate the applicability of the membrane biological reactor (MBR) process for treating sewage from single-family households in Brazil and the conditions under which this process would be recommended. Therefore, an MBR system adapted to these conditions prevailing in sewage systems from single-family households was proposed. Then, to evaluate the MBR system proposed, a simplified method for technology assessment of decentralized sewage treatment processes was developed, having a multiobjective and multi-criteria decision analysis approach by using ELECTRE III and TOPSIS methods. This methodology was used to evaluate the following technological processes and unit operations: (A1) septic tank; (A2) septic tank followed by anaerobic filter; (A3) septic tank followed by Wetlands; (A4) UASB reactor followed by submerged aerated biofilter; (A5) UASB reactor accompanied by conventional activated sludge; and (A6) septic tank accompanied by membrane bioreactor MBR. These processes were evaluated in three Brazilian scenarios: (1) Low water table level and soil with high permeability and small epidemiological and environmental risk; (2) The level of the water table high and/or low soil infiltration capacity with great epidemiological and environmental risk; and (3) nonpotable direct water reuse in urban and rural areas. Ten criteria were established, subdividing them into four technological dimensions: technical, economic, environmental and social. One of the conclusions of the use of technology analysis methodology was that although the MBR technology is still very expensive, due to its complexity, and to be still under development in Brazil, it was adequate to be installed in places that suffer from water scarcity and that need to use effluent from sewage treatment. It was evident that the high implementation and maintenance costs of the MBR technology influenced the technological analysis. However, when considering the possibility of performing water reuse, the analysis showed that the MBR is the only alternative able to meet the criteria required by actual standards and law. 


\section{SUMÁRIO}

1 - INTRODUÇÃO ......................................................................................................................................

2 - OBJETIVOS .......................................................................................................................

2.1 - GERAL .............................................................................................................................

2.2 - ESPECÍFICOS ..........................................................................................4

3 - FUNDAMENTAÇÃO TÉORICA E REVISÃO BIBLIOGRÁFICA................................5

3.1 - SISTEMAS DE TRATAMENTO DE ESGOTO..........................................................5

3.1.1 - Sistema descentralizado de tratamento de esgoto ................................................ 7

3.1.2 - Tecnologias de tratamento de esgoto no Brasil...................................................10

3.1.3 - Reúso de água e legislação vigente .........................................................................11

3.2 - REATOR BIOLÓGICO COM MEMBRANA (MBR) ..............................................14

3.2.1 - Exemplos de aplicação de MBR ...........................................................................21

3.2.2 - Configurações das aplicações de sistemas MBR descentralizados ...............24 3.3 - MÉTOdOS MULTIOBJETIVO E MULTICRITÉRIO DE APOIO À

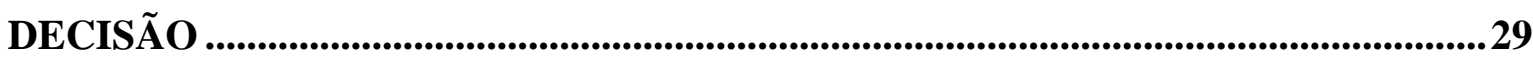

3.3.1 - Emprego dos métodos multiobjetivo e multicritério.........................................30

3.3.2 - Aplicação e desenvolvimento do TOPSIS ..........................................................33

3.3.3 - Aplicação e desenvolvimento do ELECTRE-III................................................34

3.4 - AVALIAÇÃO TECNOLÓGICA .................................................................................37

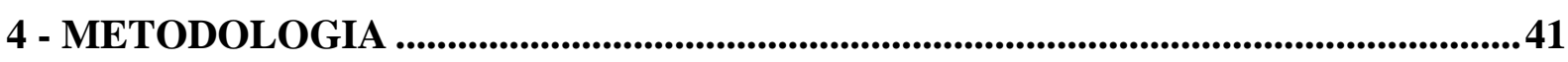

4.1 - FASE 1 - CONCEPÇÃO DO SISTEMA MBR PARA RESIDÊNCIAS UNIFAMILIARES............................................................................................41

4.2 - FASE 2 - ANÁlISE TECNOLÓGICA DO SISTEMA MBR DESENVOLVIDO ........................................................................................................................ 42

4.2.1 - Levantamento de informações ............................................................................... 45

4.2.2 - Definição dos objetivos, critérios e pesos..............................................................45

4.2.3 - Criação de cenários ...............................................................................................48

4.2.4 - Definição do método de avaliação de alternativas segundo cada critério .. 48

4.2.5 - Análise tecnológica e postulação da pay-off matrix para "n" cenário .........49

4.2.6 - Aplicação do método multiobjetivo e avaliação da solução.............................49

5 - RESULTADOS E DISCUSSÃO ..................................................................................51

5.1 - FASE 1 - CONCEPÇÃo DO SISTEMA MBR PARA RESIDÊNCIAS

UNIFAMILIARES.......................................................................................................................51 
5.1.1 - Análise dos sistemas existentes

5.1.2 - Análise para seleção do tipo de membrana a ser utilizada em função da necessidade local potencial .....................................................................................55

5.1.3 - Análise do sistema de pré-tratamento ao MBR ........................................58

5.1.4 - Análise para seleção do tipo de reator de membrana a ser utilizado ......... 62

5.1.5 - Proposta do fluxograma do sistema MBR e arranjo físico do sistema ....... 64

5.1.6 - Seleção dos parâmetros e equações de dimensionamento de todo o

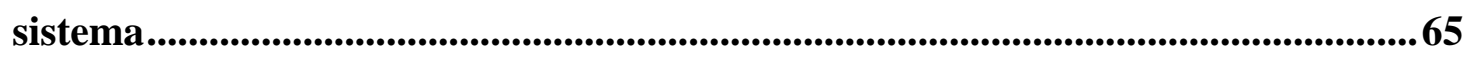

5.1.7 - Dimensionamento e configuração do sistema proposto ..............................66 5.2 - FASE 2 - ANÁLISE TECNOLÓGICA DE SISTEMAS DE TRATAMENTO DE ÁGUA RESIDUÁRIA UNIFAMILIAR ............................................................................ 68

5.2.1 - Levantamento de informações e base de dados .............................................68

5.2.2 - Definição dos Critérios e Pesos............................................................................. 70

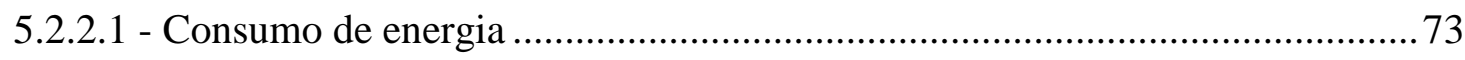

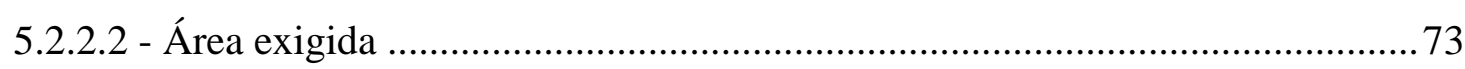

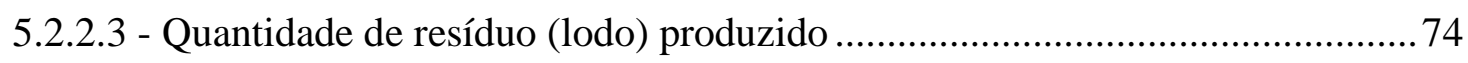

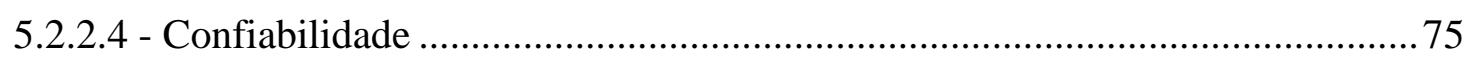

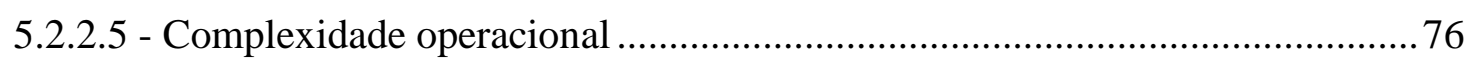

5.2.2.6 - Custo de capital ou de implantação ............................................................... 77

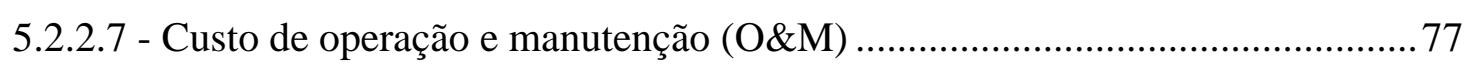

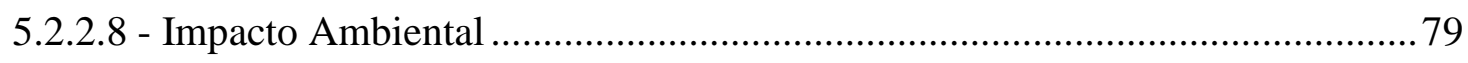

5.2.2.9 - Conformidade com a Política e Legislação Ambiental ................................. 80

5.2.2.10 - Aceitação da comunidade/família ............................................................... 81

5.2.3 - Avaliação das Alternativas e da Metodologia ..........................................882

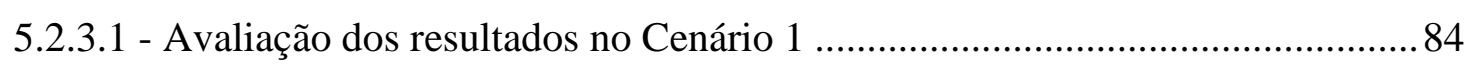

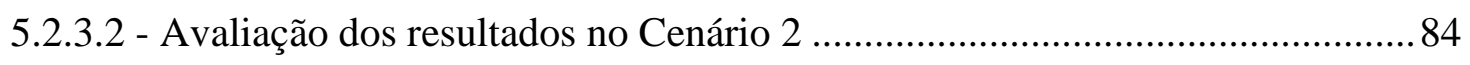

5.2.3.3 - Avaliação dos resultados no Cenário 3 ..................................................... 85

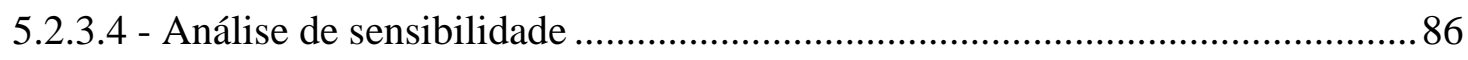

6 - CONCLUSÕES E RECOMENDAÇÕES .......................................................................90

REFERÊNCIAS BIBLIOGRÁFICAS ....................................................................................93

APÊNDICE A - DIMENSIONAMENTO ............................................................................100

APÊNDICE B - LEVANTAMENTO DE CRITÉRIOS ...................................................110 


\section{LISTA DE FIGURAS}

Figura 3.1 - Definição de sistemas descentralizados de coleta, tratamento e reutilização de esgoto

Figura 3.2 - Principais configurações dos Biorreatores com membranas. (a) Sistema MBR com membrana externa - MBR-e. (b) Sistema MBR com membrana submersa MBR-s.

Figura 3.3 - Configurações dos MBR submersos: (a) Tanque com membrana integrado; (b) tanque tipo 1 com membrana separada; (c) tanque tipo 2 com membrana separada.

Figura 3.4 - Aspectos críticos e importantes na seleção de sistemas de tratamento de esgotos em regiões desenvolvidas e em desenvolvimento (von Sperling, 2005).... 40

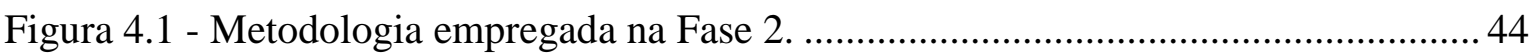

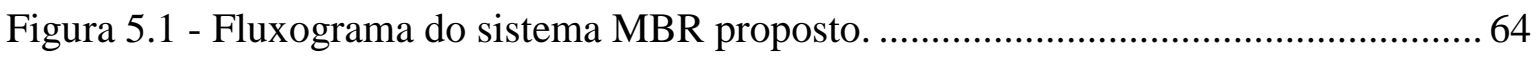

Figura 5.2 - Configuração do sistema MBR dimensionado e proposto para ser aplicado ao

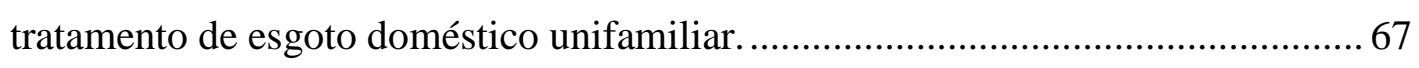

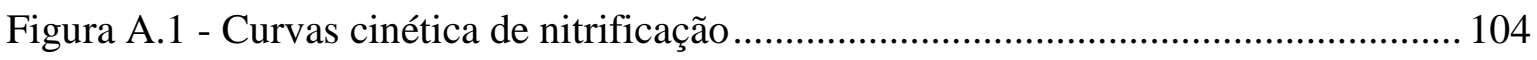




\section{LISTA DE TABELAS}

Tabela 3.1 - Processos de tratamento de água residuária: exemplos de tecnologias de interesse

Tabela 3.2 - Tipos de sistemas de tratamento utilizados no Brasil..

Tabela 3.3 - Parâmetros característicos para a qualidade da água de reúso irrestrito para fim não potável

Tabela 3.4 - Comparação do reator de membrana aeróbio com sistema de lodo ativado convencional, no tratamento de efluente doméstico.

Tabela 3.5 - Possíveis medidas para redução do custo de instalação e operação

Tabela 3.6 - Empresas que comercializam sistemas compactos de MBR no Brasil. 23

Tabela 3.7 - Resumo dos estudos sobre MBR descentralizados em pequena escala. .27

Tabela 3.8 - Levantamento de dados com maior relevância para executar a Fase 2........... 32

Tabela 5.1 - Base de dados com as principais referências levantadas para a fase 2............69

Tabela 5.2 - Dimensões e critérios de avaliação escolhidos para a análise tecnológica de processo MBR para tratamento descentralizado de esgotos.................................. 71

Tabela 5.3 - Aplicação de pesos para análise de sensibilidade do modelo ......................... 71

Tabela 5.4 - Aplicação de pesos de acordo com os cenários................................................ 72

Tabela 5.5 - Valores adotados para quantificar o critério consumo de energia................... 73

Tabela 5.6 - Valores adotados para quantificar o critério área exigida ............................... 74

Tabela 5.7 - Valores adotados para quantificar o critério quantidade de resíduo (lodo)

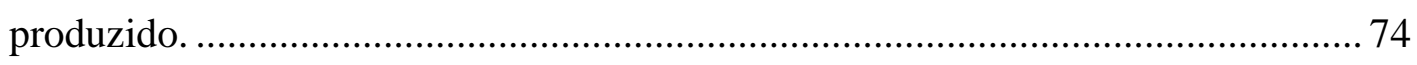

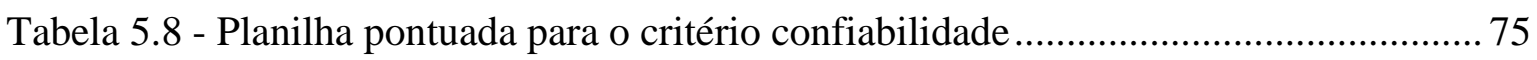

Tabela 5.9 - Valores adotados para quantificar o critério confiabilidade............................ 75

Tabela 5.10 - Planilha pontuada para o critério complexidade operacional........................ 76

Tabela 5.11 - Valores adotados para quantificar o critério complexidade operacional ...... 76

Tabela 5.12 - Valores adotados para quantificar o critério custo de implantação............... 77

Tabela 5.13 - Planilha pontuada para o critério custo de operação e manutenção ............... 78

Tabela 5.14 - Valores adotados para quantificar o critério custo de O\&M......................... 78

Tabela 5.15 - Planilha pontuada para o critério impacto ambiental .................................... 79

Tabela 5.16 - Valores adotados para quantificar o critério impacto ambiental ................... 79

Tabela 5.17 - Planilha pontuada para o critério conformidade com a política e legislação

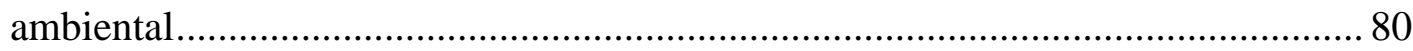


Tabela 5.18 - Valores adotados para quantificar o critério conformidade com a política e legislação ambiental.

Tabela 5.19 - Planilha pontuada para o critério Aceitação da comunidade/chefe da família

Tabela 5.20 - Planilha pontuada para o critério Aceitação da comunidade/família 82

Tabela 5.21 - Matriz de avaliação das alternativas de acordo com cada critério .82

Tabela 5.22 - Limiares de preferência e de indirença adotados para a simulação do método ELECTRE III. .83

Tabela 5.23 - Resultados da simulação nos métodos ELECTRE III e TOPSIS para o Cenário 1

Tabela 5.24 - Resultados da simulação nos métodos ELECTRE III e TOPSIS para o Cenário 2 .

Tabela 5.25 - Resultados da simulação nos métodos ELECTRE III e TOPSIS para o Cenário 3. .86

Tabela 5.26 - Resultados da simulação nos métodos ELECTRE III e TOPSIS com aplicação de pesos iguais para cada critério

Tabela 5.27 - Resultados da simulação nos métodos ELECTRE III e TOPSIS com aplicação de pesos iguais para as dimensões

Tabela 5.28 - Resultados da simulação nos métodos ELECTRE III e TOPSIS com aplicação de pesos dobrados para os critérios técnicos .88

Tabela 5.29 - Resultados da simulação nos métodos ELECTRE III e TOPSIS com aplicação de pesos dobrados para os critérios econômicos .88

Tabela 5.30 - Resultados da simulação nos métodos ELECTRE III e TOPSIS com aplicação de pesos dobrados para os critérios ambientais .88

Tabela 5.31 - Resultados da simulação nos métodos ELECTRE III e TOPSIS com aplicação de pesos dobrados para os critérios sociais.

Tabela A.1 - Dimensionamento do sistema de membrana............................................. 107

Tabela A.2 - Dimensionamento do sistema biológico aeróbio.......................................... 108

Tabela A.3 - Dimensionamento do sistema biológico anóxico ........................................ 109

Tabela A.4 - Dimensionamento do sistema de aeração.................................................... 109

Tabela B.1 - Levantamento dos critérios encontrados na literatura................................. 110

Tabela B.1 - Levantamento dos critérios encontrados na literatura (continuação)............ 111

Tabela B.1 - Levantamento dos critérios encontrados na literatura (continuação)........... 112

Tabela B.1 - Levantamento dos critérios encontrados na literatura (continuação)............ 113 


\section{LISTA DE SIGLAS}

\begin{tabular}{|c|c|}
\hline ABNT & Associação Brasileira de Normas Técnicas \\
\hline BAS & Biofiltro Aerado Submerso \\
\hline DBO & Demanda Bioquímica de Oxigênio \\
\hline DQO & Demanda Química de Oxigênio \\
\hline ELECTRE & Elimination Et Choice Expressing Reality \\
\hline EPA & Environmental Protection Agency \\
\hline FAn & Filtro Anaeróbio \\
\hline FINEP & Financiadora de Estudos e Projetos \\
\hline FS & Flat Sheet/Placa Plana \\
\hline $\mathrm{HF}$ & Hollow Fiber/Fibra Oca \\
\hline IBGE & Instituto Brasileiro de Geografia e Estatística \\
\hline LAC & Lodo Ativado Convencional \\
\hline MBR & Membrane bioreactor \\
\hline MBR & Membrane bioreactor/Reator Biológico com Membrana \\
\hline MF & Microfiltração \\
\hline MT & Multitubular \\
\hline NBR & Norma Brasileira \\
\hline NTK & Nitrogênio Total Kjeldahl \\
\hline $\mathrm{PE}$ & Polietileno \\
\hline PES & Polieterfulfona \\
\hline $\mathrm{pH}$ & Potencial Hidrogeniônico \\
\hline PNSB & Pesquisa Nacional de Saneamento Básico \\
\hline $\mathrm{PP}$ & Polipropileno \\
\hline PROSAB & Programa de Pesquisa em Saneamento Básico \\
\hline PTM & Pressão transmembrana \\
\hline PVDF & Difluoreto de Polivinilideno \\
\hline SSLM & Sólidos Suspensos no Licor Misto \\
\hline TOPSIS & Technique for Order Performance by Similarity to Ideal Solution \\
\hline TS & Tanque Séptico \\
\hline UASB & $\begin{array}{l}\text { Upward-flow Anaerobic Sludge Blanket/Reator Anaeróbio de Manta de } \\
\text { Lodo }\end{array}$ \\
\hline UF & Ultrafiltração \\
\hline Wet & Wetland \\
\hline
\end{tabular}




\section{1 - INTRODUÇÃO}

A adoção de políticas públicas para a preservação e a conservação ambiental, por meio da fixação de exigências, regulamentos e leis, é influenciada pelo mercado global e também pelas necessidades de potabilidade, de reúso de água, e de preservação dos recursos hídricos. Na medida em que aumentam a preocupação com o ambiente e as exigências pelas agências reguladoras, novas tecnologias se aperfeiçoam para atender à qualidade exigida.

No entanto, para a implantação de sistemas de tratamento de esgotos ainda são selecionadas tecnologias inadequadas em determinadas localidades, quando se consideram as condições locais climáticas e físicas, capacidades de recursos financeiros e humanos, e aceitabilidade social ou cultural, na implantação de sistemas para o tratamento de esgoto sanitário. De acordo com o Sistema Nacional de Informações sobre Saneamento (SNIS, 2014), as alternativas que têm sido adotadas para o esgotamento sanitário no Brasil contemplam as seguintes: fossas sépticas/sumidouros; fossas rudimentares; valas a céu aberto; lançamento de esgotos em curso d'água; galerias de águas pluviais; e outros. Segundo o SNIS, 67,3\% dos municípios brasileiros utilizavam em 2014 as fossas sépticas/sumidouros.

No Brasil, o índice médio de atendimento urbano com rede coletora de esgotos informados pelo SNIS (2014) aponta valores acima de 70\% apenas no Distrito Federal e nos estados de São Paulo, Minas Gerais e Paraná. Na faixa de $40 \%$ a 70\%, aparecem outros seis estados: Rio de Janeiro, Espírito Santo, Goiás, Mato Grosso do Sul, Bahia e Paraíba. Entre 20\% e 40\%, situam-se nove estados: Roraima, Rio Grande do Sul, Ceará, Alagoas, Rio Grande do Norte, Mato Grosso, Pernambuco, Sergipe e Tocantins. Enquanto que na penúltima faixa, de $10 \%$ a $20 \%$ dos municipios com rede de coleta de esgoto, encontram-se quatro estados: Santa Catarina, Acre, Maranhão e Piauí. Por fim, na menor faixa, inferior a 10\%, há quatro estados: Amazonas, Pará, Rondônia e Amapá. Em relação ao tratamento de esgoto, apenas $40,8 \%$ do esgoto gerado no Brasil apresentam algum tipo de tratamento.

Diante desse enorme déficit sanitário brasileiro, aliado ao quadro epidemiológico e à escassez de água, constata-se a necessidade do aperfeiçoamento de alternativas e 
tecnologias para os sistemas de tratamento de esgotos que propiciem efluentes de melhor qualidade.

Uma forma eficaz para proporcionar o tratamento de esgoto doméstico pode ser realizada pelo emprego de sistemas unifamiliares ou descentralizados, também chamados de sistemas individuais, que são aplicados ao próprio local onde foi gerado o efluente, podendo servir a unidades habitacionais individuais ou a um grupo de residências sem causar perturbação e impacto ao ambiente. Esses sistemas tornam-se mais atraentes em locais onde há precariedade nos sistemas de esgotamento sanitário ou que ficam isolados dos centros urbanos.

Os sistemas de tratamento descentralizados apresentam desafios significativos devido à necessidade de desempenho confiável de alta qualidade em função de uma série de restrições, incluindo longos períodos de tempo entre a manutenção e a operação das atividades, carência de mão de obra qualificada, alta variabilidade na vazão e maiores concentrações, além dos fatores específicos locais (Metcalf \& Eddy, 2007).

Em sistemas descentralizados, geralmente utiliza-se o tanque séptico como forma de tratamento. Um dos motivos de preocupação é que no efluente dos tanques sépticos não há remoção de nutrientes, nitrogênio e fósforo, patógenos e metais. Isso pode tornar-se um fator de risco para a qualidade das águas subterrâneas e superficiais e, consequentemente, para a saúde pública. Por isso, tem-se aumentado o interesse em aperfeiçoar o desempenho desse tipo de alternativa, por serem reconhecidas como possíveis causadores de impactos ao ambiente.

Com o propósito de produzir um efluente de melhor qualidade, em comparação aos processos convencionais de tratamento de esgoto, as membranas acopladas ao tratamento biológico de esgoto oferecem vantagens aos sistemas de produção de água de reúso em localidades sem sistemas de esgotamento sanitário e que sofrem com a escassez hídrica. Essa alternativa é dada pela tecnologia de Reatores Biológicos de Membrana (MBR), a qual produz retenção completa da biomassa e degradação dos poluentes mais eficientes em função da maior concentração de micro-organismos no reator. 
Apesar dessa tecnologia ter sido objeto de várias pesquisas no exterior, ainda é pouco difundida no Brasil. Entretanto, a maior dificuldade para sua larga utilização aqui era o seu custo, considerado muito alto, realidade que está se modificando rapidamente. Além disso, não foram encontradas aplicações e pesquisas feitas que abordem a possibilidade de sua utilização para o tratamento de esgotos em residências unifamiliares.

Face a esse cenário, devido ao crescente interesse em tecnologias que proporcionem um efluente de melhor qualidade, tanto para manutenção da qualidade ambiental como para produzir água para reúso, esta pesquisa dividiu-se em duas fases. Na primeira fase concebeu-se um sistema MBR adaptado às condições existentes nos sistemas de esgotos sanitários provenientes de unidades residenciais unifamiliares. E, na segunda fase metodológica, realizou-se a avaliação do sistema proposto na primeira fase, empregando um conjunto de fatores para a escolha de indicadores tecnológicos de desempenho, utilizando métodos multiobjetivo e multicritério de auxílio à decisão. 


\section{2 - OBJETIVOS}

\section{1 - GERAL}

O objetivo geral desta pesquisa foi o de verificar a possibilidade de aplicação da tecnologia de Reatores Biológicos de Membrana ao tratamento de esgotos sanitários provenientes de unidades residenciais unifamiliares no Brasil, formulando as adaptações necessárias e verificando a sua sustentabilidade.

\section{2 - ESPECÍFICOS}

Os objetivos específicos desta pesquisa são:

1. Conceber um sistema MBR adaptado às condições existentes nos sistemas de esgotos sanitários provenientes de unidades residenciais unifamiliares;

2. Analisar o sistema MBR que foi concebido no objetivo específico anterior, utilizando como base os indicadores tecnológicos de desempenho; e

3. Avaliar a contribuição da tecnologia MBR para o reúso do efluente doméstico no Brasil. 


\section{3 - FUNDAMENTAÇÃO TÉORICA E REVISÃO BIBLIOGRÁFICA}

Nesta seção são revistos termos conceituais referentes à temática desta pesquisa. Primeiramente, foram levantadas as principais características baseadas em estudos de diversos autores para aplicação do reator biológico com membranas (MBR) ao tratamento de esgoto doméstico. Em seguida, discutiu-se a aplicação dos métodos multiobjetivo e multicritério utilizados na tomada de decisão para escolhas de tecnologias de tratamento de esgotos sanitários provenientes de unidades residenciais unifamiliares.

\section{1 - SISTEMAS DE TRATAMENTO DE ESGOTO}

Os esgotos domésticos ou domiciliares provêm principalmente de residências, edifícios comerciais, instituições ou quaisquer edificações que contenham instalações de banheiros, lavanderias, cozinhas, ou qualquer dispositivo de utilização da água para fins domésticos. Esses esgotos compõem-se essencialmente de água de banho, urina, fezes, papel, restos de comida, sabão, detergentes, águas de lavagem (Jordão e Pessôa, 2009).

Muitas operações podem ser utilizadas no tratamento de esgoto antes dele ser descartado no corpo receptor. O tratamento de esgoto pode ser realizado por meio de processos físicos, químicos e biológicos. Entretanto, em um sistema completo de tratamento, esses processos se intercalam de forma individual ou combinada.

Cada estação de tratamento de água residuária, requer a seleção de pelo menos um tipo de reator para tratamento químico ou biológico. O tipo de fluxo e o padrão de mistura no reator define o modelo hidráulico do mesmo. O padrão de mistura depende da geometria do reator, do tamanho e da quantidade de energia produzida por unidade de volume. $\mathrm{O}$ fluxo no reator pode ter duas condições: fluxo intermitente (em batelada) com entrada e/ou saída descontínuas, e fluxo contínuo, com entrada e saída contínua. Os principais tipos de reatores utilizados para o tratamento de águas residuárias são: 1) batelada; 2) fluxo em pistão; 3) mistura completa; 4) fluxo disperso; 5) mistura completa em série; 6) reatores com enchimento (Metcalf e Eddy, 1991). 
Os métodos de tratamento em que predomina a aplicação da força física são conhecidos como operações unitárias. Já os métodos de tratamento em que a remoção de contaminantes é provocada por reações químicas ou biológicas são conhecidos como processos unitários (Metcalf e Eddy, 2003). A operação agrupada desses processos proporciona vários tipos de tratamentos, que se classificam em preliminar, primário, secundário (com ou sem remoção de nutrientes) e terciário ou avançado. A Tabela 3.1 resume os objetivos de tratamento e os processos típicos de cada etapa com alguns exemplos de tecnologias que podem ser adotadas.

Tabela 3.1 - Processos de tratamento de água residuária: exemplos de tecnologias de interesse (Wu et al., 2009).

\begin{tabular}{|c|c|c|}
\hline $\begin{array}{l}\text { Nível de } \\
\text { tratamento }\end{array}$ & Finalidade & Tecnologia de tratamento \\
\hline Preliminar & $\begin{array}{l}\text { Grande remoção de partículas sólidas, como } \\
\text { trapos, paus, materiais flutuantes, areia e } \\
\text { gorduras. }\end{array}$ & Peneiramento; decantação \\
\hline Primário & $\begin{array}{l}\text { Remove sólidos suspensos e uma porção da } \\
\text { matéria orgânica. }\end{array}$ & Peneiramento; sedimentação \\
\hline Secundário & $\begin{array}{l}\text { Tratamento biológico e remoção de poluentes } \\
\text { orgânicos biodegradáveis. }\end{array}$ & $\begin{array}{l}\text { Percolação ou filtro biologico } \\
\text { percolador, lodos ativados, } \\
\text { Tratamento anaerobio, lagoa de } \\
\text { estabilização/oxidação. }\end{array}$ \\
\hline $\begin{array}{l}\text { Terciário } \\
\text { ou } \\
\text { Avançado }\end{array}$ & $\begin{array}{l}\text { Remoção dos sólidos residuais em suspensão e } \\
\text { poluentes especificos, tais como nitrogenio ou } \\
\text { fósforo, cor, odor e etc. A desinfecção e a } \\
\text { remoção de nutrientes são frequentemente } \\
\text { incluídas. }\end{array}$ & $\begin{array}{l}\text { Filtro de areia; biorreator com } \\
\text { membrana; osmose reversa; } \\
\text { tratamento de ozônio; coagulação } \\
\text { química; carvão ativado. }\end{array}$ \\
\hline
\end{tabular}

Existem basicamente duas variantes para os sistemas de esgotamento sanitário: o sistema individual, também chamado de estático, e o sistema coletivo, também chamado de dinâmico (von Sperling, 2005). O Sistema Estático é aquele que propõe uma solução no local, sendo usualmente utilizado para atendimento unifamiliar ou para poucas edificações que estejam próximas entre si. Já os sistemas dinâmicos são soluções que recebem o lançamento do esgoto e a transportam, através de canalizações, até um destino final onde será tratado e posteriormente pode ser lançado em algum corpo d'água ou reaproveitado. Este sistema é adequado para locais de densidade populacional elevada. Existem duas subdivisões do sistema coletivo: sistema unitário, também chamado de combinado, e sistema separador. No sistema combinado, o esgoto sanitário é conduzido junto com as vazões de águas pluviais, em uma mesma canalização. Já no sistema separador, o esgoto e as águas de chuva são conduzidos em canalizações separadas. 
A escolha do processo de tratamento de esgoto mais adequado depende das características da água residuária em questão e dos objetivos que devem ser alcançados por intermédio desse tratamento.

Algumas características dos processos de tratamento dos sistemas unifamiliares ou descentralizados e tecnologias disponíveis, que são o foco desta pesquisa, serão apresentadas nos tópicos 3.1.1 e 3.1.2. Para o efluente tratado tornar-se um produto adequado para reutilização ou descarga, ele deve obedecer alguns padrões de qualidade que são apresentados no tópico 3.1.3 que aborda o reúso de água.

\subsection{1 - Sistema descentralizado de tratamento de esgoto}

Um sistema descentralizado de tratamento de esgoto pode ser definido como aquele que atende pequenas comunidades, incluindo-se unidades de tratamento individuais ou pequenos grupos de edifícios ligados a um sistema de tratamento com variedades de tratamento (EPA, 2002; Libralato et al., 2012).

A implantação de sistemas descentralizados consiste no tratamento eficaz das águas residuárias a partir de residências individuais, de modo que isso não cause quaisquer condições de perturbação e impacto sobre qualquer um dos usos benéficos da água subterrânea local (Metcalf e Eddy, 1991).

Além disso, existem inúmeras dificuldades ao trabalhar com esses sistemas descentralizados, por conterem um efluente doméstico concentrado, se comparado a um esgoto bruto em uma estação de tratamento de águas residuárias municipal convencional, devido à falta de diluição a partir de vazões das redes de esgotos. Além disso, os esgotos domiciliares podem conter maior presença de cabelos e partículas sólidas, o seu fluxo oscila muito mais, assim como a grande variação de carga.

Outra preocupação importante ao utilizar esses sistemas descentralizados está relacionada a inexistência do controle operacional desses sistemas, já que no Brasil a utilização de tanques sépticos é muito difundida, porém, os sistemas não são monitorados e controlados, e, consequentemente, podem acarretar problemas ao ambiente e a saúde pública. 
Mesmo com esses desafios, observa-se um enorme crescimento para adaptação e desenvolvimento de novas tecnologias para o tratamento descentralizado. A descentralização está sendo cada vez mais reconhecida como um modelo potencialmente adequado para contribuir para a redução da população mundial sem acesso ao abastecimento de água e ao saneamento adequado, bem como aumentar a eficiência de tratamento de esgotos, possibilitando o reúso de água (Libralato et al., 2012). Os sistemas descentralizados são alternativas reconhecidas como potencialmente viáveis, de baixo custo em longo prazo, ao serem aplicadas estratégias para o tratamento de águas residuárias, se forem planejadas, projetadas, instaladas, operadas e mantidas de forma adequada.

Além disso, é possível alcançar a sustentabilidade desses sistemas individuais, de grupos ou de comunidades, ao adaptá-los à reciclagem e reúso de água e remoção e/ou reciclagem de nutrientes (IWA, 2011). Na Erro! Fonte de referência não encontrada. apresenta-se um esboço das alternativas de utilização da água residuária em sistemas descentralizados.

A utilização da água residuária tratada pode ser realizada de forma indireta e direta. A forma indireta ocorre ao reintroduzir o efluente nos corpos de águas superficiais ou subterrâneas, com o propósito de serem utilizadas ao captar agua à jusante do lançamento de maneira controlada. Já o reúso de água direto pode ser feito de diversas formas, por meio de irrigação no jardim, recarga de água subterrânea, reciclagem na própria casa para fins de usos não potáveis, como uso na descarga no banheiro e lavagem de calçadas (Metcalf e Eddy, 2007).

Algumas regiões do Brasil sofrem por problemas de escassez de água, como exemplo o semiárido nordestino e os estados de São Paulo e Rio de Janeiro. Uma das formas de enfrentar a escassez de água é adotando um programa de reúso de água. Atualmente, as tecnologias que permitem realizar reúso de água estão ficando cada vez mais acessíveis e eficientes. Porém, ainda há a necessidade de uma legislação mais coerente com a realidade e as tecnologias disponíveis que possa contribuir para diminuir a escassez e utilizar essas águas usadas para fins menos nobres e exigentes, tais como irrigação de jardins, lavagem de carros e descarga de bacias sanitárias. 


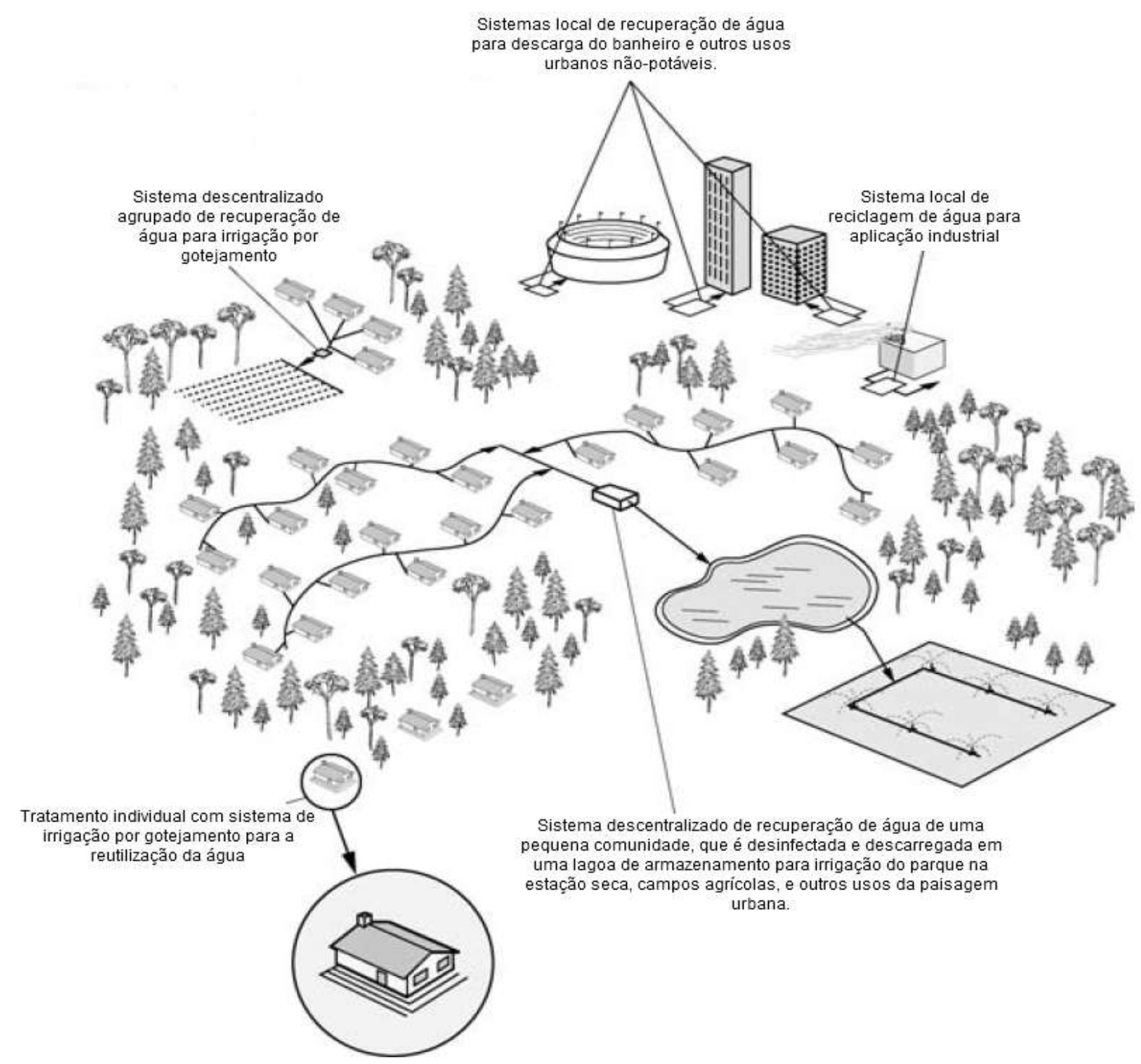

Figura 3.1 - Definição de sistemas descentralizados de coleta, tratamento e reutilização de esgoto

(Metcalf e Eddy, 2007)

Para a produção de água de reúso descentralizados em localidades sem sistemas de esgotamento sanitário, possibilitando um aproveitamento da água residuárias tratada, temse usado membranas acopladas a sistemas de tratamento de esgoto. O MBR, Membrane Biological Reactor, ou Reator Biológico com Membrana, está entre o que existe de mais avançado em tratamento de efluentes domésticos e industriais, com eficiência elevada e aplicação em diversas situações. Essa tecnologia de MBR é uma variação moderna do processo biológico aeróbio de lodos ativados. Um dos aspectos positivos do sistema MBR é o de promover uma intensa redução de microrganismos patogênicos. Além disso, o processo MBR possibilita a utilização de reatores compactos, ou seja, ele ocupa um menor 
espaço, e o controle do sistema pode ser realizado remotamente por telemetria e automação.

\subsection{2 - Tecnologias de tratamento de esgoto no Brasil}

Este tópico reúne alguns principais sistemas de tratamento de esgoto utilizados no Brasil. Levantados por meio de pesquisa ao mercado (fabricantes), companhias de saneamento, dados da literatura e do IBGE (2010).

Algumas tecnologias aplicadas ao tratamento de efluentes no Brasil utilizam tratamentos preliminares, primários, secundários e terciários, com o emprego de processos biológicos aeróbios e anaeróbios, tais como lagoas (facultativas, aeróbias, anaeróbias, mistas e de estabilização), lodo ativado (convencional, aeração prolongada ou por batelada), filtração biológica, valo de oxidação, aplicação no solo, tanques sépticos, reatores anaeróbios, e reator UASB. Esses sistemas de tratamento de esgotos vão desde alguns tratamentos unitários simples até os mais sofisticados, com a combinação de várias técnicas de tratamento para produzir um efluente de melhor qualidade. Os sistemas de tratamento de esgotos sanitários mais empregados nos municípios brasileiros estão apresentados na Tabela 3.2. Ressaltando que os de municípios da região norte são os que apresentam menor índice de tipos de sistemas de tratamento com apenas 7,8\%.

No Brasil, as tecnologias fabricadas de forma compacta que estão em fase de expansão são: as estações mistas, que combinam o sistema de tratamento aeróbio com o anaeróbio; lodos ativados com pré-desnitrificação e aeração prolongada; reator biológico com membranas (MBR); reator biológico de leito móvel (MBBR); UASB acompanhado de filtro biológico; wetland e filtros biológicos. Normalmente, esses sistemas quando são adquiridos de empresas para atender vazões menores, com aplicações em indústrias, hospitais, condomínios e pequenas comunidades.

O sistema de tratamento descentralizado que se destaca no Brasil é o anaeróbio, por apresentar custo baixo de instalação, ser de fácil operação e manutenção e simplicidade de construção. Embora esse tipo de sistema seja eficiente na remoção de matéria orgânica, apresenta alguns problemas relacionados à remoção de nutrientes (N e P) e micro- 
organismos patogênicos, que acarretam problemas para a disposição final dos efluentes tratados em corpos d'água.

$\operatorname{IBGE}(2010)$

Tabela 3.2 - Tipos de sistemas de tratamento utilizados no Brasil

\begin{tabular}{|c|c|c|c|c|c|c|c|c|c|c|c|c|}
\hline \multirow{3}{*}{$\begin{array}{l}\text { Tipo de sistema de } \\
\text { tratamento }\end{array}$} & \multicolumn{12}{|c|}{ Número de municípios com tratamento de esgoto sanitário } \\
\hline & \multicolumn{2}{|c|}{ Norte } & \multicolumn{2}{|c|}{ Nordeste } & \multicolumn{2}{|c|}{ Sudeste } & \multicolumn{2}{|c|}{ Sul } & \multicolumn{2}{|c|}{ Centro-Oeste } & \multicolumn{2}{|c|}{ Brasil } \\
\hline & Unid. & $\%$ & Unid. & $\%$ & Unid. & $\%$ & Unid. & $\%$ & Unid. & $\%$ & Unid. & $\%$ \\
\hline $\begin{array}{l}\text { Total geral de } \\
\text { municípios }\end{array}$ & 449 & 100 & 1793 & 100 & 1668 & 100 & 1188 & 100 & 466 & 100 & 5564 & 100 \\
\hline Filtro biológico & 6 & 1,3 & 67 & 3,7 & 151 & 9,1 & 82 & 6,9 & 11 & 2,4 & 317 & 5,7 \\
\hline Lod & 4 & 0,9 & 20 & 1 , & 123 & 7,4 & 34 & 2,9 & 7 & & 188 & 3,4 \\
\hline Rea & 14 & 3,1 & 84 & 4,7 & 238 & 14,3 & 178 & 15,0 & 51 & 10,9 & 565 & 10,2 \\
\hline Val & 2 & 0,5 & 4 & 0 & 14 & 0,8 & 6 & 0,5 & 1 & 0 & 27 & 0,5 \\
\hline Lag & & 2,5 & 68 & 3 & 251 & 15,1 & 4 & 4, & 5 & 11,2 & 431 & 7,8 \\
\hline $\mathrm{Laq}$ & 10 & 2,2 & 29 & 1 & 56 & 3 & 2 & 1 , & 1 & 3 & 131 & 2,4 \\
\hline Lag & 4 & 0,9 & 26 & 1 , & 42 & 2, & $\varepsilon$ & 0, & 13 & 2 & 93 & 1,7 \\
\hline Lag & 19 & 4,2 & 130 & 7 & 387 & 23,2 & 70 & 5,9 & 66 & 14,2 & 672 & 12,1 \\
\hline Lago & 2 & 0,5 & 25 & 1 , & 25 & 1, & 6 & 0,5 & 7 & 1,5 & 65 & 1,2 \\
\hline $\begin{array}{l}\text { Lagoa de } \\
\text { maturação }\end{array}$ & 6 & 1,3 & 90 & 5,0 & 78 & 4,7 & 16 & 1,4 & 48 & 10,3 & 238 & 4,3 \\
\hline $\begin{array}{l}\text { Wetland/aplicação } \\
\text { no solo, plantas } \\
\text { aquáticas }\end{array}$ & 1 & 0,2 & 5 & 0,3 & 11 & 0,7 & 3 & 0,3 & - & - & 20 & 0,4 \\
\hline $\begin{array}{l}\text { Fossa séptica de } \\
\text { sistema }\end{array}$ & 4 & 0,9 & 33 & 1,8 & 42 & 2,5 & 28 & 2,4 & 2 & 0,4 & 109 & 2 \\
\hline $\mathrm{O}$ & 2 & +5 & 4. & 2 & 54 & 3,24 & 2 & 1,6 & 1 & 2,15 & 129 & 2,3 \\
\hline Total & 35 & 7,8 & 308 & 17,2 & 782 & 46,9 & 271 & 22,8 & 117 & 25,1 & 1513 & 27,2 \\
\hline
\end{tabular}

As alternativas mais promissoras que têm apresentado destaque como processos de póstratamento de sistemas anaeróbios, com o objetivo de melhorar a remoção de nutrientes e patógenos são as seguintes: reatores biológicos em batelada sequencial; sistemas híbridos; biodiscos; reatores de leito granular expandido; reatores de leito fixo dotados de materiais de suporte alternativos; biorreatores com membranas; processos de oxidação avançado; e flotação em dois estágios (Chernicharo, 2007).

\subsection{3 - Reúso de água e legislação vigente}

Há uma variedade de formas de reaproveitamento da água proveniente de um processo de tratamento de água residuária, e a adoção de uma ou mais dessas formas depende do tipo e do grau de remoção do componente requerido e do grau de interesse pelo reúso da água. Entretanto, ao tratar de reúso de água no Brasil, ainda há um grande empecilho com a falta 
de padrões e normas técnicas, o que é um problema, pois não há legislação específica que trate de normas ou diretrizes com padrões de tratamento a serem seguidos.

A Política Nacional de Recursos Hídricos, instituída pela Lei № 9433/97, estabelece entre seus objetivos "assegurar à atual e às futuras gerações a necessária disponibilidade de água, em padrões de qualidade adequados aos respectivos usos".

Basicamente, existem apenas dois regulamentos brasileiros que tratam de reúso de água. Um é estabelecido pela Resolução n ${ }^{\circ}$ 54/2005 do Conselho Nacional de Recursos Hídricos $(\mathrm{CNRH})$, que descreve quatro modalidades para prática de reúso direto não potável para fins agrícolas, ambientais, industriais e aquicultura. Outro é a Norma NBR 13969/1997, que não é específica para reúso de água, tem um item dedicado ao tema, inclusive com a definição de classes de água de reúso e indicação de padrões de qualidade, que descreve as unidades de pós-tratamento e sugere alternativas de disposição final de efluentes líquidos de tanques séptico, como segue:

- Classe 1: Lavagem de carros e outros usos;

- Classe 2: Lavagens de pisos, calçadas e irrigação dos jardins, manutenção dos lagos e canais para fins paisagísticos, exceto chafarizes;

- Classe 3: Reúso nas descargas dos vasos sanitários;

- Classe 4: Reúso nos pomares, cereais, forragens, pastagens para gados e outros cultivos através de escoamento superficial ou por sistema de irrigação pontual.

De acordo com a NBR 13969/1997, para alcançar os níveis de tratamento apresentados na Tabela 3.3, geralmente é necessário fazer o tratamento aeróbio seguido de desinfecção.

Existem outros regulamentos que tratam da necessidade de programas de reúso água, porém não apresenta nenhuma orientação técnica para a sua aplicação. Na cidade de São Paulo, por exemplo, existe a Lei $\mathrm{n}^{\circ}$ 13276/2002, conhecida como "lei das piscininhas", para coleta e liberação lenta de águas de chuva para lotes que tenham área impermeabilizada superior a $500 \mathrm{~m}^{2}$, cujo principal objetivo é minimizar o escoamento superficial de água durante as chuvas. No entanto, essa alternativa não garante segurança na eficácia da qualidade. 
Devido ao interesse pelo tema, a Associação Brasileira de Normas Técnicas (ABNT) criou em 2007 a norma NBR 15527 referente aos requisitos para o "Aproveitamento de água da chuva em coberturas nas áreas urbanas para fins não potáveis", mas nenhuma, pelo menos por enquanto, especificamente para o reúso de água.

Atualmente, ainda não há regulamentos necessários para a implementação de sistemas alternativos de oferta de água no Brasil. No entanto, a Agência Nacional de Águas (ANA, 2005) orienta para a implantação de programas de conservação e reúso de águas em edificações comerciais, residenciais e industriais. Nessas orientações, a ANA (2005), estabelece exigências mínimas para à reutilização urbana irrestrita não potável, que inclui os usos que são suscetíveis a risco para o público e, portanto, requer um elevado nível de tratamento. Estes valores de referência apresentados na Tabela 3.3 são da Agência Nacional de Águas (ANA, 2005) e da Associação Brasileira de Normas Técnicas (ABNT, 1997).

Tabela 3.3 - Parâmetros característicos para a qualidade da água de reúso irrestrito para fím não potável

\begin{tabular}{|c|c|c|c|c|}
\hline Parâmetro & $\begin{array}{c}\text { ANA (2005) } \\
\text { 1Classe } 1\end{array}$ & $\begin{array}{c}\text { ANA (2005) } \\
\text { 2Classe } 2\end{array}$ & $\begin{array}{c}\text { ANA (2005) } \\
{ }^{3} \text { Classe } 3\end{array}$ & $\begin{array}{c}\text { NBR } \\
13969 / 1997\end{array}$ \\
\hline SST - Sólidos suspensos totais (mg/L) & $\leq 5,0$ & $\leq 30$ & $<20$ & - \\
\hline $\begin{array}{l}\text { SDT - Sólidos dissolvidos totais } \\
(\mathrm{mg} / \mathrm{L})\end{array}$ & $\leq 500,0$ & - & - & $\leq 200,0$ \\
\hline Turbidez (NTU) & $\leq 2,0$ & - & $<5,0$ & $<5,0$ \\
\hline $\mathrm{DBO}_{5}(\mathrm{mg} / \mathrm{L})$ & $\leq 10,0$ & $\leq 30$ & $<20$ & - \\
\hline Óleos e graxas (mg/L) & $\leq 1,0$ & $\leq 1,0$ & - & - \\
\hline Coliformes fecais (NMP/100 ml) & $\begin{array}{c}\text { Não } \\
\text { detectáveis }\end{array}$ & $\leq 1000$ & $\leq 200,0$ & $<500$ \\
\hline Cloro resigual $(\mathrm{mg} / \mathrm{L})$ & - & - & 1 & $0,5-1,5$ \\
\hline Nitrato $(\mathrm{mg} / \mathrm{L})$ & $<10,0$ & - & - & - \\
\hline Nitrogênio amoniacal (mg/L) & $\leq 20,0$ & - & $5-30$ & - \\
\hline Nitrito (mg/L) & $\leq 1,0$ & - & - & - \\
\hline Fósforo total (mg/L) & $\leq 0,1$ & - & - & - \\
\hline $\mathrm{pH}$ & $6,0-9,0$ & $6,0-9,0$ & $6,0-9,0$ & $6,0-8,0$ \\
\hline
\end{tabular}

${ }^{1}$ Classe 1: reúso de água em descarga de bacias sanitárias, lavagem de pisos e fins ornamentais, lavagem de roupas e de veículos; ${ }^{2}$ Classe 2: reúso associado às fases de construção da edificação - lavagem de agregados e preparação de concreto; ${ }^{3}$ Classe 3 : irrigação de áreas verdes e rega de jardins. 
Nota-se que esses padrões estabelecidos para o reúso de água no Brasil surgem a partir de consultas às diretrizes internacionais e nacionais que são bem rigorosas, provenientes de países que estão mais avançados nessa temática, como a Organização Mundial da Saúde (OMS ou WHO), Agência Americana de Proteção Ambiental (EPA) ou normas europeias.

\section{2 - REATOR BIOLÓGICO COM MEMBRANA (MBR)}

O sistema MBR, por produzir um permeado de alta qualidade, tem provocado um crescente interesse e tem sido a forma de tratamento mais utilizada para o reúso de água em diversos países, pois ele consegue atender as diretrizes mais rigorosas quanto à exigência de padrões, como os Sólidos Suspensos Totais (SST) e a turbidez em baixas concentrações (Felizatto et al., 2016).

Um exemplo de aplicação de MBR para fim de reúso foi relatado por Côté et al. (2004), que realizaram um estudo no Canadá comparando o sistema de lodos ativados sequenciado de tratamento terciário com filtros de carvão ativado e o sistema MBR para reúso do efluente de indústrias para fins de irrigação e reúso potável indireto. $\mathrm{O}$ estudo mostrou que além de se obter com o MBR um efluente dentro de padrões mais rigorosos para reúso, o MBR tem um custo $50 \%$ menor se comparado ao sistema de lodos ativados seguido de filtração por carvão ativado.

Já o estudo realizado por Alaboud e Magram (2008) na Arábia Saudita, teve como objetivo apresentar o MBR para o reúso de efluentes industriais e municipais, visto que o país possui clima desértico. A pesquisa mostrou a eficiência do MBR no tratamento tanto de efluentes municipais quanto industriais com tempos de detenção hidráulico (TDH) diferentes, e comparou com o sistema de lodos ativados seguido de filtração com carvão ativado. A qualidade do permeado obtido pelo MBR foi satisfatória, com alta remoção de orgânicos, nutrientes e coliformes totais e termotolerantes, independentemente do TDH empregado, com custo total de $20 \%$ menor do que o sistema de lodos ativados seguido de filtração.

Nas últimas décadas, a tecnologia de membranas tem se difundido no mercado, pela sua

alta eficiência no tratamento de água e de efluentes, bem como por possibilitar o aproveitamento da água residuária tratada. A aplicação dessa tecnologia tem se difundido 
por diversas áreas de interesse, como na química, biotecnologia, farmácia, biomedicina, indústrias alimentícias e bebidas, tratamento de água, tratamento de esgoto e tratamento de despejos industriais.

O termo "reator biológico com membrana" aplica-se a todos os processos de tratamento de águas residuárias integrando uma membrana permeável e seletiva com um processo biológico (Judd, 2011). Essa tecnologia aplica-se tanto para efluentes sanitários municipais, efluentes industriais e até no tratamento de chorume. Os MBR apresentam duas configurações, uma com membrana externa e outra com membrana submersa, como é mostrado na Figura 3.2.

No reator biológico com módulo externo (Figura 3.2a), o conteúdo do reator é bombeado para os módulos, geralmente, tubulares, e o processo opera em fluxo cruzado, ou seja, a solução ou suspensão escoa paralelamente à superfície da membrana, enquanto o permeado é transportado transversalmente à mesma.

Na configuração do reator biológico com módulo de membranas submerso (Figura 3.2b), o módulo ou feixe de membranas é imerso no tanque aerado e o conteúdo do biorreator está em contato com a superfície externa das membranas. O permeado é obtido por meio da sucção do conteúdo do reator que atravessa as paredes da membrana. Esta diferença de pressão que promove a separação pode ser provocada pela coluna de líquido no interior do reator ou aplicando-se vácuo no lado do permeado. Esses sistemas, geralmente, utilizam membranas do tipo fibra oca ou placa plana.

Existem duas configurações diferentes no processo MBR submerso, dependendo da existência de tanques de membrana separadas. Inicialmente, as membranas eram submersas diretamente no tanque de aeração. No entanto, percebeu-se que essa configuração é de difícil manutenção, porque todo o tanque de aeração tem de ser drenado ou o módulo de membrana tem de ser içado para fora do tanque de aeração antes da limpeza da membrana, lavagem do difusor de ar, da substituição de membrana, e assim por diante. Como resultado disso, os tanques de membrana separados começaram a ser instalados no tanque de aeração (Figura 3.3). Nessa configuração, todo o licor misto no tanque pequeno com membrana pode ser transferido para o tanque maior de aeração, sempre que necessário. Ao mesmo tempo, um tanque de membrana separada também tem 
as seguintes desvantagens quando se compara com um tanque integrado: (1) tamanho maior, (2) custos de capital mais elevados, (3) custos de energia mais elevados devido à necessidade de recirculação de licor misto e a necessidade de mais aeração no tanque de aeração (Yoon, 2015).

(a) BRM-e

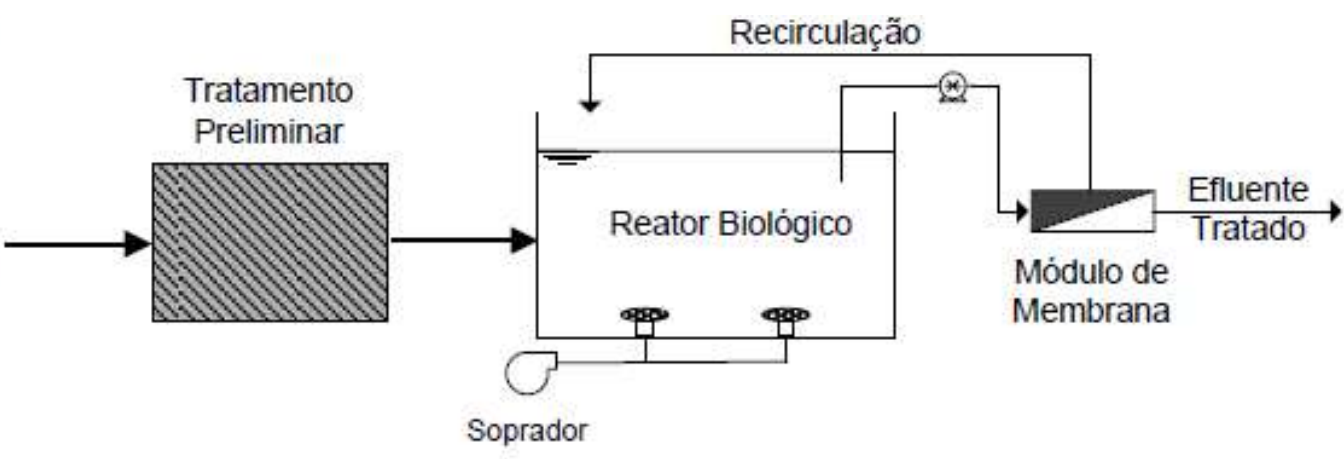

(b) BRM-s

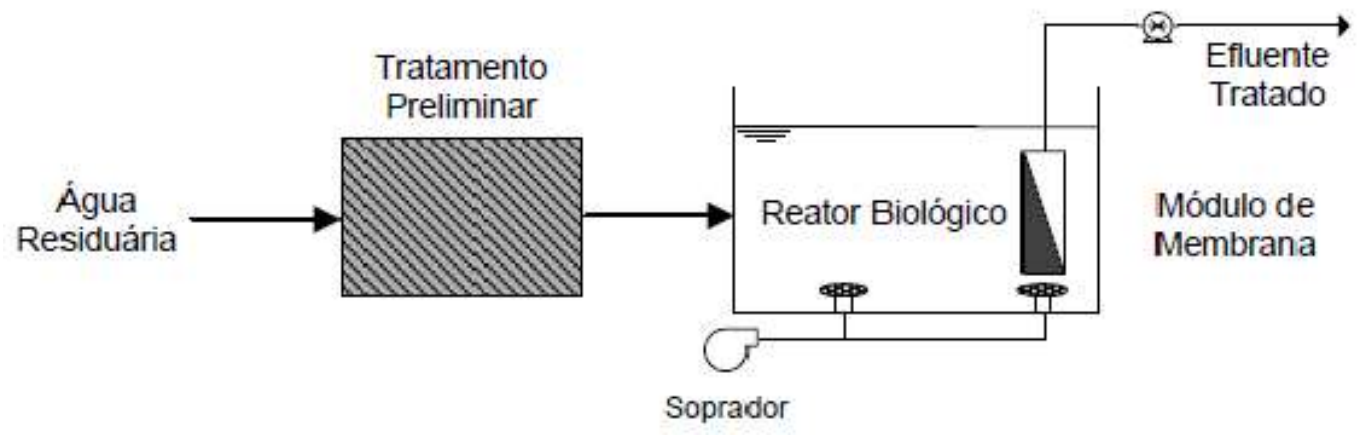

Figura 3.2 - Principais configurações dos Biorreatores com membranas. (a) Sistema MBR com membrana externa - MBR-e. (b) Sistema MBR com membrana submersa - MBR-s.

(Subtil et al., 2013).

A concepção do tanque de membrana separado novamente evoluiu para o desenho mostrado na Figura 3.3(c), onde o licor misto é bombeado a partir do tanque de membrana para o tanque de aeração. Este projeto oferece algumas vantagens, tais como: (1) economia de energia de bombeamento, reduzindo o fluxo a ser bombeado; (2) menor custo de capital por meio de bombas de reciclagem com capacidade menor; e (3) redução da incrustação na membrana por não enviar partículas finas geradas pela bomba de circulação diretamente para o tanque de membrana (Yoon, 2015).

O MBR é um tratamento biológico resultante de sistemas de lodos ativados clássicos, em que o sistema de decantação secundária, que ocupa grande espaço, é substituído por uma membrana de ultrafiltração ou microfiltração, colocada no mesmo reator, ou anexa perto 
do mesmo reator, conseguindo-se assim uma separação completa da biomassa da água tratada ou permeada.

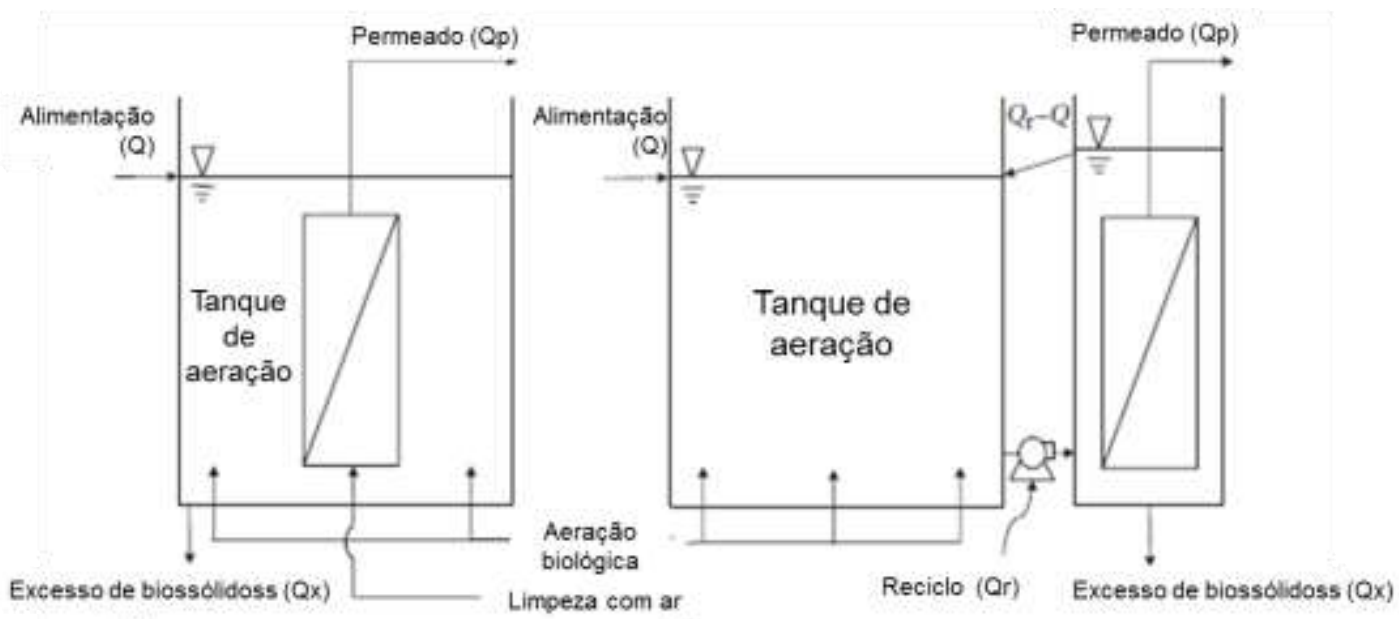

(a)

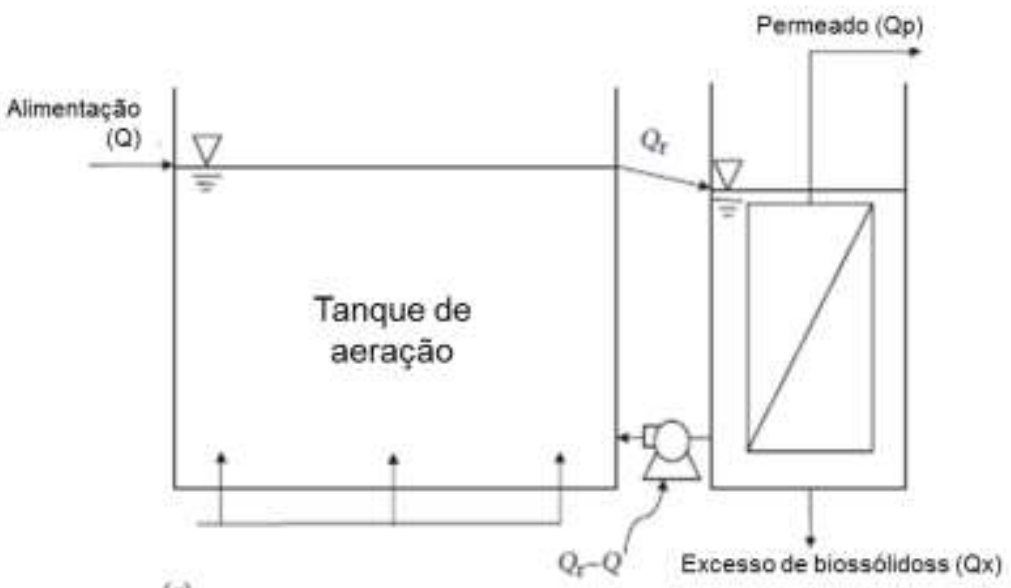

(c)

Figura 3.3 - Configurações dos MBR submersos: (a) Tanque com membrana integrado; (b) tanque tipo 1 com membrana separada; (c) tanque tipo 2 com membrana separada.

(Yoon, 2015)

O sistema independe da decantabilidade do lodo, o que faz com que a concentração da biomassa possa ser aumentada no reator até umas cinco vezes, com respeito ao processo convencional de lodos ativados. Dessa forma, o volume do reator é reduzido, mantendo a carga mássica do processo biológico. O reator pode trabalhar em condições aeróbias ou anaeróbias, escolha que dependerá das características da água a tratar.

A maioria de instalações existentes, tal como ocorre com o processo convencional, funciona com reatores biológicos aerados. O crescimento lento dos microrganismos anaeróbios e a baixa adaptação às variações de carga fazem com que os processos 
anaeróbios não sejam tão difundidos. Ainda mais que os custos de investimento são mais elevados em sistemas de membrana em condições anaeróbias e, de alguma forma, seu funcionamento apresenta maior complexidade. Além disso, os MBR anaeróbios são significativamente influenciados por inúmeros fatores, como o tipo e variabilidade de águas residuárias brutas, o tipo de contaminantes orgânicos no afluente, o seu pH, etc.

No entanto, Skouteris (2012b) mostra que os MBR anaeróbios podem tratar de forma muito eficiente as águas residuárias. Além disso, eles podem produzir biogás de boa qualidade, o que pode ser ainda utilizado dentro das próprias plantas MBR para a produção de energia renovável. No entanto, a adoção e comercialização dessa tecnologia ainda são insipientes, a maioria dos sistemas operados está em escala de bancada experimental, e a sua aplicação em planta piloto é limitada, concluindo-se que os MBR anaeróbios em escala industrial ainda não foram testados.

As membranas dos MBR estão inseridas em meios que contêm sólidos em suspensão como flocos biológicos, células microbianas, debris celulares, colóides, macromoléculas e uma gama variada de substâncias orgânicas solúveis (Dezotti et al., 2011). Na Tabela 3.4 comparam-se as caracteristicas do licor misto presente no reator biológico do sistemas com membranas com as do lodos ativados convencionais.

A elevada concentração de biomassa no reator resulta em valores de carga orgânica maiores que o tratamento convencional e produz uma relação alimento/microrganismo reduzida. O tempo de retenção da biomassa nesses reatores situa-se na faixa entre 30 e 45 dias. A alta concentração da biomassa e o longo tempo de residência do lodo no reator facilitam o crescimento lento de microrganismos e de organismos especialistas, como bactérias nitrificantes autotróficas (Schneider e Tsutiya, 2001).

O longo tempo de residência da biomassa e a reduzida carga orgânica por unidade de biomassa contribuem substancialmente para reduzir a produção de lodo, alcançando um tamanho das partículoas de lodo com cerca de 30 a $50 \%$ menor que em um sistema convencional. O tamanho reduzido dos poros das membranas permite a retenção completa de microrganismos no reator, independentemente de estarem ligados ou não aos flocos da biomassa (Schneider e Tsutiya, 2001). 
Tabela 3.4 - Comparação do reator de membrana aeróbio com sistema de lodo ativado convencional, no tratamento de efluente doméstico

(Schneider e Tsutiya, 2001).

\begin{tabular}{llc}
\hline Parâmetro & $\begin{array}{c}\text { Reator } \\
\text { com } \\
\text { membrana }\end{array}$ & $\begin{array}{c}\text { Lodo ativado } \\
\text { convencional }\end{array}$ \\
\hline Biomassa (g/L) & $15-25$ & $1,5-4,0$ \\
$\mathrm{Kg} \mathrm{DQO} / \mathrm{m}^{3} \mathrm{~d}$ & $2,6-5,0$ & $<1,0$ \\
$\mathrm{Kg} \mathrm{DBO} / \mathrm{m}^{3} \mathrm{~d}$ & $1,5-2,5$ & $<0,5$ \\
$\mathrm{Kg} \mathrm{NH} / \mathrm{m}^{3} \mathrm{~d}$ & $0,2-0,4$ & $<0,07$ \\
$\mathrm{~A} / \mathrm{M}(\mathrm{kg} \mathrm{DQO} / \mathrm{Kg} \mathrm{SSLM} \mathrm{d})$ & $<0,1$ & $0,2-0,6$ \\
Tempo de residência da biomassa (d) & $30-45$ & $5-15$ \\
Produção de lodo (Kg lodo seco/Kg de DQO): & & 0,6 \\
- A/M (0,5 a 1,0) & 0,46 & - \\
- A/M (0,1 a 0,2) & 0 & 20 \\
Diâmetro médio dos flocos ( $\mu \mathrm{m})$ & 3,5 & $3-8$ \\
Tempo de residência hidráulica $(\mathrm{h})$ & 2 & \\
\hline
\end{tabular}

SSLM-sólidos suspensos no licor misto.

Benitez et al. (2002) ressaltaram as vantagens que os processos MBR possuem em relação ao sistema convencional de lodos ativados, que estão relacionadas ao seu alto desempenho, baixa produção de lodo e reator biológico com menor tamanho. E as desvantagens do MBR são os altos custos de energia, custo de instalação de aeração, a lavagem e a substituição das membranas. Assim, indicaram que o processo MBR é particularmente adequado para tratamento de águas residuárias de baixa vazão e alto poder de poluição.

Tradicionalmente, os sistemas MBR foram projetados para operar em concentrações de SSLM semelhantes nos reatores de processos biológicos e nos tanques de membrana. O resultado é uma elevada taxa de recirculação de sólidos de 4 a 5 vezes o fluxo afluente.

Embora não seja viável em todos os projetos de MBR, em determinadas circunstâncias (por exemplo, com o uso de decantadores primários) há uma oportunidade para operar com concentrações mais baixas de SSLM e, portanto, menos massa nas bacias de aeração e ainda assim manter uma concentração maior do SSLM nos tanques de membrana. Este modo de operação pode reduzir a taxa de recirculação em até $50 \%$. A redução de consumo de energia resultante desta configuração é dupla, pois ocorre redução no bombeamento e um aumento potencial do fator alfa, que melhora a eficiência de transferência de oxigênio (WEF, 2012). 
Por meio de um levantamento dos aspectos fundamentais do MBR, Judd (2008) mostra a relação mútua e de complementariedade entre os processos e os parâmetros. Com isso, Judd (2008) conclui que os MBR oferecem maior facilidade de controle do que o processo de lodo ativado convencional, devido ao desacoplamento da TRS (tempo de retenção de sólidos) e do TRH (tempo de retenção hidráulico). Estes dois parâmetros são geralmente definidos pela biocinética de sistema, isto é, a velocidade à qual os micro-organismos ativos decompõem os componentes do esgoto no SSLM. Grandes valores de TRS são geralmente desejáveis do ponto de vista biocinético, porque isso produz mais microorganismos de crescimento lento, assim como a geração de menos lodo. O funcionamento com TRS maior se torna possível pela retenção completa dos sólidos em suspensão pela membrana. O TRH pode, então, ser definido de acordo com a microbiologia e biocinética do sistema.

Yoon et al. (2004) buscavam determinar a condição operacional mais econômica para um MBR, com o propósito de minimizar os custos operacionais e os custos de tratamento. Com isto, constaram que a condição operacional mais econômica foi utilizando um TRH de 16 h e SSLM de $11.000 \mathrm{mg} / \mathrm{L}$, quando aeração para a biodegradação era de 13,3 $\mathrm{m}^{3}$ ar/min para um volume de $1000 \mathrm{~m}^{3}$ por dia. Para os intervalos razoáveis de TRH e SSLM, o custo de tratamento de lodo supera o custo de aeração para a biodegradação. Portanto, a manutenção de uma condição de baixa produção de lodo é mais importante para a redução de custos de operação de um MBR.

Além disso, Chapman et al. (2001) ressaltam que, enquanto os custos de tecnologias convencionais estão subindo lentamente com os custos do trabalho e as pressões inflacionárias, os custos para todos os equipamentos de membrana (tanto para filtração direta e MBR) vem caindo de forma constante durante os últimos 10 anos. Na Tabela 3.5 apresentam-se possiveis medidas para reduzir o custo para implantação do MBR.

O processo MBR tem o tamanho fisicamente menor de plantas em comparação com aqueles convencionalmente empregados para o tratamento de efluentes, por isso ele se torna importante nas áreas em que: (a) os custos da terra são elevados e aumenta a uma taxa maior do que o índice geral de preços; (b) o espaço no local é limitado;e (c) restrições legais foram impostas ao impacto visual acarretado pela planta (Judd, 2011). 
O MBR com módulo externo tem um consumo de energia de 2 a $10 \mathrm{kWh} / \mathrm{m}^{3}$ de permeado produzido, dependendo do diâmetro interno dos canais utilizados (considerando módulos tubulares). Já o MBR com módulos submersos tem um consumo de energia de cerca de 0,2 a $0,4 \mathrm{kWh} / \mathrm{m}^{3}$ de permeado produzido (Côté et al., 1998).

Para reduzir a demanda de energia em MBR, Judd (2008) sugere a utilização de membranas cerâmicas com operação anaeróbia. As membranas cerâmicas são mais resistentes ao entupimento, porém elas apresentam alto custo. Os sistemas de MBR anaeróbio submerso podem oferecer vantagens em relação ao tratamento aeróbio porque exigem a operação anaeróbia não aerada e também geram o metano, que pode ser usado para geração de energia (Judd, 2011).

Tabela 3.5 - Possíveis medidas para redução do custo de instalação e operação

(Côté et al., 1998).

\begin{tabular}{ll}
\hline Fator & Possíveis medidas para redução de custo \\
\hline \multirow{4}{*}{ Membrana } & - Utilizar fibras ocas de diâmetro mínimo para maximizar a área de filtração por \\
& volume unitário de polímero e de módulo; \\
& - Filtração de fora para dentro da fibra oca, para maximizar a área de filtração exposta \\
& à água bruta. \\
& - Maximizar o comprimento das fibras para minimizar o consumo de resina de fixação \\
& das fibras; \\
& - Utilizar módulos sem envoltórios para minimizar o uso de materiais plásticos \\
& resistentes à pressão; \\
Módulo & - Limitar a perda de carga no interior da fibra a uma fração muito pequena da PTM; \\
& - Maximizar a densidade de empacotamento de membranas no módulo para reduzir ao \\
& máximo a área da planta; \\
& - Manter o tamanho dos módulos dentro de limites que permitam o manuseio por \\
& operadores individuais. \\
& - Maximizar o tamanho para reduzir ao mínimo os pontos de conexão com \\
& equipamentos auxiliares; \\
Blocos de & - Maximizar a densidade de empacotamento de módulos para reduzir a área ocupada \\
membranas & por bloco; \\
& - Permitir acesso adequado para inspeção, manutenção e troca de módulos de \\
& membrana. \\
& - Operar sistema sem recirculação da água bruta e sem aeração para reduzir o \\
& consumo de energia; \\
& - Limitar a pressão de operação e a frequência de limpeza química para reduzir o \\
consumo de energia e de produtos químicos e prolongar ao máximo a vida útil das \\
membranas.
\end{tabular}

\subsection{1 - Exemplos de aplicação de MBR}

Neste item são abordados alguns trabalhos da literatura científica referente ao tratamento de água residuária utilizando o sistema MBR e que são relevantes para esta pesquisa. 
A primeira instalação de MBR foi desenvolvida pela empresa Dorr Oliver em 1966 (Yang et al., 2006). Foi constatada na literatura uma tendência de se utilizar o MBR com membranas submersas e em sistemas aeróbios, sendo raras as pesquisas em sistemas anaeróbios. No entanto, Judd (2008) destaca que configurações alternativas de baixo consumo têm conduzido à exploração de acoplamento de biorreatores com outros processos de separação por membrana, bem como a um renovado interesse nas tecnologias MBR anaeróbias.

De acordo com Judd (2011), nos países que defendem o sistema MBR como a melhor tecnologia disponível, são feitos contratos rigorosos de qualidade da água com os fornecedores e, em caso de violação de qualidade da água do produto, são impostas medidas financeiras punitivas. Além disso, Judd (2011) ressalta que diversos países (como Reino Unido, EUA, Austrália, Canadá, Finlândia, França, Holanda, Suíça, Japão e Dinamarca) têm incentivos oferecidos em várias formas para promover tecnologias inovadoras eficientes de tratamento da água e redução no demanda de água doce. Esses incentivos em países desenvolvidos fazem com que as tecnologias avançadas se tornem mais acessíveis.

Um levantamento feito em 2006 mostrou que existiam 258 instalações de MBR em escala real na América do Norte e cerca de 2200 no mundo todo (Yang et al., 2006). Atualmente, o processo MBR se difundiu mais ainda, principalmente na China, onde se encontra em funcionamento a planta de tratamento de esgotos em MBR de Beijing, considerada a maior do mundo. Várias empresas internacionais comercializam o sistema de tratamento por MBR, como a Kubota, a Zenon-GE, a Siemens, a Mitsubishi-Rayon, a Toray-Koch, a Puron e a Huber Technology.

No Brasil, as empresas que atualmente oferecem sistemas compactos de MBR estão apresentadas na Tabela 3.6. Esses sistemas podem ser aplicados em unidades descentralizadas com alto volume de efluente gerado, por exemplo, hospitais e indústrias.

Um exemplo da aplicabilidade deste método no Brasil e primeira planta de MBR em grande escala da América Latina a tratar esgoto doméstico, é a Estação Produtora de Água e Reúso - EPAR Capivari - operada pela SANASA (Sociedade de Abastecimento de Água e Saneamento S/A de Campinas) desde 2012. Essa planta de tratamento utiliza o sistema 
MBR com membranas de ultrafiltração com configuração de fibra oca (Rosseto et al, 2014).

Tabela 3.6 - Empresas que comercializam sistemas compactos de MBR no Brasil.

\begin{tabular}{|c|c|c|c|c|}
\hline Empresa & $\begin{array}{l}\text { Localizaçã } \\
\text { o }\end{array}$ & Tipo de membrana & Configuração & Fabricação \\
\hline $\begin{array}{l}\text { Pam } \\
\text { Membranas }\end{array}$ & $\begin{array}{l}\text { Rio de } \\
\text { Janeiro } \\
\text { (RJ) }\end{array}$ & $\begin{array}{l}\text { Cilíndrica do tipo fibra oca, } \\
\text { Ultrafiltração de polietersulfona } \\
\text { Microbiltração de poli-imida. }\end{array}$ & $\begin{array}{l}\text { Variados sistemas, } \\
\text { conforme a escolha } \\
\text { do cliente. }\end{array}$ & $\begin{array}{l}\text { Pam } \\
\text { membranas, } \\
\text { Brasil }\end{array}$ \\
\hline $\begin{array}{l}\text { Huber } \\
\text { technology }\end{array}$ & $\begin{array}{l}\text { São Paulo } \\
\text { (SP) }\end{array}$ & UF $0,037 \mu \mathrm{m}$ de polieter sulfona & $\begin{array}{l}\text { Placa plana. Sucção } \\
\text { Submersa }\end{array}$ & $\begin{array}{l}\text { Huber } \\
\text { technology, } \\
\text { Alemanha }\end{array}$ \\
\hline $\begin{array}{l}\mathrm{AgE} \\
\text { Tecnologias } \\
\text { LTDA }\end{array}$ & $\begin{array}{l}\text { São José } \\
\text { (SC) }\end{array}$ & $\begin{array}{l}\text { UF polietersulfona com } \\
\text { porosidade de } 0,2 \mu \mathrm{m} \text {. }\end{array}$ & $\begin{array}{l}\text { Placa plana. Sucção } \\
\text { Submersa. }\end{array}$ & $\begin{array}{l}\text { LG Kored, } \\
\text { Coreia }\end{array}$ \\
\hline $\begin{array}{l}\text { Centroprojekt } \\
\text { do Brasil S/A }\end{array}$ & $\begin{array}{l}\text { São Paulo } \\
\text { (SP) }\end{array}$ & $\begin{array}{l}0,4 \mu \mathrm{m} \text { com dois tipos, uma com } \\
\text { tipo } 203 \text { (área real } 0,1 \mathrm{~m}^{2} / \mathrm{pc} \text { ) e } \\
\text { tipo } 510 \text { (área real } 0,8 \mathrm{~m}^{2} / \mathrm{pc} \text { ) }\end{array}$ & $\begin{array}{l}\text { Placa plana. Sucção } \\
\text { Submersa. }\end{array}$ & $\begin{array}{l}\text { Kubota } \\
\text { Japão }\end{array}$ \\
\hline $\begin{array}{l}\text { Metropolitana } \\
\text { Ambiental }\end{array}$ & $\begin{array}{l}\text { São Paulo } \\
\text { (SP) }\end{array}$ & UF de $0,15 \mu \mathrm{m}$ & $\begin{array}{l}\text { Placa plana. Sucção } \\
\text { Submersa. }\end{array}$ & $\begin{array}{l}\text { LG Kored, } \\
\text { Coreia }\end{array}$ \\
\hline $\mathrm{H}_{2}$ Life & $\begin{array}{l}\text { Santo } \\
\text { André (SP) }\end{array}$ & - & - & - \\
\hline
\end{tabular}

Atualmente, a EPAR Capivari tem capacidade de tratar 360 L/s de vazão média, podendo atender a uma população de aproximadamente 180 mil pessoas. Na sua configuração final, a EPAR terá capacidade para tratar a vazão média afluente de $725 \mathrm{~L} / \mathrm{s}$, e deverá atender às necessidades da área até o ano 2025, para uma população estimada em 351.766 habitantes. Essa estação vem produzindo efluente com valores de DQO consistentemente abaixo de 28 $\mathrm{mg} / \mathrm{L}$, concentrações de $\mathrm{NH}_{3}$ inferiores a $1 \mathrm{mg} / \mathrm{L}$, turbidez menor que $0,33 \mathrm{NTU}$ e sem odor desagradável, com o excelente índice de remoção de DBO de 99,8\% (Rosseto et al., 2014).

A segunda planta de tratamento de esgotos em MBR foi instalada em Campos do Jordão no fim de 2013 com capacidade de tratar em média $180 \mathrm{~L} / \mathrm{s}$ e terá capacidade de tratar 213 L/s no fim de plano. Essa planta emprega membranas de UF da marca Zeeweed de PVDF e configuração de fibra oca. Essa ETE de Campos do Jordão, atualmente, tem capacidade para tratar $213 \mathrm{~L} / \mathrm{s}$, atendendo à demanda atual da população fixa da cidade (47 mil habitantes) e da população flutuante. 


\subsection{2 - Configurações das aplicações de sistemas MBR descentralizados}

Neste tópico serão vistas as concepções e arranjos físicos de alguns sistemas em pequena escala descentralizados que foram implantados e que são importantes de serem relatados e destacados com o propósito de utilizar as suas melhores características.

Com o passar do tempo, houve um grande avanço no desenvolvimento da tecnologia MBR. Percebe-se que as configurações têm mudado e a eficiência dos sistemas foi melhorada. Isso decorreu devido ao crescimento de pesquisas, aplicações e investimentos na temática de tecnologias inovadoras e do interesse em produzir um efluente de boa qualidade que pudesse ser utilizado.

Abegglen et al. (2008) investigaram o tratamento de um efluente doméstico com um sistema MBR localizado no porão de uma casa com quatro moradores. Foram avaliadas duas configurações operacionais para a remoção de nutrientes. Para o primeiro período, o primeiro tanque funcionava como um clarificador primário seguido por um MBR no segundo tanque. Para o segundo período, o primeiro tanque funcionou como um reator anaeróbico/anóxico com agitação e aeração intermitente adicionando uma peneira no efluente de entrada do segundo reator biologico com membrana. O desempenho do MBR melhorou com as modificações no segundo período e, a reciclagem de lodo reduziu o problema de odor, ocorreu uma taxa mais elevada de desnitrificação e melhorou, parcialmente, a remoção biológica de fósforo em cerca de 70-90\%.

Sartor et al. (2008) constataram que há viabilidade em aplicar o MBR descentralizado no Vietnã em locais onde não há rede de esgoto municipal. O sistema aplicado é composto por uma fossa séptica, um tanque anóxico e o terceiro é um tanque biológico aeróbio com membrana. O sistema forneceu melhores condições de saúde ao local devido a um efluente quase livre de bactérias e a possibilidade de reutilizar a água tratada.

Battilani (2010) utilizou um sistema sofisticado denominado de Biobooster com disco rotativo e fluxo cruzado de aeração entre os discos de filtração de membrana do tipo cerâmica. Segundo esse autor, esse sistema opera com uma concentração de lodo de quatro 
a cinco vezes mais elevada (SSLM de 23,7 g/L) do que nos sistemas MBR convencionais com capacidade de produzir efluente para reúso direto e indireto.

Verrecht et al. (2010), para otimizarem o consumo de energia de um biorreator com membrana em pequena escala, utilizaram um modelo dinâmico para simulação da planta (Modelo ASM2d), e, por meio de traçadores, determinaram o comportamento hidráulico da planta. O modelo forneceu uma previsão precisa da remoção de nutrientes e concentrações dos SSLM usando valores padrão para todos os parâmetros biocinético e estequiométrico. A modelagem realista da planta foi obtida ao longo de um período de amostragem de quatro meses com a variação do tempo de retenção de sólidos (TRS), vazão de recicurlação e concentração de oxigênio dissolvido. Os novos valores de parâmetros operacionais estabelecidos pelo modelo foram aplicados à planta, resultando numa redução do consumo de energia em $23 \%$, sem comprometer a qualidade do efluente.

Skouteris et al. (2012a) trabalharam com um MBR piloto aeróbio submerso operado com esgoto doméstico com pré-tratamento para remoção de óleo/gordura e de areia/grão, seguido de peneiramento fino e posteriormente um tanque de tratamento biológico e um tanque de filtração por membrana. O lodo era regulado manualmente duas vezes por semana. Dessa forma, o TRS e o TRH foram controlados.

Abbas et al. (2012) avaliaram a aplicabilidade da tecnologia MBR para sistemas de tratamento descentralizado de esgoto na cidade de Bagdá no Iraque. O sistema que foi estudado era controlado automaticamente. O sistema MBR era compacto e composto por um tanque anóxico, um tanque biológico aerado e um tanque com membrana, projetado para produzir água tratada de alta qualidade e sem excesso de lodo. O MBR mostrou-se eficiente quando adotado para estações de tratamento de pequena escala.

Santasmasas et al. (2013), na Espanha, utilizaram a água cinza para reduzir o consumo de água potável em edifícios após passar a água cinza pelo tratamento com um protótipo MBR. Foi necessária a desinfecção de água cinza para garantir a conformidade com os padrões microbianos para reúso de água, para evitar o risco para a saúde e efeitos estéticos e ambientais negativos. Os níveis de compostos orgânicos foram grandemente reduzidos pelo tratamento MBR, e, consequentemente, a etapa de desinfecção requereu menos quantidade de cloro, o que representou baixos potenciais de formação na desinfecção com 
cloro de subprodutos carcinogênicos, de problemas de saúde e de impacto aos ecossistemas.

Tai et al. (2014) investigaram cinco anos de operação de uma planta de MBR descentralizado em um condomínio próximo ao Rio São Lourenço nos EUA (Whitehouse Terrace) com capacidade de $33 \mathrm{~m}$ 3/d. Nessa planta, o esgoto é encaminhado por gravidade para os tanques sépticos existentes e, em seguida, para uma bacia de equalização. Na sequência, o esgoto é bombeado para o sistema MBR, onde sofre filtração.

Um resumo das características das configurações dos sistemas apresentados anteriormente está apresentado na Tabela 3.7, junto com os principais parâmetros usados nos sistemas MBR. Constatou-se que dos oito trabalhos considerados mais relevantes para essa pesquisa em relação à operação do sistema MBR de modo descentralizado, dois sistemas utilizaram módulos de membranas do tipo fibra oca, cinco utilizaram módulos do tipo placa plana e um utilizou módulo compacto com membrana cerâmica de disco rotativo com fluxo cruzado. Apenas um trabalho utilizou membranas de microfiltração (MF). Devido à variação de dados, houve dificuldade em correlacionar as características dos sistemas em relação ao TRS, TRH, pré-tratamento, concentração do SSLM e tipo de material da membrana. Os módulos de membrana de placa plana são melhores de serem aplicados em sistemas de tratamento em escala média e pequena. Além disso, notou-se que é fundamental que se tenha um pré-tratamento antes do tanque com membranas para diminuir a incidência de incrustação na membrana e melhorar a eficiência de tratamento. 
Tabela 3.7 - Resumo dos estudos sobre MBR descentralizados em pequena escala.

\begin{tabular}{|c|c|c|c|c|c|c|c|c|}
\hline Parâmetros da planta & Abegglen (2008) & Sartor (2008) & Batillani (2010) & Verrecht (2010) & Skouteris (2012a) & Abbas (2012) & Tai (2014) & $\begin{array}{c}\text { Santasmasas } \\
(2013) \\
\end{array}$ \\
\hline Local do estudo & $\begin{array}{l}\text { Dubendorf, } \\
\text { Suíça. }\end{array}$ & Vietnã-Ásia & Italia-Bologna & Reino Unido & Sfax, Tunisia & Bagdá-Iraque & $\begin{array}{c}\text { America do Norte } \\
\text { EUA }\end{array}$ & - \\
\hline Tipo de membrana & $\begin{array}{l}\text { Placa plana UF } \\
\text { de } 0.04 \mu \mathrm{m}\end{array}$ & $\begin{array}{l}. \text { Fibra oca - } \\
\text { MF } 0.1 \mu \mathrm{m} .\end{array}$ & $\begin{array}{l}\text { Disco rotativo com } \\
\text { membrana do tipo } \\
\text { cerâmica de UF . } \\
0.06 \mu \mathrm{m} \text {. Diametro } \\
400 \mathrm{~mm} \text {, altura } 5 \mathrm{~m} \text {. }\end{array}$ & $\begin{array}{l}\text { Fibra oca. UF de } \\
0.04 \mu \mathrm{m}\end{array}$ & $\begin{array}{c}\text {.. Placa plana.UF } \\
0.04 \mu \mathrm{m} .\end{array}$ & $\begin{array}{c}. \text { Placa plana } \\
\text { UF - } 0.08 \mu \mathrm{m} .\end{array}$ & $\begin{array}{l}\text { Placa plana de } \\
\text { UF. }\end{array}$ & $\begin{array}{l}\text { Placa plana UF } \\
(0.05 \mu \mathrm{m}) .\end{array}$ \\
\hline Vazão & - & $500 \mathrm{~L} / \mathrm{h}$ & $10-200 \mathrm{~m}^{3} / \mathrm{h}$ & $25 \mathrm{~m}^{3} / \mathrm{d}$ & - & $0,5 \mathrm{~m}^{3} / \mathrm{h}$ & $33 \mathrm{~m}^{3} / \mathrm{d}$ & $1155 \mathrm{~L} / \mathrm{d}$ \\
\hline Estrutura do sistema & $\begin{array}{l}\text { Câmara de } \\
\text { hidrolise seguido } \\
\text { pelo tanque } \\
\text { aeróbio com } \\
\text { membrana com } \\
\text { recirculação }\end{array}$ & $\begin{array}{l}1^{\circ} \text { Tanque } \\
\text { septico, } 2^{\circ} \\
\text { tanque anoxico } \\
\text { e } 3^{\circ} \text { tanque } \\
\text { aeróbio }\end{array}$ & $\begin{array}{c}\text { Somente peneira } \\
\text { antes do MBR } \\
\text { Biobooster }\end{array}$ & $\begin{array}{l}\text { 1. Tanque séptico; } \\
\text { 2. Zona anóxica e } \\
\text { 3. Zona aeróbia } \\
\text { com membrana }\end{array}$ & $\begin{array}{c}\text { 1.Tanque de } \\
\text { alimentação; } 2 \text {. } \\
\text { Tanque biologico } \\
\text { aerado; } 3 \text {. Tanque } \\
\text { com membrana }\end{array}$ & $\begin{array}{l}\text { 1. Tanque } \\
\text { anóxico; } \\
\text { 2. Tanque } \\
\text { aerado; } \\
\text { 3. Tanque com } \\
\text { membrana }\end{array}$ & $\begin{array}{l}\text { 1. Tanque septico; } \\
\text { 2. Tanque de } \\
\text { aeração e } \\
\text { dosagem; } \\
\text { 3.Tanque com } \\
\text { membrana }\end{array}$ & $\begin{array}{c}1 . \\
\text { Peneiramento; } \\
\text { 2. Oxidação } \\
\text { biologica; 3. } \\
\text { Filtração; } 4 . \\
\text { Cloração }\end{array}$ \\
\hline $\begin{array}{l}\text { Malha da peneira } \\
(\mathbf{m m})\end{array}$ & $6 \mathrm{~mm}$ & $0.2 \mathrm{~mm}$ & $\begin{array}{c}100-200 \mu \mathrm{m} / 0,1- \\
0,2 \mathrm{~mm}\end{array}$ & $3 \mathrm{~mm}$ & Fino & $\begin{array}{c}0.75 \mathrm{~mm} \\
\text { rotativa }\end{array}$ & $\begin{array}{c}1.5 \mathrm{~mm} \text { antes do } \\
\mathrm{MBR}\end{array}$ & $1 \mathrm{~mm}$ \\
\hline $\begin{array}{l}\text { Área da membrana } \\
\left(\mathbf{m}^{2}\right)\end{array}$ & $4 \mathrm{~m}^{2}$ & $60 \mathrm{~m}^{2}$ & $5.85 \mathrm{~m}^{2}$ & $139 \mathrm{~m}^{2}$ & $7 \mathrm{~m}^{2}$ & - & - & $7 \mathrm{~m}^{2}$ \\
\hline PTM & - & - & - & - & 0.06 bar & $<150$ mbar & - & \\
\hline Fluxo ( LMH) & - & - & 34.9 & 10.78 & 12.81 & $16.7-35.4$ & 11 & 19.2 \\
\hline $\begin{array}{l}\text { Filtração:relaxação } \\
\text { (min) }\end{array}$ & - & - & - & $10: 0.5 \mathrm{~min}$ & $9: 1 \min$ & 10:01 $\min$ & - & - \\
\hline SSLM e relação A/M & - & - & $\begin{array}{c}\text { SSLM } 23.71 \mathrm{~kg} / \mathrm{m}^{3} \\
\text { ou } \mathrm{g} / \mathrm{L} \text { e } \mathrm{A} / \mathrm{M}=0.36 \\
\mathrm{gDQO} / \mathrm{gSSLM}\end{array}$ & $7832 \mathrm{mg} / \mathrm{L}$ & $\mathrm{SSLM}=9.21 \mathrm{~g} / \mathrm{L}$ & $10-12 \mathrm{mg} / \mathrm{L}$ & $\begin{array}{l}\text { SSLM } 6-12 \mathrm{~g} / \mathrm{L} . \\
\mathrm{A} / \mathrm{M}=0.10 \mathrm{KgDBO} \\
/ \mathrm{m}^{3} \mathrm{~d}\end{array}$ & - \\
\hline TRH & $2 d$ & - & $2 \mathrm{~h} \mathrm{e} 02 \mathrm{~min}$ & - & $1,01 \mathrm{~d}$ & $\begin{array}{l}\text { TRH anox. } 4 \mathrm{~h} \\
\text { e MBR } 8 \mathrm{~h}\end{array}$ & $29 \mathrm{~h}$ & $19.5 \mathrm{~h}$ \\
\hline $\operatorname{TRS} / \boldsymbol{\theta}_{\mathrm{c}}(\mathrm{d})$ & $50-200$ & & 20.9 & 35 & $15-30$ & 20 & - & - \\
\hline $\mathrm{DBO}_{5}(\%)$ & - & - & - & - & $98 \%$ & $97 \%$ & $99 \%$ & $95 \%$ \\
\hline DQO (\%) & $95 \%$ & $95 \%$ & - & - & $89.70 \%$ & - & - & $90 \%$ \\
\hline Nitrogenio total (\%) & $90 \%$ & $80 \%$ & - & - & - & $74 \%$ & N.amonical $99 \%$ & - \\
\hline Fosforo total $(\%)$ & $70 \%$ & - & - & - & - & - & $93 \%$ & - \\
\hline
\end{tabular}


Tabela 3.7 - Resumo dos estudos sobre MBR descentralizados em pequena escala (continuação)

\begin{tabular}{|c|c|c|c|c|c|c|c|c|}
\hline Parâmetros da planta & Abegglen (2008) & Sartor (2008) & Batillani (2010) & Verrecht (2010) & Skouteris (2012a) & Abbas (2012) & Tai (2014) & $\begin{array}{c}\text { Santasmasas } \\
(2013)\end{array}$ \\
\hline SS (\%) & - & - & - & - & $100 \%$ & - & $95 \%$ & $98 \%$ \\
\hline pH & - & - & 6.8 & - & - & - & 7.4 & - \\
\hline Turbidez ( NTU ou \%) & $<5$ (NTU) & $<5$ (NTU) & - & - & $99 \%$ & $<0.2 \mathrm{NTU}$ & - & $98 \%(1.2 \mathrm{NTU})$ \\
\hline $\begin{array}{l}\text { E. Coli e } \\
\text { microbiológicos (\%) }\end{array}$ & - & - & E. Coli $99.9 \%$ & - & $\begin{array}{c}\text { Ausente exceto } \\
\text { Bactéria aeróbica } \\
\text { mesofilica }\end{array}$ & - & - & Ausente \\
\hline $\begin{array}{l}\text { Principais } \\
\text { recomendações e } \\
\text { conclusões }\end{array}$ & $\begin{array}{l}\text { Modo de } \\
\text { operação variava } \\
\text { e era desligado } \\
\text { das 22:00 até as } \\
\text { 5:30 h. } \\
\text { O excesso de } \\
\text { lodo era } \\
\text { armazenado em } \\
\text { um bag num } \\
\text { intervalo de 1-2 } \\
\text { semanas. O } \\
\text { problema de mau } \\
\text { odor no porão foi } \\
\text { resolvido com a } \\
\text { reciclagem do } \\
\text { lodo e modo de } \\
\text { aeração } \\
\text { intermitente }\end{array}$ & $\begin{array}{l}\text { Recirculação da } \\
\text { biomassa do } \\
\text { tanque aerado } \\
\text { para o tanque } \\
\text { anóxico. } \\
\text { Concluíram que } \\
\text { é possível } \\
\text { construir um } \\
\text { MBR com } \\
\text { métodos simples } \\
\text { sob condições } \\
\text { locais de países } \\
\text { em } \\
\text { desenvolvimento } \\
\text {. }\end{array}$ & $\begin{array}{l}\text { Remoção maior } \\
\text { que } 80 \% \text { de } \\
\text { metais } \mathrm{Cd}, \mathrm{Cr}, \mathrm{As} \text {, } \\
\mathrm{Cu}, \mathrm{Pb} \text {. }\end{array}$ & $\begin{array}{l}\text { Água recuperada } \\
\text { de } 25 \mathrm{~m}^{3} / \mathrm{d} \text { para } \\
\text { usar em descarga } \\
\text { de banheiro e } \\
\text { irrigação. } \\
\text { Consumo de } \\
\text { energia de } 3.11 \\
\mathrm{kWh} / \mathrm{m}^{3} \text { com o } \\
\text { modelo otimizado } \\
\text { alcançaria } 2.99 \\
\mathrm{kWh} / \mathrm{m}^{3} \text {. } \\
\text { Remoção de } \mathrm{N} \\
\text { diminuiu com a } \\
\text { diminuição do } \\
\text { TRS. Com o } \\
\text { aumento da Q de } \\
\text { recirculação } \\
\text { melhorou a } \\
\text { remoção de NT e a } \\
\text { deterioração da } \\
\text { remoção PT. }\end{array}$ & $\begin{array}{l}\text { A natureza da água } \\
\text { tratada livre de } \\
\text { patógenos } \\
\text { confirmou a sua } \\
\text { aptidão para } \\
\text { irrigação irrestrita. } \\
\text { O aeradores } \\
\text { consumiam } 60 \% \\
\text { da energia. A } \\
\text { bolha fina para a } \\
\text { limpeza do módulo } \\
\text { não é eficiente. O } \\
\text { lodo era retirado } \\
\text { manualmente } 2 \\
\text { vezes semana para } \\
\text { controlar o TRS e } \\
\text { o TRH }\end{array}$ & $\begin{array}{l}\text { O oxigénio } \\
\text { dissolvido no } \\
\text { reator anóxico } \\
\text { é }<0,5 \mathrm{mg} / \mathrm{L} \text {, } \\
\text { enquanto o } \\
\text { oxigénio } \\
\text { dissolvido na } \\
\text { MBR é na } \\
\text { faixa de } 7,0- \\
8,0 \mathrm{mg} / \mathrm{l} \text {. }\end{array}$ & $\begin{array}{l}\text { A remoção de } \mathrm{P} \text { e } \\
\text { por precipitação. } \\
\text { Dosagem cloreto } \\
\text { férrico. Requisito } \\
\text { operacional de } \\
\text { visita a estação é } \\
\text { de } 1 \text { vez na } \\
\text { semana. } \\
\text { O alto teor de } \\
\text { SSLM, e um TRS } \\
\text { maior foi } \\
\text { facilmente } \\
\text { atingível, } \\
\text { assegurando um } \\
\text { processo de } \\
\text { nitrificação } \\
\text { completa, mesmo } \\
\text { a uma temperatura } \\
\text { baixa de } 8^{\circ} \mathrm{C} \text {. }\end{array}$ & $\begin{array}{l}\mathrm{DBO}_{5}(6,2 \\
\text { mg/L) não } \\
\text { atendeu ao } \\
\text { regulamento } \\
\text { Espanhol } \\
\text { RD1620/2007 } \\
\text { para uso urbano } \\
\text { irrestrita no } \\
\text { Texas (5 mg/L). } \\
\text { Somente para } \\
\text { uso em } \\
\text { represamentoe } \\
\text { paisagem (10 } \\
\text { mg/L). }\end{array}$ \\
\hline Fabricante e site & $\begin{array}{c}\text { Sem } \\
\text { especificação }\end{array}$ & $\begin{array}{l}\text { Czech company, } \\
\text { Eidos Ltd } \\
\text { http://www.zena- } \\
\text { membranes.cz/ }\end{array}$ & $\begin{array}{c}\text { Grundfos } \\
\text { Biobooster } \\
\text { www.grundfos.co } \\
\text { m/biobooster }\end{array}$ & $\begin{array}{l}\text { ZW500c aGE } \\
\text { Zenon, Canadá }\end{array}$ & $\begin{array}{c}\text { Water Systems by } \\
\text { Weise } \\
\text { MicroClear } \\
\text { http://www.microc } \\
\text { lear.de/en }\end{array}$ & $\begin{array}{c}\text { Ecologix } \\
\text { technologies } \\
\text { (USA) } \\
\text { http://www.eco } \\
\text { logix.com/ }\end{array}$ & $\begin{array}{c}\text { Water Systems by } \\
\text { Weise } \\
\text { MicroClear } \\
\text { http://www.microc } \\
\text { lear.de/en }\end{array}$ & $\begin{array}{c}\text { Sem } \\
\text { especificação }\end{array}$ \\
\hline Catalogo disponível & Não & Sim & Sim & Sim & Sim & Sim & Sim & Não \\
\hline
\end{tabular}




\section{3 - MÉTODOS MULTIOBJETIVO E MULTICRITÉRIO DE APOIO À DECISÃO}

De acordo com Gomes et al. (2004) há duas vertentes que marcam o desenvolvimento de pesquisas na escolha dos métodos de apoio a decisão multicritério, denominadas de Escola Americana (cujos principais métodos são o AHP e o MAULT e a Escola Francesa (cujos principais métodos são o ELECTRE e o PROMÉTHÉE). A Escola Francesa também é chamada por alguns autores como Escola Europeia .

Desenvolveu-se na Escola Francesa um modelo mais flexível do problema, que não pressupõe uma comparação entre as alternativas e não impõe ao tomador de decisão uma estruturação hierárquica dos critérios existentes, ao contrário dos métodos da Escola Americana (Gomes et al., 2004).

Diferentes classificações para os Métodos Multicritério têm sido apresentadas na literatura, como em Roy (1985), que os divide em: (1) Métodos com critério de aproximação única de síntese, desconsiderando qualquer incomparabilidade; (2) Métodos de aproximação hierárquica de síntese, aceitando incomparabilidades; e (3) Métodos de aproximação do julgamento local interativo, com interações do tipo tentativa-e-erro.

Devido a complexidade dos problemas ambientais, Souza (2014) afirma que esses problemas podem ser mais bem analisados se considerados sob a ótica de múltiplos objetivos e múltiplos critérios. Uma forma importante de entender e aplicar esses métodos é entender como são classificados.

Souza (2014) sugere a classificação dos métodos em diferentes aspectos, permitindo que um método se enquadre em mais de uma classe simultaneamente:

(1) Quanto às variáveis de decisão:

- Métodos contínuos;

- Métodos discretos.

(2) Quanto ao modo de atuar frente ao agente decisor:

- Articulação prévia de preferências;

- Articulação progressiva de preferências.

(3) Quanto à maneira de enfrentar o problema (tipo de função objetivo):

- Determinísticos; 
- Estocásticos;

- Conjuntos Difusos (Fuzzy Analysis).

(4) Quanto ao tipo de aplicação:

- Métodos de classificação (hierarquização);

- Métodos de alocação (qualificação de alternativas).

(5) Quanto ao modo de solução:

- Teoria da Utilidade;

- Deslocamento Ideal;

- Compensações (trade-offs);

- Funções de Valor;

- Relações de Dominância.

(6) Quanto ao número de agentes de decisão:

- Com um único Agente Decisor;

- Com multigestores (Decisão em Grupo).

Para um aprofundamento do tema em métodos multiobjetivo e multicritério de apoio à decisão, sugere-se $a$ leitura das seguintes referências: Belton (1986), Boer et al. (2001), Poh (1998), Zanakis et al. (1998), Mendoza e Martins (2006), Wang et al. (2009), Ho et al (2010), Kelemenis e Askounis (2010).

\subsection{1 - Emprego dos métodos multiobjetivo e multicritério}

Esta seção aborda alguns aspectos básicos relacionados à utilização e aplicação dos métodos multiobjetivo e multicritério como ferramenta para resolver problemas relacionados ao saneamento.

Souza (1992) desenvolveu o modelo PROSEL-I (Process Selection Version I) usando princípios de tecnologia apropriada e análise de decisão com múltiplos objetivos e múltiplos critérios, com o objetivo de eleger processos de tratamento de águas residuárias. No modelo PROSEL-I , foram aplicados os métodos da Ponderação Aditiva Simples, Programação de Compromisso e ELECTRE-I para a análise do processo decisório. 
Para uma seleção preliminar de sistemas de tratamento de esgotos, von Sperling (1995) organizou critérios e dados baseados em comparações qualitativas entre alternativas, comparações diagramáticas, e balanço de vantagens e desvantagens de diversos sistemas.

Souza et al. (2001), por meio da utilização de métodos de análise multiobjetivo e multicritério, avaliaram o desempenho de alternativas tecnológicas para tratamento de efluentes de reatores anaeróbios. A metodologia constou do desenvolvimento das seguintes atividades: (1) Pesquisa bibliográfica, de dados e de opinião; (2) Avaliação, seleção e adaptação de métodos de análise multiobjetivo; (3) Escolha dos critérios de avaliação das alternativas tecnológicas; e (4) Aplicação dos métodos selecionados e adaptados ao objetivo pretendido. A etapa de análise final foi realizada utilizando-se três métodos de análise: Ponderação Aditiva, Programação de Compromisso e ELECTRE-III.

Neder et al. (2002) avaliaram a seleção da alternativa mais apropriada para a remoção de algas do efluente de lagoa de estabilização, considerando cinco diferentes processos de tratamentos naturais testados, para selecionar o processo que fosse mais satisfatório para tal aplicação.

Brites (2008) para selecionar sistemas de reúso de água em irrigação paisagística com dados obtidos em um estudo piloto utilizou abordagem multicritério aplicada aos métodos Compromise Programming, PROMETHEE 2 e o TOPSIS.

Hunt (2013) desenvolveu uma metodologia para a seleção de tecnologia de tratamento de esgoto, especificamente para pequenos municípios brasileiros, por meio da análise multiobjetivo e multicritério, particularmente a teoria da utilidade multiatributo - MAUT. Neste sistema, as trinta e duas alternativas consideradas foram separadas em alternativas factíveis e não factíveis, onde as factíveis atendem aos objetivos de tratamento e as restrições de cada tecnologia. Para comparar as alternativas factíveis, utilizou-se o método MAUT e consideraram-se dezenove critérios econômicos, ambientais, sociais e tecnológicos. Os resultados indicaram que o sistema poderá auxiliar na escolha de tecnologias de tratamento de esgoto. Verificou-se que, os critérios econômicos e tecnológicos são o mais priorizado no Brasil. 
Em função do conjunto de informações consideradas relevantes para esta pesquisa construiu-se uma base de dados e, estão apresentadas na Tabela 3.8 as principais referências que foram utilizadas como base de informações para a elaboração da Fase 2.

Tabela 3.8 - Levantamento de dados com maior relevância para executar a Fase 2.

\begin{tabular}{|c|c|c|}
\hline Autor & Aplicação & $\begin{array}{l}\text { Métodos } \\
\text { utilizados }\end{array}$ \\
\hline Souza (1992) & $\begin{array}{l}\text { Propõe um modelo para a tomada de decisão na escolha da } \\
\text { tecnologia apropriada para o tratamento de água residuária }\end{array}$ & $\begin{array}{l}\text { PA; CP com } \\
\text { adaptação; } \\
\text { Electre I. }\end{array}$ \\
\hline $\begin{array}{l}\text { Souza } \\
(2001)\end{array}$ & $\begin{array}{l}\text { Análise das alternativas de pós-tratamento de efluentes de } \\
\text { reatores anaeróbios }\end{array}$ & $\begin{array}{ll}\mathrm{PA} ; & \mathrm{CP} \\
\text { Electre III }\end{array}$ \\
\hline Carneiro (2001) & $\begin{array}{l}\text { Um modelo de seleção tecnológica de alternativas para o } \\
\text { tratamento de água residuária municipal }\end{array}$ & $\begin{array}{l}\text { PA; } \quad \mathrm{CP} ; \\
\text { Electre III }\end{array}$ \\
\hline Brostel (2002) & $\begin{array}{l}\text { Formulação de modelo de avaliação de desempenho global } \\
\text { de duas estações de tratamento de esgoto }\end{array}$ & ELECTRE TRI \\
\hline Werner (2009) & $\begin{array}{l}\text { Verificou a sustentabilidade sistemas remotos de água e } \\
\text { esgoto na Austrália }\end{array}$ & $\begin{array}{l}\text { PROMETHEE } \\
\text { e ELECTRE }\end{array}$ \\
\hline $\begin{array}{l}\text { Nogueira et al. } \\
\text { (2009) }\end{array}$ & $\begin{array}{l}\text { Avaliação econômica e ambiental de sistemas de tratamento } \\
\text { de água residuária pequena e descentralizada }\end{array}$ & $\begin{array}{l}\text { Análise de } \\
\text { ciclo de vida }\end{array}$ \\
\hline Mendonça (2009) & $\begin{array}{l}\text { Metodologia para avaliação de desempenho de sistemas de } \\
\text { drenagem urbana }\end{array}$ & $\begin{array}{l}\text { ELECTRE TRI } \\
\text { e TOPSIS }\end{array}$ \\
\hline $\begin{array}{l}\text { Oakley } \\
(2010)\end{array}$ & $\begin{array}{l}\text { Estratégias de desempenho e gestão de alternativas para o } \\
\text { controle de nitrogênio em estação de tratamento de água } \\
\text { residuária }\end{array}$ & - \\
\hline Ganoulis (2011) & $\begin{array}{l}\text { Avaliação de alternativas estratégicas para a reciclagem de } \\
\text { água residuária na área do mediterrâneo }\end{array}$ & $\begin{array}{l}\text { CP, ELECTRE } \\
\text { III e IV }\end{array}$ \\
\hline $\begin{array}{l}\text { Molinos-Senante } \\
\text { et al. (2012) }\end{array}$ & $\begin{array}{l}\text { Ferramentas de análise de custo-benefício com } \\
\text { externalidades ambiental a grande quantidade de } \\
\text { conhecimento de tecnologias de tratamento contida no } \\
\text { sistema de suporte a decisão foi aplicado em diferentes }\end{array}$ & $\begin{array}{l}\text { Análise de } \\
\text { ciclo de vida; } \\
\text { Análise de } \\
\text { custo-beneficio }\end{array}$ \\
\hline Vanzetto (2012) & $\begin{array}{l}\text { Metodologia de análise tecnológica de alternativas para o } \\
\text { desaguamento de lodos produzidos em estações de } \\
\text { tratamento de esgoto }\end{array}$ & $\begin{array}{l}\text { CP, TOPSIS, } \\
\text { ELECTRE III e } \\
\text { AHP }\end{array}$ \\
\hline Sadr et al. (2013) & $\begin{array}{l}\text { Avaliou a seleção da tecnologia de membrana para sistema } \\
\text { de tratamento centralizados }\end{array}$ & - \\
\hline $\begin{array}{l}\text { Tjandraatmadja } \\
\text { et al. (2013) }\end{array}$ & $\begin{array}{l}\text { Seleção de um sistema de tratamento de águas residuárias } \\
\text { para sist remotos com falha no tanque séptico }\end{array}$ & PROMETHEE \\
\hline Guo et al. (2014) & $\begin{array}{l}\text { Estudo em } 62 \text { estações de tratamento de esgoto } \\
\text { descentralizadas instalada em áreas rurais na China }\end{array}$ & - \\
\hline $\begin{array}{l}\text { Ouyang } \\
\text { (2015) }\end{array}$ et al. & $\begin{array}{l}\text { Seleção de alternativa de tratamento natural de água } \\
\text { residuária }\end{array}$ & $\begin{array}{l}\text { Lógica FUZZY } \\
\text { e AHP }\end{array}$ \\
\hline Sadr et al. (2015) & $\begin{array}{l}\text { Utilização de aplicação de membranas em diversos } \\
\text { tipos/fases de tratamento }\end{array}$ & $\begin{array}{l}\text { Logica FUZZY } \\
\text { e TOPSIS }\end{array}$ \\
\hline $\begin{array}{l}\text { Aydiner } \\
(2016)\end{array}$ & $\begin{array}{l}\text { Como objetivo é a utilização da água residuária da indústria } \\
\text { de laticionio o que prevalece a alternativa que apresenta um } \\
\text { melhor retorno financeiro. }\end{array}$ & AHP \\
\hline
\end{tabular}

PA: Ponderação aditiva; CP: Programação de compromisso. 


\subsection{2 - Aplicação e desenvolvimento do TOPSIS}

O método TOPSIS (Technique for Order Performance by Similarity to Ideal Solution) baseia-se no princípio de que a alternativa escolhida deveria ter a menor distância vetorial a partir de uma solução positiva ideal (PIS - Positive Ideal Solution) e a maior distância a partir de uma solução negativa ideal (NIS - Negative Ideal Solution). O Método TOPSIS utiliza um coeficiente de similaridade para ordenar as alternativas e é um aperfeiçoamento do Método CP (Programação de Compromisso) (Souza, 2014).

Dada uma matriz e a definição de valores máximos e mínimos dentre as alternativas com critério crescente $\mathrm{j}\left(\mathrm{f}_{\mathrm{j}}{ }^{*} ; \mathrm{f}_{\mathrm{j}}^{-}\right)$e a definição dos máximos e mínimos valores dentre as alternativas com critério decrescente $\mathrm{i}\left(\mathrm{f}_{\mathrm{i}}{ }^{*} ; \mathrm{f}_{\mathrm{i}}^{-}\right)$, pode-se realizar o cálculo dos vetores com os melhores e piores valores, ou seja, os valores de PIS ( $\left.f^{*}\right)$ e NIS (f $f^{-}$, utilizando as distâncias entre as alternativas. De posse dos valores encontrados para PIS (f*) e NIS (f-), pode-se obter as funções de distância, onde $\mathrm{w}_{\mathrm{j}}$, com $\mathrm{j}=1,2, \ldots$, J é o valor da importância relativa (peso) da alternativa para cada objetivo, com $p=1,2, \ldots, \infty$, pelas Equações (3.1) e (3.2). Sendo p considerado a métrica do sistema (Souza, 2014).

$$
\begin{aligned}
& d_{p}^{P I S}=\left\{\sum_{j \in J} w_{j}^{p}\left[\frac{f_{j}^{*}-f_{j}(x)}{f_{j}^{*}-f_{j}^{-}}\right]^{p}+\sum_{i \in I} w_{i}^{p}\left[\frac{f_{i}(x)-f_{i}^{*}}{f_{i}^{-}-f_{i}^{*}}\right]^{p}\right\}^{1 / p} \\
& d_{p}^{N I S}=\left\{\sum_{j \in J} w_{j}^{p}\left[\frac{f_{j}(x)-f_{j}^{-}}{f_{j}^{*}-f_{j}^{-}}\right]^{p}+\sum_{i \in I} w_{i}^{p}\left[\frac{f_{i}^{-}-f_{i}(x)}{f_{i}^{-}-f_{i}^{*}}\right]^{p}\right\}^{1 / p}
\end{aligned}
$$

Quando $\mathrm{p}$ aumenta, a distância de $\mathrm{d}_{\mathrm{p}}$ decresce, dando maior destaque ao desvio de cada alternativa em relação à solução ideal. Especificamente, p reflete a importância atribuída aos desvios máximos. Se $\mathrm{p}=1$, todos os desvios em relação ao ideal tem peso igual na determinação do comprimento. Se $\mathrm{p}=2$, significa que os desvios possuem pesos proporcionais à sua magnitude. $\mathrm{E}$ se $\mathrm{p}=\infty$, o maior desvio recebe a máxima importância. 
Encontrados os valores de $\mathrm{d}_{\mathrm{p}}^{\mathrm{PIS}}$ e $\mathrm{d}_{\mathrm{p}}^{\mathrm{NIS}}$ para cada alternativa (somatório das alternativas com critério crescente e decrescente), pode-se calcular o coeficiente de similaridade $\left(\mathrm{C}_{\mathrm{k}}{ }^{*}\right)$ para cada alternativa em relação à f*$^{*}$, definido pela Equação (3.3).

$$
C_{k}^{*}=\frac{d_{p}^{N I S}}{d_{p}^{P I S}+d_{p}^{N I S}}
$$

$\mathrm{O}$ ordenamento das alternativas é feito a partir do Coeficiente de Similaridade $\left(\mathrm{Ck}^{*}\right)$, o qual coloca que a melhor alternativa será aquela mais próxima da solução ideal, isto é, aquela em que $\mathrm{C}_{\mathrm{k}}{ }^{*}$ está mais próximo de 1 , ou seja, mais próxima da solução positiva ideal (PIS) e, simultaneamente, mais afastada da solução negativa ideal (NIS).

\subsection{3 - Aplicação e desenvolvimento do ELECTRE-III}

O método conhecido como Elimination Et Choice Expressing Reality (ELECTRE) define uma série de processos sobre as alternativas consideradas, as quais pertencem ao conjunto de possíveis soluções do problema (Gomes et al., 2004).

O método ELECTRE-III elabora as comparações internamente, a partir de informações fornecidas pelo agente decisor, que proporcionam o estabelecimento de conceitos de limiares de "indiferença", "preferência fraca", "preferência estrita" e "veto". Sua lógica de funcionamento é análoga aos outros métodos da série ELECTRE, onde são estabelecidas diferentes ordenações preferenciais das alternativas: uma ascendente, uma descendente, e uma ordenação final formada a partir das anteriores (Roy, 1991; Duckstein et al., 1994).

Deve-se notar que não existem verdadeiros valores para os limiares, os valores escolhidos para atribuir aos limiares são os que melhor se adaptam para expressar o caráter imperfeito do conhecimento (Figueira et al., 2005).

Com o objetivo de considerar a imprecisão, incerteza e a indeterminação, além de outras relações de preferência entre as alternativas, utilizam-se, no caso de muitos métodos multicritério, os limiares, p e q. Quando p e q são nulos, o critério é chamado de verdadeiro, ou seja, há completa transitividade entre as alternativas. Para p e q diferentes 
de zero, o critério passa a ser denominado de "pseudocriterio", porque permite outros tipos de relações de preferências entre ações (Roy, 1991).

O limiar de veto (v) indica o nível a partir do qual uma alternativa A é tão melhor que uma alternativa B sob um determinado critério que, mesmo considerando os outros critérios, B nunca poderá ser considerada globalmente melhor que A (Roy, 1991).

O método ELECTRE-III é considerado o mais aceitável para os casos de incerteza e imprecisão na avaliação das alternativas e permite analisar situações onde nem todas as alternativas são comparáveis entre si devido a consideráveis diferenças de pontos de vista (Cordeiro Netto et al., 2000).

Define-se $i_{m}(a)$ como o valor do critério $m$ atribuído para a alternativa $a, q\left(i_{m}(a)\right), p\left(i_{m}(a)\right)$, $q\left(i_{m}(a)\right)$ e $v\left(i_{m}(a)\right)$ como as funções de indiferença, preferência e veto, respectivamente. Sabendo que as alternativas são avaliadas duas a duas, há quatro situações possíveis: indiferença, preferência fraca, preferência forte e incomparabilidade. Essas situações são definidas conforme as inequações (3.4) para um critério decrescente.

$$
\begin{gathered}
\text { Indiferença: } \mathrm{i}_{\mathrm{m}}(\mathrm{b})<\mathrm{i}_{\mathrm{m}}(\mathrm{a})+\mathrm{q}\left(\mathrm{i}_{\mathrm{m}}(\mathrm{a})\right) \\
\text { Preferência fraca: } \mathrm{i}_{\mathrm{m}}(\mathrm{a})+\mathrm{q}\left(\mathrm{i}_{\mathrm{m}}(\mathrm{a})\right)<\mathrm{i}_{\mathrm{m}}(\mathrm{b})<\mathrm{i}_{\mathrm{m}}(\mathrm{a})+\mathrm{p}\left(\mathrm{i}_{\mathrm{m}}(\mathrm{a})\right) \\
\text { Preferência forte: } \mathrm{i}_{\mathrm{m}}(\mathrm{a})+\mathrm{p}\left(\mathrm{i}_{\mathrm{m}}(\mathrm{a})\right)<\mathrm{i}_{\mathrm{m}}(\mathrm{b}) \\
\text { Incomparabilidade: } \mathrm{i}_{\mathrm{m}}(\mathrm{a})+\mathrm{v}\left(\mathrm{i}_{\mathrm{m}}(\mathrm{a})\right)<\mathrm{i}_{\mathrm{m}}(\mathrm{b})
\end{gathered}
$$

No método ELECTE-III são calculados índices de acordo com as Equações (3.5), para cada critério, que são os índices de concordância entre as alternativas. Cada um desses índices indica o grau de confiança com que se afirma que a alternativa $a$ é tão boa quanto a alternativa $b$. Logo é construída uma matriz de concordâncias para o critério $m$, semelhante ao que é feito para o ELECTRE-I.

$$
\begin{gathered}
\mathrm{C}_{\mathrm{m}}(\mathrm{a}, \mathrm{b})=0 \text {, se } \mathrm{i}_{\mathrm{m}}(\mathrm{a})+\mathrm{p}\left(\mathrm{i}_{\mathrm{m}}(\mathrm{a})\right) \mathrm{i}_{\mathrm{m}}(\mathrm{b}) \\
\mathrm{C}_{\mathrm{m}}(\mathrm{a}, \mathrm{b})=1 \text {, se } \mathrm{i}_{\mathrm{m}}(\mathrm{a})+\mathrm{q}\left(\mathrm{i}_{\mathrm{m}}(\mathrm{a})\right) \mathrm{i}_{\mathrm{m}}(\mathrm{b}) \\
\mathrm{C}_{\mathrm{m}}(\mathrm{a}, \mathrm{b}) \text { é linear, se } \mathrm{i}_{\mathrm{m}}(\mathrm{a})+\mathrm{q}\left(\mathrm{i}_{\mathrm{m}}(\mathrm{a})\right)<\mathrm{i}_{\mathrm{m}}(\mathrm{b})<\mathrm{i}_{\mathrm{m}}(\mathrm{a})+\mathrm{p}\left(\mathrm{i}_{\mathrm{m}}(\mathrm{a})\right)
\end{gathered}
$$


Nesse método, também é criada uma matriz de discordância com os índices calculados conforme as inequações mostradas na Equação (3.6). Os índices de discordância, que compõem essa matriz variam entre 0 e 1 e medem, para cada critério, o grau de desconfiança ou refutação em se afirmar que a alternativa a é tão boa quanto a alternativa b.

$$
\begin{gathered}
D_{m}(a, b)=0 \text { se } i_{m}(a)+p\left(i_{m}(a)\right) i_{m}(b) \\
D_{m}(a, b)=1 \text { se } i_{m}(a)+v\left(i_{m}(a)\right) i_{m}(b) \\
D_{m}(a, b) \text { é linear se } i_{m}(a)+p\left(i_{m}(a)\right)<i_{m}(b)<i_{m}(a)+v\left(i_{m}(a)\right)
\end{gathered}
$$

Existe no ELECTRE-III o cálculo de um índice de credibilidade, que permite a construção de uma matriz de credibilidade. Isso é feito utilizando os valores das matrizes de concordância e discordância para um determinado critério $m$. O índice de credibilidade mostra com que medida uma "alternativa $a$ desclassifica a alternativa $b$ ", ou a verossimilhança com a qual o decisor escolhe a alternativa $a$ em detrimento à $b$.

O primeiro passo na construção da matriz de credibilidade é o cálculo de uma matriz de concordância global, que calcula um índice geral da concordância entre duas alternativas levando em conta todos os critérios simultaneamente. Esse cálculo é feito conforme a Equação (3.7):

$$
C(a, b)=\sum_{m=1}^{I} C_{m}(a, b) \cdot w_{m}
$$

Na qual:

$\mathrm{w}_{\mathrm{m}}$ é o peso atribuído ao critério $\mathrm{m}$.

O próximo passo é definir $\mathrm{L}(\mathrm{a}, \mathrm{b})$, que é o conjunto dos critérios em que o índice de discordância é maior que o de concordância global, ou seja, $\operatorname{Dm}(a, b) C(a, b)$. Se esse conjunto é vazio, o valor do índice de credibilidade é igual ao do índice concordância, $C r(a, b)=C(a, b)$. Caso contrário, o índice de credibilidade é dado pela Equação (3.8). 


$$
C r(a, b)=C(a, b) . \prod_{i \in L(a, b)} \frac{\left[1-D_{m}(a, b)\right]}{[1-C(a, b)]}
$$

Enquanto os pesos dos critérios determinam a importância relativa dada a cada critério, possuindo assim um grau mais elevado de arbítrio, os limiares guardam uma relação maior com a natureza do critério e com a qualidade da avaliação (incertezas e imprecisões).

\section{4 - AVALIAÇÃO TECNOLÓGICA}

O esgotamento dos recursos naturais nos países desenvolvidos, aliado ao crescente descontentamento gerado pelo processo de produção capitalista e o crescente problema ecológico e, sobretudo, a consciência cada vez maior e generalizada de que a tecnologia empregada não é só uma das principais causas dessa situação, como é incapaz de resolvêla, fez crescer o interesse em tecnologias alternativas (Dagnino, 1978).

No Brasil, os princípios fundamentais que se destacam à oferta de saneamento básico dispostos na Lei $n^{\circ}$. 11445 de 2007 são a universalização do acesso, a eficiência e sustentabilidade econômica, a adoção de técnicas e processos de acordo com as características locais e regionais, e a utilização de tecnologia apropriada, considerando a capacidade de pagamento dos usuários e a adoção de soluções graduais e progressivas. Deste modo, diversos fatores devem ser considerados na escolha da melhor alternativa tecnológica.

A ideia de uma seleção mais eficaz de tecnologia parte das seguintes constatações: (1) existência de alternativas mais eficazes que outras; (2) possibilidade de definir critérios e métodos para avaliar projetos e selecionar a tecnologia mais apropriada; e (3) possibilidade de adaptar tecnologias às condições econômicas locais (Buarque, 1983).

Willoughby (1990) verificou que frequentemente ocorre a escolha de tecnologias inapropriadas, isso reafirma a ideia da importância da escolha tecnológica. Essa "impropriedade" é evidenciada em efeitos colaterais na sociedade e na dinâmica da estrutura social. A “impropriedade" pode ser observada de diversas formas, tais como: (a) a tecnologia é desenvolvida em um contexto diferente do qual ela é aplicada; (b) a 
tecnologia é boa para uma classe social, mas é ruim para outra; (c) existe incompetência e/ou inabilidade do projetista. A prática da escolha tecnológica requer especialistas e técnicos capazes de incorporar dados sócio-políticos e considerações ético-pessoais ao processo de concepção técnica (Willoughby, 1990).

No Brasil, a utilização de tecnologias apropriadas iniciou-se na passagem da década de 1970 para 1980, quando surgiu uma maior preocupação com o paradigma que regia as práticas profissionais sanitárias (Oliveira e Moraes, 2005). Para Kligerman (1995), a decisão de implantação de inovação tecnológica, no campo do saneamento não pode ser individual, deve envolver um consenso social que é difícil de ser alcançado por consequência das mudanças e condições locais, isto é, existe diversidade territorial, econômica e cultural entre as regiões, e uma tecnologia padronizada não necessariamente domina todas essas diversidades. Por isso há necessidade de se conceber sistemas de esgotamento sanitário com tecnologias apropriadas, ou seja, que se adaptem às características locais, reduzindo custos sem diminuir a eficiência.

O processo de decisão e avaliação tecnológica envolve diversos critérios de avaliação, os quais se baseiam em conhecimentos e experiência técnica, visando trazer para a realidade local, mão de obra e materiais disponíveis, sempre em busca de aperfeiçoamento para melhor atender às comunidades e aos objetivos específicos.

Kligerman (1995) ressalta que, para compreender a utilização de uma tecnologia, é importante conhecer as formas de gestão para a sua implementação, as condições, conjunturas e os contextos políticos de sua utilização quanto as suas características técnicas. Em relação à descentralização de sistemas de tratamento de esgotos, Kligerman (1995) aponta que a descentralização é necessária mas não é suficiente para levar à utilização de tecnologias apropriadas. Caso uma regulação para implantação de sistemas descentralizados fosse bem feita, consequentemente, conduziria a tecnologias mais adequadas e apropriadas. No entanto, isso depende da vontade política. O modelo de gestão atual que é implantado no município por companhias concessionárias devem ser revisto além da necessidade de incluir a comunidade no planejamento das ações de saneamento. 
Souza et al. (2001) abordaram algumas pesquisas em que aplicaram a análise tecnológica multiobjetivo ao problema de águas residuárias, entre elas: a metodologia de Wolf (1987) para análise de processos de tratamento de águas residuárias; a metodologia de Tecle et al. (1988) para a gestão de águas residuárias; o modelo PROSEL-I (Souza, 1992) para seleção de tecnologias para tratamento de águas residuárias. Baseados nessas aplicações, propuseram uma metodologia de análise tecnológica composta de cinco fases, que são: Fase I - Instruções gerais e informação de dados; Fase II - Pré-seleção de alternativas viáveis ao caso; Fase III - Análise “técnica”; Fase IV - Análise sócioeconômica; e Fase V Análise tecnológica global (multiobjetivo).

Souza e Foster (1996) fizeram uma revisão crítica das metodologias que foram desenvolvidas para auxiliar a seleção do processo a ser implantado em uma instalação para tratamento de águas residuárias e sugeriram alguns quesitos para o potencial usuário usar alguns critérios para se decidir sobre qual metodologia deverá utilizar, respondendo as seguintes questões:

(1) Conjunto de alternativas: o conjunto de alternativas contido ou gerado pelo modelo satisfaz às exigências do caso específico?

(2) Técnica de solução: a) qual é a técnica de solução que se deseja (tabular, gráfica, ou computacional)? b) há tempo suficiente e condições para instalar um programa de computador? Com que frequência necessita-se deste tipo de decisão?

(3) Dados de entrada: a) os dados requeridos pela metodologia são disponíveis? b) quais são os custos e qual é o tempo necessário para o levantamento destes dados?

(4) Fatores influentes na seleção: a) quais são os fatores de decisão mais importantes no caso específico? b) quais são os modelos que contemplam estes fatores?

A decisão do processo de tratamento de efluente a ser adotado deve resultar de um balanceamento entre critérios técnicos e econômicos, com um julgamento quantitativo e qualitativo de cada alternativa. Para que a escolha conduza à alternativa mais adequada para a configuração em análise, critérios ou pesos devem ser atribuídos a diversos aspectos, vinculados à realidade em foco. Na Figura 3.4 apresenta-se uma comparação dos aspectos mais relevantes na seleção de tecnologia de tratamento entre os países desenvolvidos e em desenvolvimento (von Sperling, 2005). 
Na Figura 3.4 nota-se que os itens críticos para os países em desenvolvimento, como os custos de operação e implantação, sustentabilidade e simplicidade apresentam um grau de importância maior. No entanto, contrariamente, os países desenvolvidos prezam mais pela eficiência e confiabilidade do sistema. Ou seja, em regiões desenvolvidas há uma preocupação maior com a preservação dos recursos naturais e esses padrões são estabelecidos por meio de regulamentos de controle e manutenção que são muito criteriosos.

\section{ASPECTOS IMPORTANTES NA SELEÇÃO DE SISTEMAS DE TRATAMENTO DE ESGOTOS}

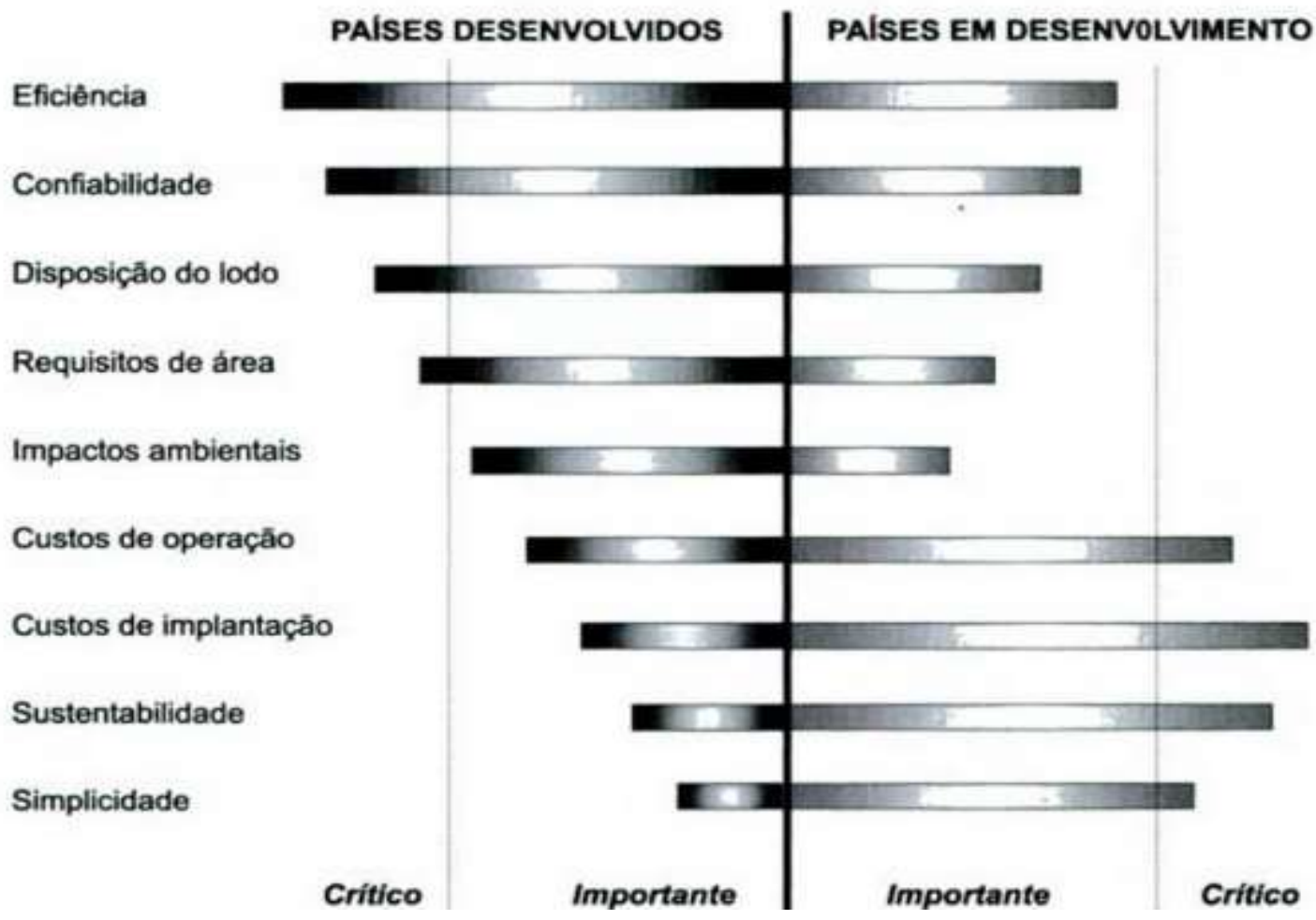

Figura 3.4 - Aspectos críticos e importantes na seleção de sistemas de tratamento de esgotos em regiões desenvolvidas e em desenvolvimento (von Sperling, 2005).

Vários trabalhos no âmbito internacional quanto nacional, alguns exemplos incluem os trabalhos de Souza (1992), PROSAB (1999), Carneiro et al. (2001), Brostel (2002), Werner (2009), Tjandraatmagia et al. (2013), Molinos-Senante et al. (2012), Sadr et al. (2015), Aydiner et al. (2016), foram resgatados, analisados e complementados por novos estudos e foram utilizados como base para desenvolver esta pesquisa. 


\section{4 - METODOLOGIA}

Essa pesquisa decorreu da demanda por sistemas de tratamento de esgotos domésticos em locais que não possuem uma rede de coleta e tratamento de esgoto, ou que sofrem com a escassez hídrica, ou embarcações, ou comunidades rurais. Escolheu-se como forma de tratamento a tecnologia do reator biológico aeróbio com membrana (MBR), com a finalidade de gerar um efluente de melhor qualidade, em menor espaço, e tendo a praticidade na aplicabilidade, por serem vendidos pré-montados, para que, dessa forma, sejam oferecidas condições sanitárias mínimas para a população e reduzidos os impactos ao ambiente, uma vez que é possível reaproveitar a água tratada por esses sistemas. Por causa do alto custo dos sistemas MBR, necessitava-se de uma metodologia para avaliar a viabilidade de aplicação desses sistemas.

Por conseguinte, elaborou-se a metodologia desta pesquisa de modo a se poder realizar a Análise Tecnológica do processo MBR mediante a aplicação de métodos multicritério e multiobjetivo de análise de decisão. É importante estabelecer que, em um problema de Análise Tecnológica, busca-se a alternativa que melhor se ajusta ao ambiente e às condições de um determinado local ou cenário, conceito conhecido como "Ajuste Tecnológico". Nesse caminho, precisou-se responder a algumas questões, tais como: Quais são os principais objetivos e critérios que devem ser considerados para verificar a aplicabilidade do processo MBR a sistemas descentralizados de esgotos no Brasil? - Em que condições ou cenários o processo MBR seria recomendável para ser utilizado em sistemas descentralizados de esgotos no Brasil?

Deste modo, organizou-se as atividades planejadas nesta pesquisa em duas fases que serão detalhadas nos próximos tópicos.

\section{1 - FASE 1 - CONCEPÇÃO DO SISTEMA MBR PARA RESIDÊNCIAS UNIFAMILIARES}

A primeira fase está baseada em resultados de pesquisas realizadas no contexto geral e relacionadas ao tratamento de esgoto doméstico pelo processo de reator biológico aeróbio com membranas. Procurou-se obter uma visão ampla do processo MBR quando aplicado a 
sistemas descentralizados, em escala global e regional, e, posteriormente, correlacionaramse os dados à realidade do Brasil.

A metodologia da pesquisa incluiu a concepção de um sistema de reator biológico aeróbio com membrana a partir de experiências anteriores com relativo sucesso, obtidas pelo levantamento bibliográfico, tendo-se realizado a seleção de tipologia do processo e seus detalhes de dimensionamento.

A revisão bibliográfica foi realizada em diversas bases de dados, concentrando-se em tratamento descentralizado de esgotos empregando Reatores Biológicos com Membrana, estações compactas de tratamento de esgoto, e reúso de água. Além disso, a partir da consulta a catálogos de empresas, feiras especializadas e sites, foi realizado um estudo investigativo direcionado aos sistemas de tratamento de esgotos sanitários disponíveis para comercialização.

A caracterização da membrana teve o intuito de identificar as propriedades iniciais das membranas para que pudessem ser avaliadas as modificações destas propriedades durante a operação do sistema. Dentre os melhores sistemas identificados na etapa de levantamento bibliográfico sistematizado, foram separados aqueles mais viáveis para a situação brasileira, tendo sido coletados desses sistemas os valores dos parâmetros de projeto e operacionais mais relevantes para o dimensionamento do processo, bem como os métodos e equações de dimensionamento mais eficientes.

Essa etapa teve como objetivo apresentar a concepção do sistema com dados numéricos, utilizando os resultados da avaliação teórica que foram fundamentais para dá sequencia ao trabalho para a execução da Fase 2. Assim, concluiu-se a primeira fase da metodologia, apresentando um sistema de tratamento de esgoto sanitário adequado à realidade brasileira com desempenho que atenda às normas e a legislação vigente.

\section{2 - FASE 2 - ANÁLISE TECNOLÓGICA DO SISTEMA MBR DESENVOLVIDO}

A segunda fase metodológica visa avaliar o sistema proposto na Fase 1, ou seja, as informações obtidas por meio da primeira fase metodológica serviram como subsídio para adquirir fundamentos e experiências sobre a tecnologia MBR, empregando um conjunto de 
fatores para a escolha de indicadores tecnológicos de desempenho, utilizando métodos multiobjetivo de auxílio à decisão.

Na Figura 4.1 é apresentado o esboço adotado para a análise tecnológica do processo MBR para tratamento de esgoto em sistemas descentralizados. Foi proposto um procedimento de análise tecnológica do processo MBR baseado em uma abordagem de análise de decisão com múltiplos objetivos e múltiplos critérios. Para facilitar o procedimento de análise, propôs-se converter o processo decisório em uma problemática de hierarquização de alternativas de tratamento de esgotos descentralizados, fazendo-se uma comparação com outros processos de tratamento de esgotos comumente usados no Brasil com a mesma finalidade.

Considerando-se que a consulta a um painel de especialistas, ou de atores, ou mesmo de decisores, demandaria um tempo muito grande na pesquisa, além de que existem poucos especialistas com conhecimento prático de utilização da tecnologia de MBR, foi proposto a realização do levantamento de dados e informações da bibliografia disponível, ou seja, não foi realizada a consulta direta, mas a consulta às pesquisas realizadas por autores e seus respectivos dados e resultados obtidos em casos reais. Em função desse conjunto de base de dados e informações é que toda a metodologia foi construída.

A partir do levantamento bibliográfico, o prosseguimento da Fase 2 subdividiu-se em três rotas, sendo a primeira para a criação de cenários, tendo-se proposto quatro cenários simples, a segunda para geração das alternativas de sistemas de tratamento de esgotos utilizadas no Brasil, e a terceira rota composta pelos passos necessários para realização da análise tecnológica, a qual foi realizada em três passos concomitantes, que foram a definição de objetivos ou subobjetivos, definição dos critérios e definição dos pesos.

Com os objetivos definidos, também chamados de dimensões tecnológicas, escolheu-se o que foi utilizado no passado para análise tecnológica em termos de critérios que medem essas dimensões ou objetivos, e ao mesmo tempo providenciou-se a definição dos pesos que foram utilizados para realizar a análise tecnológica. A partir daí, seguiu-se para o próximo passo que foi a definição de modelos de avaliação do desempenho de cada alternativa em cumprir cada um dos critérios escolhidos anteriormente, e fazer essa avaliação para o preenchimento da matriz de consequências, a chamada de pay-off matrix, 
para que fosse, a partir dela, possível o emprego do método multiobjetivo escolhido (ou dos métodos escolhidos). Com isso, o processo de hierarquização proporcionado por esses métodos gerou os resultados de avaliação tecnológica do processo MBR para os três cenários previamente definidos, dentro do contexto de sistemas descentralizados de tratamento de esgotos. Quando os resultados não corresponderam ao que seria normalmente esperado, tratou-se de fazer a retroalimentação dos dados, verificando o que poderia estar causando a discrepância.

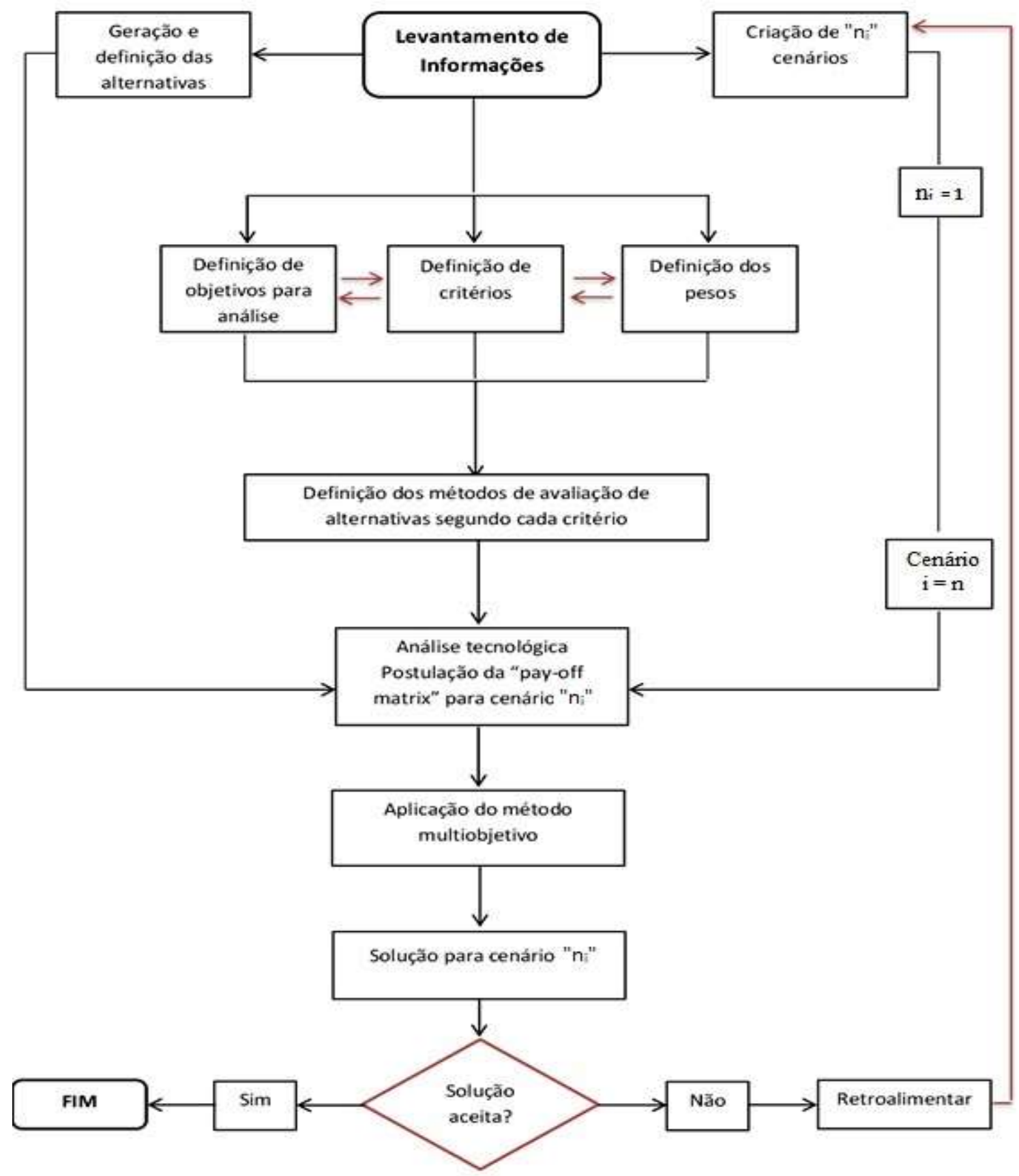

Figura 4.1 - Metodologia empregada na Fase 2. 


\subsection{1 - Levantamento de informações}

O levantamento de informações para executar a Fase 2 abordou as metodologias de avaliação tecnológica de alternativas para o tratamento de águas residuárias e os modelos de avaliação que levam em consideração métodos multiobjetivo e multicritério. Ao mesmo tempo, levantaram-se dados de trabalhos técnicos, experimentais e reais dos sistemas escolhidos para serem avaliados tecnologicamente. Foi particularmente importante o registro dos principais resultados e da experiência obtida da Fase 1 do presente trabalho. Assim, criou-se a base de dados com as informações consideradas mais relevantes para esta pesquisa.

Esta etapa teve como foco levantar um conjunto de informações de pesquisas científicas nacionais e internacionais aplicadas ao tema da dissertação, auxiliar na abordagem do problema na obtenção de dados, na escolha dos critérios, dos pesos e dos métodos que auxiliam na tomada de decisão.

\subsection{2 - Definição dos objetivos, critérios e pesos}

Os objetivos foram levantados a partir da consulta à literatura. Os objetivos delineados para o caso estudado foram traduzidos em metas claras e quantificáveis, por meio da especificação de escalas muito bem definidas, como sugerido em Souza e Foster (1996). Essas escalas constituíram as várias métricas pelas quais foi possível avaliar as alternativas escolhidas.

Levou-se em consideração que, para selecionar e avaliar processos unitários para o tratamento de águas residuárias, idealmente devem ser utilizados diversos fatores que variam desde a aplicabilidade do processo, característica do efluente, necessidade de insumos, restrições ambientais, a confiabilidade, análise de ciclo de vida e disponibilidade de áreas (Metcalf e Eddy, 2007).

Por isso foi considerado como o objetivo geral da metodologia de análise (interesse global) o de verificar a possibilidade de implantação de um sistema descentralizado de tratamento de esgoto doméstico com o processo MBR, com o propósito de se criar uma alternativasolução compatível com alguns cenários brasileiros. 
A partir dessa definição do objetivo geral, e mediante consulta a trabalhos similares, foram definidos os seguintes objetivos específicos da análise tecnológica:

(1) Avaliar e comparar alternativas de tratamento de água residuária utilizadas no Brasil com o processo MBR em se adequar às realidades locais diferentes existentes no País; e

(2) Escolher um sistema de tratamento de água residuária seguro e confiável que se ajuste aos aspectos financeiros, ambientais, técnicos e institucionais propiciando benefícios para os usuários locais.

Partindo desse interesse e das informações disponíveis, constatou-se que os critérios eram agrupados em dimensões de avaliação obtidas a partir dos objetivos selecionados. No total foram levantadas nove dimensões e cento e dez critérios. Ao verificar a variedade de critérios e dimensões, escolheram-se os que eram usados com maior frequência e os que eram mais relevantes para avaliação de sistemas de tratamento de água residuária doméstica descentralizado.

Deve-se ressaltar que um procedimento que produziria um critério mais consistente para as avaliações seria a composição de uma equipe de especialistas que pudessem avaliar tanto a pertinência das premissas, quanto a pontuação dada às mesmas. Entretanto, tal procedimento tornou-se inviável de ser realizado.

Para o desenvolvimento da metodologia de análise tecnológica, foram utilizados quatro dimensões e dez critérios de avaliação. Os critérios não utilizados, por apresentarem menor frequência de uso, mostraram aspectos semelhantes a outros critérios adotados, além da irrelevância para sistemas de tratamento descentralizados.

Para avaliar e quantificar os critérios, foram utilizados dois procedimentos ou modelos para avaliação, o da planilha pontuada e o da planilha padronizada.

A proposta de construção de planilhas pontuadas, utilizadas com sucesso por Brostel (2002), Mendonça (2009), Cordeiro (2010) e Vanzetto (2012), busca, por meio de perguntas, levantar numericamente a resposta para a avaliação quantitativa de cada alternativa segundo cada critério. O sistema de pontos das planilhas pontuadas segue uma escala de pontuação, que pode ser de zero a cem, sendo que quanto maior ou menor a pontuação do critério, avalia-se o desempenho do critério. Uma vez que, se a preferência 
for maximizar, quanto mais próximo de cem, melhor. Se a preferência for minimizar, quanto mais próximo de zero, melhor. $\mathrm{O}$ valor numérico de cada pergunta foi atribuído pontuação igual, para que o processo de pontuação não influenciasse nos graus de importância das perguntas, já que não houve consulta a um painel de especialistas.

Para a construção de planilhas padronizadas, obtiveram-se valores reais da literatura que representassem a realidade das alternativas levantadas nesta pesquisa, de modo que, por meio de ponderação quantitativa, se fizesse a padronização desses valores.

A padronização linear no intervalo de 0 a 100 foi feita pela seguinte Equação (4.1). Para auxiliar o preenchimento desses dois tipos de planilhas, foram construídas tabelas de apoio com dados numéricos obtidos na literatura e por analogia.

$$
f(x)=\left(\frac{X-\operatorname{Min}}{\operatorname{Max}-\operatorname{Min}}\right) \cdot 100
$$

A determinação dos pesos dos critérios ( $\left(\begin{array}{lll}0 & \text { a } & 1\end{array}\right)$, neste trabalho, foi executada cuidadosamente, levando-se em conta, ainda, o estudo de trabalhos prévios sobre metodologias de processo de seleção de tratamento de águas residuárias.

A seguir, descrevem-se os critérios utilizados e o procedimento adotado para as suas respectivas avaliações. Devido à quantidade de alternativas a serem avaliadas e a escassez de dados na literatura, muitas vezes foi necessário o preenchimento das tabelas de apoio por meio de analogia entre dados presentes nas próprias tabelas que mais se aproximasse de alternativas semelhantes.

Geração e definição das alternativas

A geração das alternativas deram-se partir dos sistemas mais empregados no país, com base em dados do IBGE (2010) apresentados na Tabela 3.2, e do Programa de Pesquisa em Saneamento Básico (PROSAB), por considerar que estes possuem tecnologia já consolidada no Brasil, mais fácil acesso e com mais informações publicadas. Foram escolhidas cinco alternativas, com o propósito de criar um conjunto de alternativas tecnologicamente apropriadas para o caso de sistemas de tratamento de efluente doméstico 
unifamiliar. Além dessas tecnologias adicionou-se o sistema MBR que é objetivo principal desta pesquisa. Os sistemas de lagoas são bem difundidos no Brasil, porém, não se aplica a sistemas descentralizados por ocupar uma grande área.

Desse modo, os processos e operações unitárias que foram avaliados tecnologicamente para o caso estudado, são: A1. Tanque séptico (TS); A2. Tanque séptico seguido de filtro anaeróbio (TS+FAn); A3. Tanque séptico seguido de Wetland (TS+Wet); A4. UASB seguido por biofiltro aerado submerso (UASB+BAS); A5. UASB acompanhado por lodo ativado convencional (UASB+LAC); e A6. Tanque séptico acompanhado por reator biológico com membrana (TS+MBR).

\subsection{3 - Criação de cenários}

Os cenários estabelecidos para escolha da melhor alternativa estão descritos a seguir:

(1) Nível do lençol freático baixo e com alta permeabilidade e com risco epidemiológico e ambiental pequeno ( o efluente poderá ser infiltrado no solo);

(2) Nível do lençol freático alto e/ou com capacidade de infiltração baixa com risco epidemiológico e ambiental grande (efluente deverá ser lançado ao corpo receptor) ou quando é necessário fazer a descarga direta em corpo de água superficial (caso de embarcações, palafitas, etc.);

(3) Realização de reúso direto não potável da água em área urbana que sofre com a escassez hídrica (lavagem de roupas e de veículos, descarga de bacias sanitárias, lavagem de pisos e fins ornamentais, chafarizes, espelhos de água etc.) ou reúso direto não potável da água em irrigação para locais rurais.

\subsection{4 - Definição do método de avaliação de alternativas segundo cada critério}

A escolha do método multicritério a ser utilizado está ligada à disponibilidade de informações e familiaridade do analista com os métodos. Um ponto que deve ser destacado é a recomendação de que se utilizem vários métodos para aprimorar a solução do problema (Souza, 1992; Tecle et al., 1988).

Deste modo, optou-se por trabalhar com o método de análise multicritério ELETRE-III e TOPSIS, por ser considerado de fácil aplicação e apontar como um método de fácil 
entendimento que pode ser aplicado em várias áreas. Esses métodos já foram aplicados na área de saneamento por Souza et al., (2001), Werner (2009), Mendonça (2009), Ganoulis (2011), Vanzetto (2012) e Sadr et al., (2015).

Além disso, optou-se também pela utilização desses métodos, no caso do TOPSIS pela facilidade em programar e executar o método em Excel, e, no caso do ELECTRE-III, pela acessibilidade ao seu programa computacional para utilização.

Para o método TOPSIS foi desenvolvido um programa para planilhas em Excel, e para o método ELECTRE III utilizou-se o software disponível em MCDA ULaval (http://cersvr1.fsa.ulaval.ca/mcda/?q=en/node/11). A essência e a forma de funcionamento desses dois métodos foram apresentadas anteriormente na revisão bibliográfica.

\subsection{5 - Análise tecnológica e postulação da pay-off matrix para "n" cenário}

A pay-off matrix é a maneira ou o modelo lógico, matemático, real ou racional que foi usado para mensurar ou estimar o desempenho de cada alternativa segundo cada critério.

Nesta etapa, foram registradas as eficiências de todas as alternativas propostas de cumprimento de cada critério de avaliação definido no tópico 4.2.2. Para isso, foram estabelecidas as escalas de valores nas quais variaram os desempenhos de cada alternativa segundo cada critério. Embora para o método de análise multiobjetivo utilizado não seja exigido um intervalo de valores específicos a se adotar para essas escalas, foi utilizado uma mesma escala de variação para todos os critérios considerados, onde os dados obtidos foram normalizados, com o propósito de facilitar a interpretação dos resultados e a aplicação dos métodos multicritério.

\subsection{6 - Aplicação do método multiobjetivo e avaliação da solução}

Após terem sido estabelecidos os critérios, os pesos, os cenários e as alternativas, e o ajuste entre o que o cenário exige e o que a alternativa dispõe para aquele cenário, fez-se a análise multiobjetivo por meio dos dois métodos anteriormente indicados, o TOPSIS e ELECTRE III.. O processo de hierarquização proporcionada por esses métodos gerou os resultados 
deste trabalho. Para cada cenário, obteviveram-se os resultados referentes a hierarquização das alternativas. Ou seja, uma lista pela ordem de preferências das alternativas.

Consequentemente, na concepção original de métodos multiobjetivo é preciso ser realizado um estudo de aceitabilidade da solução que foi feito por análise de sensibilidade, e chegouse ao resultado final. Caso as soluções não fossem aceitas, seria necessário retroalimentar o modelo.

Para essa confirmação, fez-se a análise de sensibilidade, o que permitiu verificar quais seriam as alterações no resultado final caso os desempenhos das alternativas variassem, ou os pesos das dimensões tecnológicas fossem reanalisados. 


\section{5 - RESULTADOS E DISCUSSÃO}

\section{1 - FASE 1 - CONCEPÇÃO DO SISTEMA MBR PARA RESIDÊNCIAS UNIFAMILIARES}

\subsection{1 - Análise dos sistemas existentes}

A evolução do processo MBR desde os anos 90 até hoje, foi abordado por Crawford, Judd e Zsirai (IWA, 2014), com uma visão dos sistemas divididos em quatro estágios. O primeiro estágio da tecnologia utilizava um longo tempo de retenção de sólidos (TRS ou Өc) e alta concentração do SSLM (sólidos em suspensão no licor misto). No segundo estágio, adaptou-se a remoção de nutrientes (N e P) ao sistema MBR, adicionando uma zona anóxica antes do reator biológico, com recirculação do concentrado no tanque biológico aerado. Já no terceiro estágio, a planta MBR ganhou destaque ao destinar esforço para aumentar a capacidade de fluxos na membrana e para minimizar o TRS e o SSLM com o intuito de otimizar o custo total do MBR. E finalmente veio a quarta geração dos sistemas MBR, que foi impulsionada por duas forças, pelo aumento da escala e tamanho do sistema MBR, e pelo aumento do número de fabricantes de membranas, criando concorrência no mercado. Nota-se que ainda existem muitos desafios, principalmente em relação ao melhor desempenho do sistema MBR em relação à diversos parâmetros, como o TRS, e concentração do SSLM, volume do reator e a gestão do lodo produzido, para conceberem sistemas mais eficientes e com menor custo.

O tratamento biológico empregado nos MBR é normalmente aeróbio, embora existam instalações de MBR anaeróbio, porém sendo estas muito raras, ainda em estágio experimental. Em razão disso, esta pesquisa concentra-se nos sistemas de tratamento descentralizado com MBR aeróbio submerso.

O uso de biorreatores com membrana tem crescido exponencialmente ao longo das últimas duas décadas seguintes após a introdução de membranas submersas ao reator biológico, que se deu na década de 90. A tecnologia evoluiu rapidamente com ganhos significativos no desempenho e confiabilidade, e redução de custos (Cote et al., 2012). 
Para aplicações de MBRs em pequenas comunidades (Sartor et al., 2008; Battilani et al., 2010; Verrecht et al., 2010; Abbas et al., 2012; Gil et al., 2012; Skouteris et al., 2012a; Santasmasas et al., 2013; Tai et al. , 2014) ou em residências unifamiliares (Abegglen et al., 2008), existem grandes desafios, devido a grandes variações das vazões e, proporcionalmente, valores grandes para os fatores de carga de pico. Além disso, nesses casos, são necessários sistemas pequenos e compactos, que são energeticamente menos eficientes.

Atualmente, os aspectos de maior interesse relacionados aos sistemas MBR são a redução do consumo de energia e a obstrução do fluxo na membrana. Em uma visão geral, os principais contribuintes para o consumo de energia são a transferência de lodo, produção de permeado e a aeração, sendo que esta última é responsável por cerca de $50 \%$ do consumo total de energia (Neoh et al., 2016), chegando mesmo até 60\% (Skouteris et al., 2012a). Para Krzeminski et al. (2012), o consumo específico de energia é dependente da concepção do sistema e do arranjo físico, do volume de efluente tratado, do tipo de membrana, e da estratégia operacional.

Existem algumas limitações ao comparar a tecnologia MBR com os processos de tratamento biológico convencional, devido à complexidade do processo e o custo de investimento e operacional. Para uma possível comparação entre sistemas de tratamentos, Hai e Yamamoto (2011) afirmam que se deve considerar sistemas que produza um efluente com a mesma qualidade, além disso, o MBR por ser modular e facilmente expansível, torna-se relativamente menos caro em maior escala por população equivalente. Ou seja, é mais interessante comparar sistemas que tenham o mesmo nível de complexidade. Porém, essa não é a melhor forma de comparação. Apesar dos custos serem um fundamental fator de decisão, deve-se considerar diversos outros fatores, como a qualidade do efluente, área demandada, impacto ambiental que possa gerar e a realidade local para implantação.

As tecnologias MBR melhoraram e continuaram se desenvolvendo ao longo dos anos para reduzir ainda mais os custos do ponto de vista tecnológico. Buer e Cumin (2010) afirmam que, no decorrer do tempo, as membranas tiveram um melhor desempenho no fluxo (200$300 \%$ a mais) e os módulos e sistemas de filtração requerem apenas uma parte da energia, mas, ao mesmo tempo, são capazes de lidar com um fluxo de 5-10 vezes maior que 
unidades instaladas nos anos anteriores. Assim, os custos globais por unidade de água tratada eram, em 2010, 10\% a menos do que há 15 anos.

Como estratégias operacionais para reduzir os problemas irreversíveis na membrana e um tratamento mais eficaz, diversas pesquisas dos sistemas existentes adicionam um prétratamento antes do reator com membrana, como um tanque séptico, clarificador primário e/ou tanque anóxico, que servem para equalizar a carga de efluente, evitar obstrução na membrana, e, quando ocorre reciclo de lodo ou do licor misto, aumentam a eficiência na remoção de nutrientes (Abegglen et al., 2008; Sartor et al., 2008; Verrecht et al., 2010; Abbas et al., 2012;). Segundo Tai et al. (2012), além do pré-tratamento, é possível melhorar a eficiência na remoção de fósforo por meio do emprego de precipitação química.)

O tratamento biológico e a separação física por membrana asseguram que a qualidade do efluente é mantida ao longo do tempo, em relação aos parâmetros turbidez, sólidos suspensos e microbiológicos, independentemente das variações de fluxo e a contaminação da água de entrada (Santasmasas, 2013).

Sartor et al. (2008) mostraram que é possível construir um MBR com métodos simples utilizando a mão de obra local de países em desenvolvimento, como no caso aplicado ao Vietnã. Isso ajuda a favorecer a implemenação dessa tecnologia descentralizada em locais onde não há tratamento de esgoto municipal, bem como o reúso de água para atender à demanda atual e futura.

Battilani et al. (2010) utilizaram um sistema compacto, pré montado e com facilidade de instalação, chamado de Biobooster, com capacidade de operar com uma concentração de lodo de quatro a cinco vezes mais elevada do que um sistema MBR convencional. Este MBR cumpria as normas de qualidade da água de irrigação exigidas pelas diretrizes internacionais permitindo a reutilização da água direta e indiretamente.

Santasmasas et al. (2013) estudaram a viabilidade de utilizar água cinza após tratamento realizado com um MBR que atende a uma pequena comunidade com 40 pessoas, por meio da instalação de um protótipo. Eles notaram que o protótipo pode produzir $1155 \mathrm{~L} / \mathrm{dia}$ com um consumo de energia de $2,9 \mathrm{kWh} / \mathrm{m}^{3}$, o que representa $1,8 € / \mathrm{m}^{3}$. Porém, ao comparar 
esses resultados com uma unidade com capacidade três vezes maior, o consumo de energia é reduzido para $2,0 \mathrm{kWh} / \mathrm{m}^{3}$. Ele concluiu que gastos menores de energia estão relacionados com a aeração e com as diferentes configurações geométricas que ajudam a melhorar o desempenho de sistemas maiores.

A planta MBR consome uma quantidade relativamente elevada de energia, independentemente da escala, uma característica da natureza do MBR de pequena escala é a de consumir quantidades similares de energia (Skouteris, 2012a; Santasmasas, 2013).

A planta MBR carrega custos adicionais associados à substituição da membrana. Os vários mecanismos de envelhecimento que provocam o fim de vida dos produtos atuais de membrana são determinados pelo aumento lento da pressão de operação e a necessidade de limpeza química mais frequente (Cote et al., 2012).

Judd (2015) revisou o status quo da tecnologia MBR aplicada ao tratamento de águas residuárias municipal e industrial, e relatou que, apesar do grande interesse nesta tecnologia e da sua penetração no mercado aumentar significativamente, ainda há uma falta de compreensão das restrições do processo-chave, como o entupimento da membrana e a produção do conhecimento acerca dos processos de limpeza da membrana.

Com a escassez hídrica na Ilha de Creta na Grécia, Maton et al. (2010) compararam os custos e benefícios de estratégias alternativas para o tratamento de águas residuárias para uso na irrigação de vegetais utilizando um biorreator com membrana. Os valores foram estimados e comparados em dois cenários, o primeiro correspondente a implementação das opções convencionais de tratamento de água residuária e o segundo usando um MBR. Esse trabalho de pesquisa teve o intuito de orientar os analistas na Grécia e outros países áridos que desejam avaliar a viabilidade financeira de métodos alternativos de tratamento de águas residuais para uso na agricultura. O reúso da água tratada por esta tecnologia mostraram que os agricultores pagariam menos para tal água do que para água doce convencional. Além disso, o uso de nível de água recuperada na agricultura poderia gerar benefícios sociais líquidos, motivando, assim, aos tomadores de decisão á subsidiar agricultores dispostos a investir em projetos de água de reúso.

Há diversos trabalhos que buscam soluções para otimizar os sistemas MBR, entre os quais se destaca o de Verrecht et al., (2010), que utilizaram o modelo dinâmico ASM2d para 
otimizar o consumo de energia de um biorreator com membrana em pequena escala para o tratamento de águas residuárias domésticas de alta resistência para reciclagem de água. Por meio de variação de alguns parâmetros foi possível reduzir o consumo de energia em $23 \%$. Assim, percebe-se que é fundamental o uso da ferramenta de modelagem para a otimização de parâmetros, principalmente, para os sistemas com pequenas vazões tornarem-se mais baratos.

Skouteris et al. (2012a) operaram uma estação piloto com MBR aeróbio submerso, com objetivo principal de avaliar o potencial dos MBR para o tratamento descentralizado de esgotos no Norte da África com análise de desempenho da membrana e avaliação comparativa de energia. Inicialmente, foi avaliado o potencial para produzir água tratada adequada para utilização em irrigação de culturas sem restrições. Demonstraram o potencial para a utilização da água adequada para irrigação irrestrita e, consequentemente, que isso pode ter um impacto significativo em termos de segurança hídrica e alimentar para a região.

Embora o sistema MBR produza um efluente de ótima qualidade, ainda têm-se alguns desafios com a utilização do permeado, em consequência da sua aparência estética, como a cor amarela-castanha típica desta água, o que pode levar à sua rejeição por parte dos consumidores para determinados fins de utilização do efluente produzido (Arévalo et al., 2012).

Os estudos e aplicações reais de sistemas de tratamento utilizando o MBR têm aumentado significativamente, tornando-o mais atrativo e economicamente viável. Mesmo quando aplicados a uma menor capacidade de tratamento, esses sistemas apresentam maior demanda de energia e maior o custo por pessoa equivalente, o qual, é um desafio que tem sido superado pela possibilidade da reutilização do permeado, pela otimização dos parâmetros de funcionamento para um melhor desempenho e pelo crescimento dessa tecnologia no mercado.

\subsection{2 - Análise para seleção do tipo de membrana a ser utilizada em função da necessidade local potencial}


Ao fazer um levantamento caracterizando as aplicações dos sistemas MBR conforme a porosidade da membrana, observa-se uma vasta tendência para o uso de membranas de ultrafiltração - UF (Costanzi et al., 2005; Abegglen et al., 2008; Verrecht et al., 2010; Skouteris et al., 2012a; Abbas et al., 2012; Belli et al., 2012; Santasmas et al., 2013; Subtil et al., 2013; Tai et al., 2014) e uma redução do uso de microfiltração - MF (Sartor et al., 2008; Giacobbo et al., 2011; Gil et al., 2012). Isso pode ser em decorrência das membranas de UF reterem uma gama maior de micropartículas, como por exemplo vírus, e o custo de fabricação dos tipos de membrana terem se igualado. Também existem instalações que utilizam membranas do tipo cerâmica (Battilani et al., 2010), mas estas ainda são raras, devido o seu alto custo.

Arévalo et al. (2012) avaliaram e compararam a eficiência das membranas de MF e UF para produzir efluente utilizável baseado nas diretrizes espanholas de reúso de água. Os dois tipos de sistema funcionavam de modo diferente, onde a torta formada sob a camada da membrana é muito mais significativa no sistema de MF, pois nesse sistema estudado não acontecia a retrolavagem, ao contrário do sistema de UF. Com isso, esses autores observaram que não havia diferenças estatisticamente significativas entre os principais parâmetros físico-químicos e microbiológicos, donde se pode concluir que o tipo de membrana do sistema MBR não influencia na qualidade do efluente. Entretanto, mesmo não apresentando diferença significativa na qualidade do permeado, os sistemas de UF apresentam maior segurança em decorrência do tamanho dos poros da membrana e, consequentemente, mantendo a qualidade microbiológica e físico-química do efluente dentro dos padrões.

A configuração de membranas do tipo placa plana (FS) é utilizada principalmente em plantas pequenas $\left(<5.000 \mathrm{~m}^{3} / \mathrm{d}\right)$; fibras ocas (HF) são usadas em toda a gama de vazão e dominam em plantas maiores (> $10.000 \mathrm{~m}^{3} / \mathrm{d}$ ). Estima-se que cerca de $75 \%$ da capacidade total instalada de MBR utilizam fibras ocas (Cote et al., 2012). O MBR submerso com placas planas funcionam similar ao formato fibra oca, mas devido o uso de ar elevado e custo operacional mais baixo, tendem a ser selecionado para escalas pequenas e de médio porte (Pearce, 2008).

De acordo com Krzeminski et al. (2012), o consumo de energia específica para aeração da membrana do tipo placa plana é de 33-37\% maior do que num sistema de fibras ocas. 
Isso ocorre devido à exigência de ar para a limpeza. No entanto, as aplicações do tipo placa plana são normalmente operadas em concentrações de SSLM mais elevadas e conhecidas pelas vantagens operacionais em termos de entupimento e de limpeza, facilidade de instalação, operação e manutenção em comparação com a configuração de fibra oca (Pearce, 2008; Santasmasas et al., 2013).

Embora cada configuração de membrana tenha as suas vantagens, Tai et al. (2014) afirmam que a configuração do tipo FS são bem adequadas para aplicações compactas e descentralizadas, permitem as concentrações mais elevadas do SSLM para um espaço menor, e dada a natureza dessas aplicações remotas, quaisquer melhorias em requisitos operacionais são valiosos para os usuários finais. Embora os módulos de placa plana proporcionem um desempenho robusto, os mesmos não são adequados para retrolavagem em alta pressão e são muitas vezes mais caros do que as membranas de fibras ocas, devido aos elevados custos de produção do módulo por área de membrana (Yoon, 2015). O desempenho real dos módulos de placa plana e a capacidade de retrolavagem ainda não estão bem conhecidos.

As aplicações de reúso de água em grande escala são muito restritas, comparado com um sistema menor de reciclagem de água com aplicação no próprio local de tratamento. Isto acontece porque o custo de aplicação de reúso de água, em larga escala, permanece alto e muitas vezes economicamente inviável devido à necessidade de readaptar e investir nos sistemas existentes de distribuição de água (Hai e Yamamoto, 2011).

Uma membrana utilizada em um sistema MBR precisa ser mecanicamente robusta, quimicamente resistente a altas concentrações de cloro molecular usadas na limpeza, e não biodegradável (Pearce, 2008). Phillips (2015) relata que a empresa "Koch Membrane Systems" desenvolveu uma nova tecnologia do módulo de membrana de fibra oca de ultrafiltração, cujo "design" inovador contém uma única ligação da fibra com a parte superior do módulo, permitindo que as fibras de membrana possam mover-se livremente dentro do cartucho. Essa configuração aberta permite que a aeração penetre no feixe de fibras e solte sólidos filtrados durante a lavagem com ar. Ao comparar esse novo módulo com os modelos convencionais de fibra oca que possuem as duas extremidades presas, Phillips (2015) afirma que o movimento dessas fibras impede com que os sólidos se 
acumulem em zonas mortas, consequentemente evitando a redução da área da superfície da membrana, a obstrução do sistema de saída e a redução da eficiência energética.

Esses novos modelos que estão sendo desenvolvidos simplificam o modo de operação, e muitas vezes eliminam a necessidade de pré-tratamento como a clarificação, além disso minimizam o tempo de inatividade e reduzem o uso de produtos químicos. Esses benefícios se somam a um menor custo total decorrente (Phillips, 2015).

Em virtude desse levantamento, constatou-se que para o presente caso, o tipo de membrana ideal a ser utilizado para aplicação em um MBR descentralizado ou unifamiliar são as membranas do tipo placa plana de ultrafiltração, por serem os mais recomendados a sistemas com baixas vazões e por apresentarem maior segurança na qualidade do efluente.

\subsection{3 - Análise do sistema de pré-tratamento ao MBR}

Para sistemas descentralizados que têm grande variação de carga, é importante que se tenha um pré-tratamento antes do reator biológico com membrana, como a crivagem para a retenção do material grosseiro e um tanque para equalizar o efluente.

Os processos e operações unitários utilizados em instalações de tratamento com um sistema MBR podem ser os seguintes: peneiramento grosso e fino; remoção de areia; remoção de óleos e gorduras; tanque de equalização; clarificador primário; tratamento biológico; separação por membrana; e desinfecção (WEF, 2012).

Como os sistemas de membrana em aplicações de tratamento de águas residuárias municipais são sensíveis a danos causados por detritos e diminuição da eficiência de dispositivos de aeração de bolha grosseira, o pré-tratamento é necessário para remover sólidos grosseiros, como plásticos, folhas e trapos e partículas finas e coloidais incluindo óleos, gorduras, e cabelo (Metcalf e Eddy, 2007).

Para as plantas pequenas, é necessário um sistema com peneiramento, sendo que aberturas de menos de 1 até $3 \mathrm{~mm}$ estão se tornando mais comuns em instalações MBR (Metcalf e Eddy, 2007), que seja de preferência automático (WEF, 2012). Abegglen et al. (2008) utilizaram uma peneira de $6 \mathrm{~mm}$ que não foi eficiente, pois cabelos e algumas particulas 
solidas suspensas atrapalharam o fluxo na membrana. Algumas aplicações têm utilizado malhas menores que $1 \mathrm{~mm}$, entre 0,1 e $0,75 \mathrm{~mm}$, que funcionaram com bom desempenho (Sartor et al., 2008; Battilani et al., 2010; Abbas, 2012).

O pré-tratamento tem outros benefícios na redução de sólidos inertes e cargas de matéria orgânica no biorreator. O tratamento primário irá remover cerca de $30 \%$ da matéria orgânica e cerca de $60 \%$ do SST. As telas finas irão remover cerca de 10 a $15 \%$ da DQO. O percentual de sólidos inertes também é inferior em efluente primário de águas residuárias, em comparação com o peneiramento. A concentração de substrato afluente (medido como DBO) e a concentração de sólidos inertes afetam a produção de sólidos totais e os requisitos de descarte do biorreator (Metcalf e Eddy, 2007).

Um reator com agitação antes do reator com membrana pode servir como um amortecedor, gerando uma variação menor de carga. Abegglen et al. (2008) ao fazerem a recirculação do lodo e aeração de modo intermitente, resolveram o problema de mau odor de um sistema MBR em uma residência, o que também auxiliou na produção de um lodo mais estabilizado.

Além do pré-tratamento, para alcançar a remoção biológica de nutrientes no MBR, normalmente é feito por meio de uma combinação deste sistema aeróbio com condições anóxicas e anaeróbias, com a recirculação do licor misto (ou lodo) feita através dos diferentes tanques (Judd, 2015).

Sartor et al. (2008) obtiveram êxito na aplicação de um MBR em um sistema aplicado em uma pequena comunidade, com mais de $95 \%$ da carga de DQO e $80 \%$ do nitrogênio total removidos. O sistema possuía pré-tratamento, composto por um tanque séptico para a equalização, um tanque anóxico para propiciar a fase de desnitrificação e o tanque biológico aeróbio com membrana. A biomassa era bombeada por uma bomba de recirculação da fase de nitrificação para a fase de desnitrificação. Em excesso, o lodo ativado é reencaminhado para o estágio de nitrificação, onde o módulo de membrana está instalado.

Outro fator que deve ser considerado para um bom desempenho do MBR é o modo com que é dada a partida do sistema. A opção de dar partida com e sem inóculo em um MBR 
submerso foi estudada por Di Bella et al. (2010). Ambas as condições iniciais de operação foram capazes de garantir uma excelente eficiência de remoção orgânica. Contudo, os diferentes mecanismos de deposição da torta sobre a membrana influenciaram negativamente a eficiência de filtração durante a fase sem inóculo, ocasionando uma incrustação intensa e irreversível nos primeiros dias, devido aos componentes dissolvidos e coloidais responsáveis pela resistência do bloqueio dos poros. Este efeito não foi observado na fase com inóculo, onde a deposição da torta atuou como um pré-filtro.

Pode-se concluir disso que as águas residuárias devem ser evitadas em qualquer circunstância para inocular um reator biológico acoplado a uma membrana, devido ao seu elevado potencial de incrustação irreversível. O lodo ativado de uma estação de tratamento é preferível para a inoculação, uma vez que a biomassa seja aclimatada para efluentes domésticos (Gil et al., 2012).

Há uma grande importância em manter a concentração de biomassa dentro do reator para aumentar a eficiência do tratamento e diminuir a frequência de limpezas ocasionadas por uma incrustração profunda. Por essa razão, Gil et al. (2012) perceberam que nenhum dos parâmetros analisados (SSLM, índice volumétrico de lodo e carbono orgânico dissolvido) influenciaram significativamente na capacidade de filtração do inóculo inicial. Contrariamente, esses autores notaram que a entrada de água residuária demonstrou ser o fator mais importante que regula o processo de "fouling" na membrana, em vez das alterações na microbiologia.

De acordo com Gil et al. (2012), para uma situação ideal na partida do MBR, o fluxo inicial deve ser "baixo", e a vazão ser aumentada gradualmente até seu fluxo nominal durante a fase de partida, quando o lodo apresentar flocos bem formados e estiver bem aclimatado. Portanto, o fluxo deve ser reduzido para uma região suficientemente longe do fluxo crítico, mas não demasiadamente baixa para evitar a afluência em massa de partículas finas na membrana.

Yoon (2015) afirma que a lavagem com ar é realizada em membranas submersas para mitigar o entupimento da membrana. A combinação efetiva de baixo fluxo e aeração contínua mostrou-se eficaz para minimizar a incrustação biológica e, consequentemente, a retrolavagem não foi necessária (Trinh, et al., 2016). No entanto, Yoon (2015) afirma que 
a aeração contínua pode ser substituída por aeração intermitente, cujo consumo de energia reduz-se em cerca de $30 \%$ para as membranas de fibras ocas.

A maioria dos fabricantes de sistemas de membrana submersa recomenda concentrações do SSLM entre 8000 e $12.000 \mathrm{mg} / \mathrm{L}$ nos tanques de membrana, com a operação ocasional chegando até $15.000 \mathrm{mg} / \mathrm{L}$. Para algumas membranas planas pode-se estender o limite de concentração superior para 15.000 e 20.000 mg/L. Concentrações mais elevadas são possíveis, mas podem exigir mais baixo fluxo por causa do aumento da resistência à filtração e maiores custos operacionais para a limpeza adicional e redução da eficiência de transferência de oxigênio (WEF, 2012).

Quanto ao funcionamento do MBR aplicado a uma residência, após um longo período sem alimentação, ou seja, quando os moradores estão ausentes durante as férias, Trinh et al. (2016) e Abegglen et al. (2008) notaram que, ao retomar o funcionamento do sistema, a eficiência na remoção de DQO é alcançada rapidamente, mostrando que o sistema se recupera ligeiramente as condições iniciais de operação e que responde bem à choque de cargas.

Diversos parâmetros são importantes para monitorar a eficiência de um sistema MBR. Por exemplo, um turbidímetro automático é importante de ser instalado na linha de saída de permeado para controlar as condições físicas da membrana (Tai et al., 2014; Trinh, et al., 2016). Além da turbidez, a DQO também é um bom parâmetro para indicar os danos causados a membrana. No entanto, a DQO ainda não é uma técnica analítica medida on line (Trinh et al., 2016).

Ao ter um sistema totalmente automatizado, nota-se que é possivel o monitoramento e controle da planta serem feitos por telemetria em uma unidade remota (Abegglen et al., 2008; Tai et al., 2014), tendo a necessidade de o operador ir ao local apenas uma vez por semana (Tai et al., 2014).

Conclui-se que o efluente do MBR independe da variação de fluxo e de carga, mostrando que o mesmo se aplica a sistemas unifamiliares. E como forma de evitar problemas de incrustação na membrana, rompimento e falha no sistema, observou-se que é necessário 
um pré-tratamento, como, por exemplo, a instalação de um tanque séptico antes do reator biológico com membranas.

\subsection{4 - Análise para seleção do tipo de reator de membrana a ser utilizado}

Nas configurações convencionais dos MBR, combinam-se o tratamento biológico com a separação por membrana por microfiltração (MF) ou ultrafiltração (UF), com a membrana sendo colocada tanto na parte interna, conhecido como MBR Submerso, como na parte externa do biorreator, conhecido como MBR de Corrente Lateral ou MBR sidestream. As membranas geralmente tem a configuração de placa plana (FS) ou de fibra oca (HF), se colocadas no interior do biorreator, ou multitubular (MT), se colocadas na parte externa ao biorreator.

A evolução dos sistemas MBR tem demonstrado que alguns módulos de membrana desenvolveram-se vantagens significativas, tais como densidade de empacotamento, exigência de energia de aeração, capacidade de tratamento por módulos, robustez na membrana, e processos de limpeza automáticos em comparação a outros sistemas (Buer e Cumin, 2010).

Cada um dos formatos dos MBR, com base nas configurações submersas ou externa, apresenta suas próprias vantagens e desvantagens para diferentes tipos de aplicação e tamanhos de planta.

O fato dos sistemas com módulos submersos demandarem menos energia decorre da pressão transmembrana requerida. Em sistema com módulo externo ou corrente lateral, geralmente a PTM é muito mais elevada do que o utilizado para a configuração submersa (Judd, 2015).

O custo de energia para circular o líquido a ser filtrado de um MBR com módulo externo é alto, porque apenas $1 \%$ a $5 \%$ da alimentação bombeada para o sistema de membrana é recuperado como permeado em condições típicas e, assim, de 20 a 100 vezes mais água de alimentação deve ser pressurizada e ou circulada que a quantidade de permeado obtido. $\mathrm{O}$ consumo de energia específico para a filtração é maior do que $4 \mathrm{kWh} / \mathrm{m}^{3}$ de permeado. Apesar dos elevados custos de capital e de energia, o MBR externo pode ser competitivo 
para pequenos sistemas, talvez com capacidade menor que $100 \mathrm{~m} 3 / \mathrm{d}$, devido à operação e manutenção relativamente fácil (Yoon, 2015).

A predominância de módulos submersos de MBR é indiscutível, como mais de $99 \%$ do total instalado. Essa porção significativa é devida porque os módulos submersos apresentam custos operacionais baixos como consequência da elevada eficiência do mecanismo de lavagem da membrana e da pressão de vácuo ser baixa, quase sempre inferior a 0,3 bar (Yoon, 2015).

O MBR com módulo externo, ou de corrente lateral, fornece um desempenho confiável, com menos preocupação em relação ao entupimento em comparação com MBR submerso. Ao mesmo tempo, as membranas individuais são de fácil acesso para manutenção e esta pode ser feita com um pequeno volume de solução de limpeza. No entanto, a necessidade de construção de um sistema de membrana compatível com pressão elevada (3-6 bar) faz com que os custos de capital sejam elevados (Yoon, 2015).

Krzeminski et al. (2012), ao realizarem uma visão geral de sistemas MBR em grande escala, mostraram que o consumo de energia relacionado aos módulos de membrana está na faixa de 0,5-0,7 kWh/m³. Além disso, a aeração é um grande consumidor de energia, muitas vezes superior a 50\% do total de consumo de energia, com um mínimo de $35 \%$ sendo utilizada apenas para aeração na membrana.

Uma das vantagens relatadas por Judd (2008) é que as concentrações dos sólidos em suspensão no licor misto (SSLM) são mais elevadas no reator, o que reduz o tamanho do reator exigido e promove o desenvolvimento de bactérias nitrificantes específicas, melhorando assim a remoção da amônia.

A aplicação da tecnologia MBR com concentrações de sólidos em suspensão acima de 10 $\mathrm{g} / \mathrm{L}$ favorece o uso dos módulos de membranas do tipo placa plana e multitubular, abaixo deste limiar, para as membranas de fibra oca (Judd, 2015).

Dos mais de 55 produtos de membranas MBR comerciais considerados por Judd (2015), quase $50 \%$ são baseados em materiais de difluoreto de polivinilideno (PVDF), oferecido em todas as três configurações de membrana (placa plana, fibra oca, e multitubular). Os 
materiais do tipo Polietersulfona (PES) e membranas de poliolefínica (polietileno, PE e polipropileno, PP) também foram encontrados disponíveis em configurações de placa plana e fibra oca, respectivamente. A maioria dos produtos tem um tamanho de poro entre 0,03 e $0,4 \mu \mathrm{m}$.

Um pré-tratamento eficiente com um tempo de retenção hidráulica e fluxos baixos e uma sucção intermitente podem ajudar a prolongar a operação e alcançar uma transição mais fácil entre o arranque e o estado estacionário (Gil et al. , 2012).

Baseado nas informações levantadas, por meio de outras experiências que obtiveram sucesso, constatou-se que o tanque com membrana que melhor se aplica ao sistema proposto é do tipo submerso, onde o mesmo deve ser separado do reator biológico para facilitar a limpeza e a manutenção do sistema.

\subsection{5 - Proposta do fluxograma do sistema MBR e arranjo físico do sistema}

Em pequenas comunidades, as casas normalmente são colocadas distantes umas das outras, a densidade populacional é baixa e, portanto, o uso de um sistema local para uma residência individual ou para um conjunto de residências pode ser uma opção rentável. A tecnologia MBR fornece um tratamento robusto, com efluente de alta qualidade, ocupa pouco espaço, tem capacidade de expansão, e pode ser empregada para melhorar as estações de tratamento convencionais existentes. Baseado no levantamento bibliográfico, principalmente no estudo feito por Sadr et al. (2015), que compararam diversos arranjos e combinações utilizando membranas, foi constatado que a melhor aplicação para um cenário de reúso de água não potável em uma comunidade em desenvolvimento que sofre com a escassez hídrica é um sistema composto por um tratamento primário seguido de um MBR (anóxico + aeróbio + UF) + desinfecção. Com isso, propõe-se o fluxograma do sistema MBR que está representado na Figura 5.1.

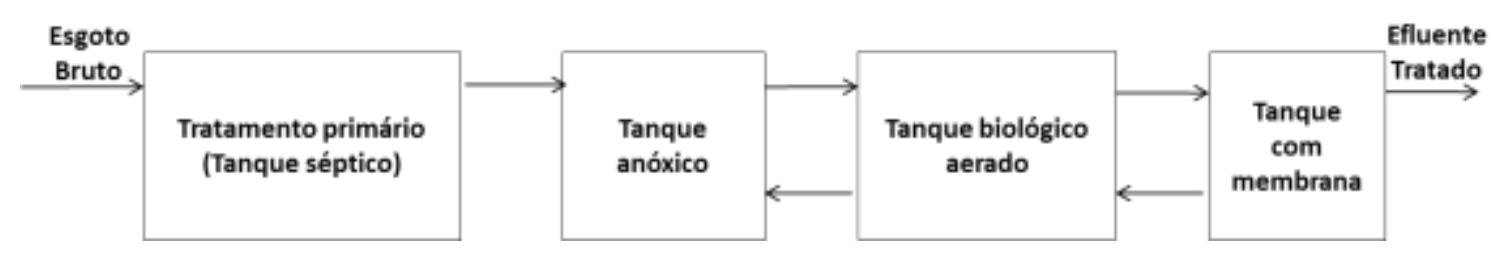

Figura 5.1 - Fluxograma do sistema MBR proposto. 
O sistema sugerido foi baseado em Abegglen (2008), pois este foi o sistema que melhor atendeu as características requeridas por esta pesquisa, sendo o único que aplicou o MBR em uma residência, e, por operar de modo intermitente, deve reduzir ao máximo o consumo de energia. O sistema proposto contempla um tanque séptico, seguido por um tanque anóxico, tanque biológico aerado e tanque submerso com membrana. O módulo de membrana será o de placa plana e ficará em um tanque separado, por apresentar vantagens adicionais de manutenção, além de atuar como um tanque de aeração de segundo estágio. Assim, o sistema se comporta como um reator de fluxo em pistão até certo ponto, e há probabilidades de diminuir as concentrações dos contaminantes não tratados (Yoon, 2015).

\subsection{6 - Seleção dos parâmetros e equações de dimensionamento de todo o sistema}

O dimensionamento realizado como parte desta pesquisa segue os passos estabelecidos por Judd (2011) para um MBR submerso com modelo em estado estacionário. Nesse método, o dimensionamento é baseado em uma combinação de dados empíricos ou heurísticos e biocinéticos ou estequiométricos, com base na bioquímica do processo biológico aeróbio de tratamento de esgoto. Com informação adequada à inter-relação entre os parâmetros de aeração, de qualidade da água de alimentação, de fluxos, e biocinéticos para o componente biológico, o projeto pode ser dividido em três partes distintas, a do processo de membrana, a do processo biológico e a do sistema de aeração. A permeabilidade e a limpeza para o componente de permeação da membrana dependem das especificações do fabricante.

A aplicação da proposta do sistema destina-se a uma estação de tratamento de esgotos domésticos de uma residência unifamiliar com cinco moradores. A vazão de esgoto doméstico pode ser calculada com base no consumo médio de água diário per capita, considerando uma faixa de contribuição entre pequena localidade e cidade média (von Sperling, 2005), adotou-se uma contribuição de 150 L/hab.dia. Portanto, estimou-se que as vazões média e máximas são as seguintes: $Q_{\text {média }}=800 \mathrm{~L} / \mathrm{d}, \mathrm{Q}_{\text {máxima }}=960 \mathrm{~L} / \mathrm{d}$ e a $\mathrm{Q}_{\text {máximahorária }}=1440 \mathrm{~L} / \mathrm{d}$.

O sistema MBR será precedido por um tanque séptico, o cálculo do volume do tanque séptico foi baseado na NBR 7229/1993, chegando-se ao volume de aproximadamente $2 \mathrm{~m}^{3}$. As características do efluente após tratamento primário consideradas para o 
dimensionamento foram os de DQO, $\mathrm{DBO}_{5}, \mathrm{NTK}, \mathrm{SST}$ e SSV, com os valores de 481 $\mathrm{mg} / \mathrm{L}, 229 \mathrm{mg} / \mathrm{L}, 40 \mathrm{mg} / \mathrm{L}, 151 \mathrm{mg} / \mathrm{L}, 107 \mathrm{mg} / \mathrm{L}$, respectivamente. Os valores biocinéticos típicos do sistema de lodos ativados podem ser usados para o MBR, mesmo não sendo os valores apropriados, o seu uso não apresenta erro significativo (Judd, 2011). Esses valores são: coeficiente de saturação $\left(K_{\mathrm{s}}=20\right)$; coeficiente de decaimento endógeno heterotrófico $\left(\mathrm{k}_{\mathrm{e}}=0,12\right)$; taxa máxima de crescimento específico heterotróficos $\left(\mu_{\mathrm{m}}=6\right)$; coeficiente de produção heterotrófico $(\mathrm{Y}=0,4)$; meio coeficiente de saturação para a nitrificação $\left(\mathrm{K}_{\mathrm{n}}=\right.$ 0,74); coeficiente de decaimento endógeno nitrificação $\left(k_{e, n}=0,08\right)$; taxa de nitrificação máxima de crescimento específico $\left(\mu_{\mathrm{m}, \mathrm{n}}=0,75\right)$; e coeficiente de produção de nitrificação $\left(Y_{n}=0,12\right)($ Judd, 2011).

Para dimensionar o sistema MBR é necessário considerar três etapas: (1) dimensionamento da membrana; (2) dimensionamento do sistema biológico, e (3) dimensionamento do sistema de aeração. Os detalhes do dimensionamento estão apresentados no Apêndice B.

\subsection{7 - Dimensionamento e configuração do sistema proposto}

Baseado nos passos descritos foi realizado o dimensionamento do sistema MBR que estão detalhados no Apêndice A. Com os resultados obtidos foi possível chegar a configuração do sistema MBR apresentado na Figura 5.2. Os níveis e a cota do desenho dependerá da topografia do terreno e como se deseja implantar com o uso ou não de bombeamento. 


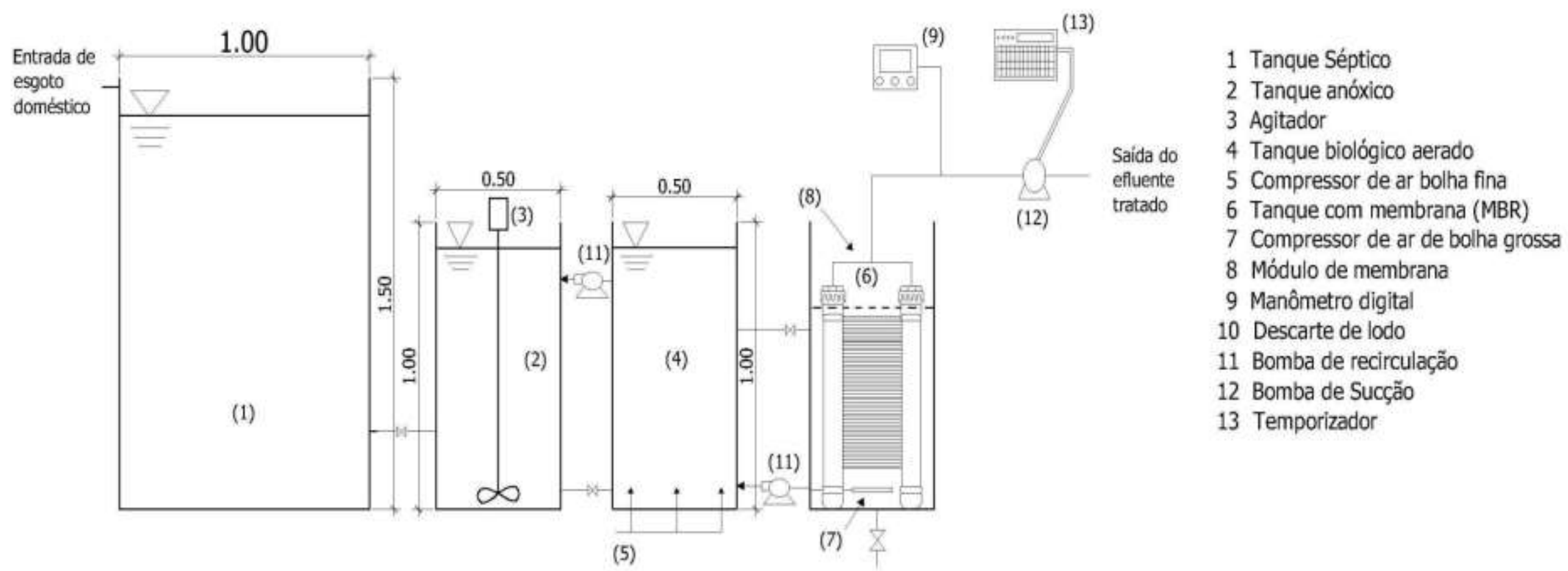

(10)

Figura 5.2 - Configuração do sistema MBR dimensionado e proposto para ser aplicado ao tratamento de esgoto doméstico unifamiliar.

(1) Tanque séptico: volume de $2 \mathrm{~m}^{3}$. Profundidade 1,5 m. Largura : $1 \mathrm{~m}$; Comprimento 1,5 $\mathrm{m}$.

(2) Tanque anóxico: volume de 0,25 $\mathrm{m}^{3}$. Profundidade 1,0 m. Largura : 0,5 m; Comprimento 0,5 m

(4) Tanque biológico aerado: volume de 0,30 $\mathrm{m}^{3}$. Profundidade 1,0 m. Largura : 0,5 m; Comprimento 0,6 m

(6) Tanque com membrana submersa: as dimensões do tanque dependerá da caracteristica do módulo fornecida pelo fabricante. 


\section{2 - FASE 2 - ANÁLISE TECNOLÓGICA DE SISTEMAS DE TRATAMENTO DE ÁGUA RESIDUÁRIA UNIFAMILIAR}

A análise tecnológica é essencial para aumentar as chances de sucesso na aplicação prática de uma tecnologia. Neste tópico serão apresentados os resultados e a discussão da melhor alternativa tecnológica dos sistemas de tratamento de água residuária escolhida de acordo com a metodologia proposta. O grande desafio desta pesquisa é de como e quando selecionar uma tecnologia de membrana para cenários específicos à realidade brasileira. Para isso, selecionaram-se cinco sistemas de tratamento de esgotos para comparar e avaliar qual é a melhor alternativa para cada cenário. A partir disso, por não haver muitos especialistas na área (aplicações práticas), surgiu outro desafio relacionado ao agrupamento de diversas opiniões obtidas por meio de publicações disponíveis na literatura acerca do processo de tomada de decisão. Baseado nisso, desenvolveu-se uma metodologia para a avaliação de tecnologias de tratamento de águas residuárias que integra um processo de tomada de decisão utilizando a informação disponível na literatura e adaptando-a aos cenários brasileiros.

\subsection{1 - Levantamento de informações e base de dados}

Do levantamento bibliográfico realizado, pôde-se verificar a evolução de metodologias dessa natureza ao longo do tempo, onde se puderam constatar a análise de decisão com enfoque econômico e ambiental e a análise de decisão com considerações de Tecnologia Apropriada, sendo este último, o tipo de abordagem adotado pelo modelo proposto neste trabalho.

Com a preocupação em identificar simultaneamente vários objetivos para solucionar problemas, principalmente, em relação à qualidade de vida e do ambiente, se faz necessária a definição e compreensão dos objetivos da análise a ser realizada, para obter sucesso na tomada de decisão. Existem inúmeros critérios que merecem consideração ao avaliar tecnologias para o tratamento de água residuária. Dependendo do estudo, a quantidade de critérios considerados varia e alguns critérios apresentam importâncias maiores do que outros. Na Tabela 5.1 estão apresentados os principais trabalhos que utilizaram métodos multiobjetivo e multicritério, e a frequência de uso das dimensões utilizadas por esses autores, assim como o número de critérios e de alternativas. 
Tabela 5.1 - Base de dados com as principais referências levantadas para a fase 2.

\begin{tabular}{|c|c|c|c|c|c|c|c|c|c|c|c|c|}
\hline $\begin{array}{l}\text { Autor/ } \\
\text { Dimensão }\end{array}$ & $\begin{array}{l}\text { Souza } \\
(1992)\end{array}$ & $\begin{array}{l}\text { Souza } \\
\text { et al. } \\
(2001)\end{array}$ & $\begin{array}{l}\text { Carneiro } \\
\text { et al. } \\
(2001)\end{array}$ & $\begin{array}{l}\text { Brostel } \\
(2002)\end{array}$ & $\begin{array}{l}\text { Werner } \\
(2009)\end{array}$ & $\begin{array}{c}\text { Ganoulis } \\
\text { (2011) }\end{array}$ & $\begin{array}{l}\text { Sadr } \\
\text { et al. } \\
(2013)\end{array}$ & $\begin{array}{c}\text { Tjandraatmadja } \\
\text { et al. } \\
\text { (2013) }\end{array}$ & $\begin{array}{l}\text { Sadr } \\
\text { et al. } \\
(2015)\end{array}$ & $\begin{array}{c}\text { Ouyang } \\
\text { et al } \\
(2015)\end{array}$ & $\begin{array}{c}\text { Aydiner } \\
\text { et al. } \\
\text { (2016) }\end{array}$ & $\begin{array}{l}\text { Frequência } \\
\text { de uso }(\%)\end{array}$ \\
\hline Técnica & $\mathrm{x}$ & & $\mathrm{x}$ & $\mathrm{x}$ & $\mathrm{x}$ & $\mathrm{x}$ & $\mathrm{x}$ & $\mathrm{x}$ & $\mathrm{x}$ & $\mathrm{x}$ & $\mathrm{x}$ & 90,9 \\
\hline Ambiental & $\mathrm{x}$ & $\mathrm{x}$ & $\mathrm{x}$ & $\mathrm{x}$ & $\mathrm{x}$ & $\mathrm{x}$ & & $\mathrm{x}$ & $\mathrm{x}$ & $\mathrm{x}$ & $\mathrm{x}$ & 90,9 \\
\hline Institucional & & & & & $\mathrm{x}$ & & & & & & & 9,1 \\
\hline Administrativa & & & & $\mathrm{x}$ & & & & & & & & 9,1 \\
\hline Sócio-econômica & & & & $\mathrm{x}$ & & & & & & & & 9,1 \\
\hline Cultural & $\mathrm{x}$ & & $\mathrm{x}$ & & & & & & & & & 18,2 \\
\hline N. ${ }^{o}$ de critérios & 44 & 18 & 10 & 18 & 13 & 8 & 5 & 26 & 10 & 14 & 11 & \\
\hline $\mathrm{N}^{\circ}{ }^{\circ}$ de alternativas & 106 & 10 & 6 & --- & 5 & 14 & 8 & 9 & 10 & 5 & 5 & \\
\hline
\end{tabular}


Esse levantamento de informações foi fundamental para a avaliação tecnológica proposta no Capítulo 4. Os autores apontam um ponto de convergência com diferentes dimensões, destacando-se e sendo escolhidas para esta pesquisa, as dimensões técnica, econômica, social e ambiental, as quais constituíram o conjunto que instrumentou o processo de análise tecnológica realizado.

\subsection{2 - Definição dos Critérios e Pesos}

Com o levantamento preliminar dos critérios apresentados no Apêndice B, escolheram-se os que obtiveram maior frequência de uso, totalizando nove critérios, sendo adicionado mais um. O critério adicionado foi o nível de complexidade, avaliado por Sadr et al. (2013) como o mais importante para serem considerados nos países em desenvolvimento.

Como o foco deste trabalho são sistemas de tratamento de esgoto descentralizados, outro critério importante de ser considerado seria a resistência a choques de cargas. No entanto, esse critério foi descartado, já que todas as alternativas de tratamento tem um tanque séptico que auxilia no pré-tratamento e serve para equalizar a carga de efluente, e esse mesmo critério foi avaliado indiretamente dentro do critério de confiabilidade.

Com o propósito de facilitar a compreensão e obter uma boa simulação, nesta pesquisa, portanto, estabeleceram-se dez critérios, subdividindo-os em dimensões de avaliação técnica, econômica, ambiental e social, com os mecanismos de avaliação que estão apresentados na Tabela 5.2.

Para a solução do comportamento de cada critério, identificaram-se a preferência crescente, para aqueles que se aproximam de um ótimo quando seus valores aumentam e, decrescentes, quando seus valores diminuem.

As estratégias dos pesos atribuídos para cada critério estão apresentadas nas Tabela 5.3 e Tabela 5.4. Com o intuito de não convergir na escolha de uma alternativa, critério e/ou dimensão, primeiramente considerou-se pesos iguais para todos os critérios (1/10). Posteriormente, estabeleceram-se os pesos de acordo com as dimensões, considerando que os pesos dos critérios da dimensão priorizada seriam o dobro das dimensões não 
priorizadas. E por último priorizaram-se os objetivos de acordo com a necessidade dos cenários e os pesos atribuídos foram definidos pela pesquisadora.

Tabela 5.2 - Dimensões e critérios de avaliação escolhidos para a análise tecnológica de processo MBR para tratamento descentralizado de esgotos.

\begin{tabular}{|c|c|c|c|}
\hline Dimensão & Critério & $\begin{array}{l}\text { Mecanismo de } \\
\text { avaliação }\end{array}$ & Preferência \\
\hline \multirow{5}{*}{ Técnica } & C1. Consumo de energia & $\begin{array}{c}\text { Planilha } \\
\text { padronizada }\end{array}$ & Decrescente \\
\hline & C2. Área exigida & $\begin{array}{l}\text { Planilha } \\
\text { padronizada }\end{array}$ & Decrescente \\
\hline & C3. Quantidade de resíduo (lodo) produzido & $\begin{array}{l}\text { Planilha } \\
\text { padronizada }\end{array}$ & Decrescente \\
\hline & C4. Confiabilidade & Planilha pontuada & Crescente \\
\hline & C5. Complexidade opera & Planilha pontuada & Decrescente \\
\hline \multirow[t]{2}{*}{ Econômica } & C6. Custo de capital ou de implantação) & $\begin{array}{l}\text { Planilha } \\
\text { padronizada }\end{array}$ & Decrescente \\
\hline & C7. Custo de O\&M & Planilha pontuada & Decrescente \\
\hline & C8. Impacto Ambiental & Planilha pontuada & Decrescente \\
\hline Ambiental & $\begin{array}{l}\text { C9. Conformidade com a Política e Legislação } \\
\text { Ambiental }\end{array}$ & Planilha pontuada & Crescente \\
\hline Social & $\begin{array}{l}\text { C10. Aceitação da comunidade/chefe da } \\
\text { família }\end{array}$ & Planilha pontuada & Crescente \\
\hline
\end{tabular}

Tabela 5.3 - Aplicação de pesos para análise de sensibilidade do modelo

\begin{tabular}{cccccccc}
\hline \multirow{2}{*}{ Dimensão } & Critérios & \multicolumn{7}{c}{ Estratégias } \\
\cline { 3 - 8 } & $\begin{array}{c}\text { Peso igual } \\
\text { para os } \\
\text { critérios }\end{array}$ & $\begin{array}{c}\text { Peso igual } \\
\text { para as } \\
\text { dimensões }\end{array}$ & Técnica & $\begin{array}{c}\text { Econômic } \\
\text { a }\end{array}$ & Ambiental & Social \\
\hline \multirow{2}{*}{ Técnica } & C1 & 0,1 & 0,05 & $\mathbf{0 , 1 3 3}$ & 0,0831 & 0,0831 & 0,091 \\
& C2 & 0,1 & 0,05 & $\mathbf{0 , 1 3 3}$ & 0,0831 & 0,0831 & 0,091 \\
& C3 & 0,1 & 0,05 & $\mathbf{0 , 1 3 3}$ & 0,0831 & 0,0831 & 0,091 \\
& C4 & 0,1 & 0,05 & $\mathbf{0 , 1 3 3}$ & 0,0831 & 0,0831 & 0,091 \\
& C5 & 0,1 & 0,05 & $\mathbf{0 , 1 3 3}$ & 0,0831 & 0,0831 & 0,091 \\
\hline \multirow{2}{*}{ Econômica } & C6 & 0,1 & 0,125 & 0,067 & $\mathbf{0 , 1 6 7}$ & 0,0831 & 0,091 \\
& C7 & 0,1 & 0,125 & 0,067 & $\mathbf{0 , 1 6 7}$ & 0,0831 & 0,091 \\
\hline \multirow{2}{*}{ Ambiental } & C8 & 0,1 & 0,125 & 0,067 & 0,0831 & $\mathbf{0 , 1 6 7}$ & 0,091 \\
& C9 & 0,1 & 0,125 & 0,067 & 0,0831 & $\mathbf{0 , 1 6 7}$ & 0,091 \\
\hline \multirow{2}{*}{ Social } & C10 & 0,1 & 0,25 & 0,067 & 0,0831 & 0,0831 & $\mathbf{0 , 1 8 1}$ \\
\hline
\end{tabular}

Para o Cenário 1, de acordo com a realidade local, considerou-se que o efluente poderia ser infiltrado no terreno, e, por isso, os critérios escolhidos que apresentam maior relevância 
nesta situação estão relacionados ao funcionamento técnico do sistema de tratamento, especificamente, confiabilidade e complexidade. Adotou-se peso dobrado a esses critérios em relação aos demais critérios.

No Cenário 2, os aspectos mais importantes de serem considerados estão relacionados com a qualidade do efluente tratado, risco de falha da tecnologia e o impacto que possa ocasionar no local. Por isso, os critérios confiabilidade, impacto ambiental e conformidade com a legislação foram atribuídos valores duas vezes maiores que os demais critérios.

Com o intuito de representar diversas realidades brasileiras que sofrem com a escassez hídrica e de fazer o reúso da água, propôs-se o cenário 3. Neste cenário, os parâmetros que têm maior influência estão relacionados à capacidade de produzir um efluente de ótima qualidade. Consequentemente, este cenário exige uma alternativa mais complexa e deve-se considerar o comportamento da família/comunidade quanto à aceitabilidade do processo. Portanto, enfatizaram-se os critérios confiabilidade, impacto ambiental, conformidade e aceitação da comunidade, com o dobro do peso dos demais critérios e, para o critério conformidade com a legislação, com o peso três vezes maior que os demais.

Tabela 5.4 - Aplicação de pesos de acordo com os cenários

\begin{tabular}{|c|c|c|c|c|}
\hline \multirow[b]{2}{*}{ Dimensões } & \multirow[b]{2}{*}{ Critérios } & \multicolumn{3}{|c|}{ Estratégias } \\
\hline & & Cenário 1 & Cenário 2 & Cenário 3 \\
\hline \multirow{5}{*}{ Técnica } & C1. Consumo de energia & 0,083 & 0,077 & 0,067 \\
\hline & C2. Área exigida & 0,083 & 0,077 & 0,067 \\
\hline & $\begin{array}{l}\text { C3. Quantidade de resíduo (lodo) } \\
\text { produzido }\end{array}$ & 0,083 & 0,077 & 0,067 \\
\hline & C4. Confiabilidade & 0,166 & 0,154 & $\mathbf{0 , 1 3 3}$ \\
\hline & C5. Nível de complexidade & 0,166 & 0,077 & 0,067 \\
\hline \multirow{2}{*}{ Econômica } & $\begin{array}{l}\text { C6. Custo de capital ou de } \\
\text { implantação }\end{array}$ & 0,083 & 0,077 & 0,067 \\
\hline & C7. Custo de O\&M & 0,083 & 0,077 & 0,067 \\
\hline \multirow[b]{2}{*}{ Ambiental } & C8. Impacto Ambiental & 0,083 & 0,154 & $\mathbf{0 , 1 3 3}$ \\
\hline & $\begin{array}{l}\text { C9. Conformidade com a Política } \\
\text { e Legislação Ambiental }\end{array}$ & 0,083 & 0,154 & 0,201 \\
\hline Social & $\begin{array}{lll}\text { C10. } & \text { Aceitação } & \text { da } \\
\text { comunidade/chefe da família }\end{array}$ & 0,083 & 0,077 & $\mathbf{0 , 1 3 3}$ \\
\hline
\end{tabular}


$\mathrm{Na}$ formulação dos cenários não foram consideradas as condições do local quanto aos fatores econômicos, de demanda por área e de consumo de energia, pois estes devem ser avaliados de forma mais criteriosa de quando usar ou não uma alternativa.

\subsubsection{1 - Consumo de energia}

A quantidade de energia necessária ou requerida para cada alternativa é determinada pela tecnologia que ela utiliza no processo de tratamento. O critério de consumo de energia é importante, uma vez que não só tem implicações financeiras, mas também afeta o meio ambiente. Os valores deste critério foram difíceis de serem encontrados na literatura para sistemas descentralizados, por isso consideraram-se pontuações iguais para os sistemas que não necessitam de energia para o seu funcionamento, e, para os que precisam de energia elétrica foram dados valores por analogia. Adotou-se o valor máximo para a alternativa A6 por considerar um consume maior de energia ocasionado por usar mais equipamentos que consomem energia elétrica que a alternativa A5. A mesma situação aconteceu para a alternativa A5 que tem maior consumo de energia que a alternativa A4. Na Tabela 5.5 estão apresentados os valores adotados para quantificar esse critério.

Tabela 5.5 - Valores adotados para quantificar o critério consumo de energia

\begin{tabular}{lc}
\multicolumn{2}{c}{ Consumo de energia } \\
\hline Alternativa & Valor adotado \\
\hline A1. TS & 0 \\
A2. TS + FAn & 0 \\
A3. TS + Wet & 0 \\
A4. UASB + BAS & 50 \\
A5. UASB + LAC & 75 \\
A6. TS + MBR & 100 \\
\hline
\end{tabular}

\subsubsection{2 - Área exigida}

Este critério fornece uma indicação comparativa do tamanho da área que ocupa uma tecnologia de tratamento. Utilizou-se, para medir este critério, a variável área demandada por metro cúbico de esgoto tratado, que é um parâmetro médio fornecido pela literatura para cada processo ou operação unitária. Os valores de área demandada por $\mathrm{m}^{3}$ de esgoto tratado foram adotados por meio de padronização de valores disponíveis na literatura, 
sendo que a pontuação mais alta é atribuída à tecnologia que exige uma menor área e uma pontuação baixa é atribuída à tecnologia que exige uma maior área (Tabela 5.6).

Tabela 5.6 - Valores adotados para quantificar o critério área exigida

\begin{tabular}{lccc}
\hline Alternativa & Área total $\left(\mathbf{m}^{2} / \mathbf{m}^{3}\right)$ & Referências & Valor padronizado \\
\hline A1. TS & 0,7 & Leroy Merlin $(2016)^{*}$ & 0 \\
A2. TS + FAn & 0,85 & ALFAMEC $(2016)^{*}$ & 3 \\
A3. TS + Wet & 5,83 & Guo et al. $(2014)$ & 100 \\
A4. UASB + BAS & 1,43 & Analogia** & 14 \\
A5. UASB + LAC & 2,01 & Tega Engenharia $(2016)^{*}$ & 26 \\
A6. TS + MBR & 0,83 & Guo et al. $(2014)$ & 3 \\
\hline
\end{tabular}

*Área calculada de acordo com a característica dos sistema ofertados no mercado. **Considerou-se esse sistema maior que a alternativa 2 e menor que a alternativa 5 .

\subsubsection{3 - Quantidade de resíduo (lodo) produzido}

Este critério considera a quantidade de produção de resíduo normalmente apresentada para cada sistema ou operação unitária avaliado sob condições normais de operação. Como no caso o único resíduo que se apresentava era o lodo, sendo este o resíduo computado. Os valores de produção de lodo foram adotados por meio de padronização de valores disponíveis na literatura. Para as tecnologias com menor quantidade de lodo gerado foi atribuída pontuação mais alta, enquanto que, para as de maior produção de lodo atribuiu-se pontuação menor (Tabela 5.7).

Tabela 5.7 - Valores adotados para quantificar o critério quantidade de resíduo (lodo) produzido.

\begin{tabular}{lccc}
\multicolumn{4}{c}{ Quantidade de resíduo (lodo) produzido } \\
\hline Alternativa & $\begin{array}{c}\text { Produção de lodo } \\
\text { (g/hab d) }\end{array}$ & Referência & $\begin{array}{c}\text { Valor } \\
\text { padronizado }\end{array}$ \\
\hline A1. TS & 30 & & 40 \\
A2. TS + FAn & 39 & von Sperling* (2005) & 100 \\
A3. TS + Wet & 30 & Alem Sobrinho e & 40 \\
A4. UASB + BAS & 30 & Jordão* (2001) & 40 \\
A5. UASB + LAC & 27 & Abegglen (2008) & 20 \\
A6. TS + MBR & 24 & & 0 \\
\hline
\end{tabular}

\footnotetext{
* considerou-se o valor máximo de produção de lodo.
} 


\subsubsection{4 - Confiabilidade}

O critério "confiabilidade" foi avaliado considerando-se a frequência com que cada alternativa de tratamento de esgoto apresenta falhas, sua capacidade de lidar com variação de vazão e carga, o risco inerente de interromper o processo de tratamento. Foram estimados os valores de "confiabilidade" para cada processo ou operação unitária fornecida. Para as alternativas que produziram maior confiabilidade foram atribuídas pontuações mais altas e vice-versa. O cálculo deste critério foi obtido pela planilha pontuada apresentada na Tabela 5.8.

Tabela 5.8 - Planilha pontuada para o critério confiabilidade

\begin{tabular}{ll}
\hline \multicolumn{1}{c}{ Confiabilidade } \\
\hline \multicolumn{1}{c}{ Item } & \multicolumn{1}{c}{ Pontuação } \\
\hline \multirow{2}{*}{ 1. Frequência com que o processo apresenta falhas? } & 0 - Alta \\
& 12,5 - Média \\
2. A alternativa apresenta risco de ser interrompida? & 25 - Baixa \\
\hline \multirow{2}{*}{ 3. A alternativa tem capacidade de lidar com vazão e cargas variáveis? } & 0 - Sim \\
\hline & 25 - Não \\
\hline \multirow{2}{*}{ 4. Como as condições operacionais podem afetar a qualidade do efluente? } & 0 - Não \\
& 25 - Sim \\
\hline
\end{tabular}

$\mathrm{Na}$ Tabela 5.9 apresentam-se as respostas e as referências utilizadas para responder a planilha pontuada referente ao critério confiabilidade.

Tabela 5.9 - Valores adotados para quantificar o critério confiabilidade

\begin{tabular}{|c|c|c|c|c|c|}
\hline \multicolumn{6}{|c|}{ Confiabilidade } \\
\hline Alternativa & $\begin{array}{c}\text { Tendências a } \\
\text { falhas }\end{array}$ & $\begin{array}{l}\text { Risco de ser } \\
\text { interrompida }\end{array}$ & $\begin{array}{c}\text { Lida com } \\
\text { variações de } \\
\text { carga e vazão }\end{array}$ & $\begin{array}{l}\text { Variação do } \\
\text { efluente }\end{array}$ & Pontuação \\
\hline A1. TS & Baixa & Não & Sim & Nenhum & 100 \\
\hline $\mathrm{A} 2 . \mathrm{TS}+\mathrm{FAn}$ & Baixa & Não & Sim & Pouco & 87,5 \\
\hline A3. TS + Wet & Baixa & Não & Sim & Pouco & 87,5 \\
\hline A4. UASB + BAS & Média & Sim & Sim & Pouco & 50 \\
\hline A5. UASB + LAC & Média & Sim & Sim & Pouco & 50 \\
\hline A6. $T S+M B R$ & Média & Sim & Sim & Muito & 37,5 \\
\hline
\end{tabular}




\subsubsection{5 - Complexidade operacional}

A dificuldade de se operar e manter um processo de tratamento pode ser medida por seu "nível de complexidade". Como este critério indica o nível de habilidade necessária para operação e manutenção da tecnologia de tratamento, para as tecnologias menos complexas são atribuídas pontuações mais elevadas e vice-versa. A mensuração do valor deste critério em cada alternativa foi obtida por planilha pontuada representada na Tabela 5.10. Na Tabela 5.11 apresentam-se as respostas e as referências utilizadas para responder a planilha pontuada referente ao critério complexidade operacional.

Tabela 5.10 - Planilha pontuada para o critério complexidade operacional.

\section{Complexidade operacional}

\begin{tabular}{ll}
\hline Item & Pontuação \\
\hline 1. A alternativa possui uma tecnologia complexa? & $\begin{array}{l}0-\text { Não } \\
16,7-\text { Sim }\end{array}$ \\
\hline $\begin{array}{l}\text { 2. Para o funcionamento da alternativa é necessário a incorporação de } \\
\text { outros equipamentos? }\end{array}$ & $\begin{array}{l}0-\text { Não } \\
16,7-\text { Sim }\end{array}$ \\
\hline 3. Qual o grau de automação necessário para a execução automática da & $\begin{array}{l}0 \text { - Nenhum } \\
8,35-\text { Médio } \\
\text { alternativa? }\end{array}$ \\
\hline 4. É necessária mão de obra especializada para a operação da & $0-$ Não \\
alternativa? & 16,7 - Sim \\
\hline 5. É necessário realizar o monitoramento e o controle operacional & $0-$ Não \\
remoto? & 16,7 - Sim \\
\hline \multirow{2}{*}{ 6. Com que frequência a alternativa depende da assistência técnica de } & $0-$ Raramente \\
terceiros? & 8,35 - Às vezes \\
& 16,7 - Sempre \\
\hline
\end{tabular}

Tabela 5.11 - Valores adotados para quantificar o critério complexidade operacional

\begin{tabular}{|c|c|c|c|c|c|c|c|}
\hline \multicolumn{8}{|c|}{ Complexidade operacional } \\
\hline Alternativa & $\begin{array}{l}\text { Tecnologia } \\
\text { complexa }\end{array}$ & $\begin{array}{l}\text { Necessidade } \\
\text { de equip. }\end{array}$ & $\begin{array}{c}\text { Grau de } \\
\text { automação }\end{array}$ & $\begin{array}{c}\text { Espec. } \\
\text { para } \\
\text { operação }\end{array}$ & $\begin{array}{l}\text { Controle } \\
\text { operac. } \\
\text { remoto }\end{array}$ & $\begin{array}{l}\text { Frequência } \\
\text { assistência }\end{array}$ & Pontuação \\
\hline A1. TS & Não & Não & Nenhum & Não & Não & Raramente & 0 \\
\hline $\begin{array}{l}\text { A2. TS + } \\
\text { FAn }\end{array}$ & Não & Não & Nenhum & Não & Não & Raramente & 0 \\
\hline $\begin{array}{l}\text { A3. TS + } \\
\text { Wet }\end{array}$ & Não & Sim & Nenhum & Não & Não & Às vezes & 25,05 \\
\hline $\begin{array}{l}\text { A4. UASB } \\
+ \text { BAS }\end{array}$ & Não & Sim & Nenhum & Sim & Não & Às vezes & 41,75 \\
\hline $\begin{array}{l}\text { A5. UASB } \\
+ \text { LAC }\end{array}$ & Não & Sim & Nenhum & Sim & Não & Sempre & 50 \\
\hline $\begin{array}{l}\text { A6. TS + } \\
\text { MBR }\end{array}$ & Sim & Sim & Alto & Sim & Sim & Sempre & 100 \\
\hline
\end{tabular}


5.2.2.6 - Custo de capital ou de implantação

Este critério normalmente exerce grande influência no processo decisório de seleção da tecnologia, principalmente nas regiões que apresentam maiores limitações econômicas e financeiras. Para as tecnologias associadas a elevados custos de capital são atribuídas pontuações altas, enquanto que para aquelas associadas com menores custos de capital são atribuídas pontuações mais baixas. Os valores foram adotados por meio de padronização de valores fornecidos por empresas que vendem esses sistemas de tratamento, encontrados na literatura e por analogia, como apresentados na Tabela 5.12.

Tabela 5.12 - Valores adotados para quantificar o critério custo de implantação

\begin{tabular}{lccc}
\hline \multicolumn{3}{c}{ Custo de Implantação } \\
\hline Alternativa & Valor $(\mathrm{R} \$ / \mathrm{hab})$ & Referência & Valor ponderado \\
\hline A1. TS & 596,18 & Leroy Merlin $(2016)^{*}$ & 0 \\
A2. TS + FAn & 1534,00 & Delta Saneamento ambiental & 13 \\
A3. TS + Wet & 2526,90 & $(2016)^{*}$ & 26 \\
A4. UASB + BAS & 4963,45 & Molinos-Senante et al. $(2012)$ & 59 \\
A5. UASB + LAC & 7400,00 & Tega Engenharia $(2016)^{*}$ & 92 \\
A6. TS + MBR & 8000,00 & Pam Membranas $(2015)^{*}$ & 100
\end{tabular}

*Dados informados por empresas que vendem sistemas de tratamento de esgoto (o valor de custo foi dividido pela capacidade de tratamento). ${ }^{*}$ Considerou-se mais barato que alternativa 5 e mais caro que a alternativa 2, valor adotado pela média dessas duas alternativas.

Sistemas de tratamento de efluentes, quando em menor escala, tornam-se mais caros. Há uma dificuldade em encontrar na literatura valores de custos disponíves que tenham a mesma convergência de dados para sistemas descentralizados. Por isso, fez-se uma consulta de preço as empresas/indústrias que comercializam alguns desses sistemas para estimar o valor real. No caso da Alternativa 4 em que não foi possível estimar o preço, usou-se uma abordagem de raciocínio de prova para marcar sistemas em relação ao outro com analogia e média entre os preços.

\subsubsection{7 - Custo de operação e manutenção (O\&M)}

Este critério leva em conta os custos associados com o funcionamento da cada processo de tratamento durante a sua vida útil, importando em materiais para troca e substituição de 
equipamentos, consumo de energia e de produtos químicos. Para as tecnologias associadas a altos custos de O\&M são atribuídas pontuações altas, enquanto para aquelas associadas com menores custos de O\&M são atribuídas pontuações mais baixas. Os valores foram adotados por meio de planilha pontuada que está apresentada na Tabela 5.13.

Tabela 5.13 - Planilha pontuada para o critério custo de operação e manutenção

\begin{tabular}{ll}
\hline \multicolumn{1}{c}{ Custo de Operação e Manutenção } \\
\hline Item & Pontuação \\
\hline 1. Qual a magnitude do consumo de energia elétrica proveniente da & $\begin{array}{l}0 \text { - Não consome energia } \\
8,35-\text { Média } \\
\text { operação da alternativa? }\end{array}$ \\
\hline \multirow{2}{*}{ 2. Qual é a quantidade de equipamentos exigida? } & $\begin{array}{l}0 \text { - Baixa } \\
8,34-\text { Média } \\
16,7-\text { Alta }\end{array}$ \\
\hline \multirow{2}{*}{ 3. A alternativa exige o uso de produtos químicos? } & $\begin{array}{l}0-\text { Não } \\
16,7-\text { Sim }\end{array}$ \\
\hline \multirow{2}{*}{ 4. A alternativa necessita de substituição equipamentos ou materiais? } & $\begin{array}{l}0-\text { Não } \\
16,7-\text { Sim }\end{array}$ \\
\hline \multirow{2}{*}{ 5. Qual a frequência de manutenção do sistema? } & $\begin{array}{l}0-\text { Baixa } \\
8,34-\text { Média } \\
16,7-\text { Alta }\end{array}$ \\
\hline \multirow{2}{*}{ 6. Qual o nível de qualificação exigida para a operação da } & 0 - Baixa \\
alternativa? & 8,34 - Média \\
\end{tabular}

As respostas e as referências utilizadas para responder a planilha pontuada referente ao critério O\&M estão expostas na Tabela 5.14.

Tabela 5.14 - Valores adotados para quantificar o critério custo de O\&M

\begin{tabular}{|c|c|c|c|c|c|c|c|}
\hline \multicolumn{8}{|c|}{ Custo de operação e manutenção } \\
\hline Alternativa & $\begin{array}{l}\text { Consumo } \\
\text { de energia }\end{array}$ & $\begin{array}{l}\text { Exigência } \\
\text { de equip. }\end{array}$ & $\begin{array}{l}\text { Produto } \\
\text { químico }\end{array}$ & $\begin{array}{l}\text { Substit. de } \\
\text { equip. }\end{array}$ & $\begin{array}{c}\text { Freq. de } \\
\text { manut. }\end{array}$ & $\begin{array}{c}\text { Nível de } \\
\text { qualificação } \\
\text { na operação }\end{array}$ & Pontuação \\
\hline A1. TS & Não & Baixa & Não & Não & Baixa & Baixa & 0 \\
\hline $\begin{array}{l}\text { A2. TS + } \\
\text { FAn }\end{array}$ & Não & Baixa & Não & Não & Baixa & Baixa & 0 \\
\hline $\begin{array}{l}\text { A3. TS + } \\
\text { Wet }\end{array}$ & Não & Baixa & Não & Sim & Média & Baixa & 25,05 \\
\hline $\begin{array}{l}\text { A4. UASB } \\
+ \text { BAS }\end{array}$ & Média & Média & Não & Sim & Média & Média & 50 \\
\hline $\begin{array}{l}\text { A5. UASB } \\
+ \text { LAC }\end{array}$ & Alta & Média & Não & Sim & Alta & Alta & 75,15 \\
\hline $\begin{array}{c}\text { A6. TS + } \\
\text { MBR }\end{array}$ & Alta & Alta & Sim & Sim & Alta & Alta & 100 \\
\hline
\end{tabular}




\subsubsection{8 - Impacto Ambiental}

A variável envolvida na mensuração deste critério foi a combinação de possibilidades de uma alternativa de tratamento de esgotos provocar problemas ambientais devido à ocorrência associada de: produção de maus odores e de ruídos; maior consumo de energia e de produtos químicos. poluição do solo e da água. O impacto causado sobre o meio ambiente é considerado um critério fundamental no processo de seleção. Para a tecnologia de tratamento com menor impacto ambiental é atribuída uma pontuação baixa e vice-versa. O cálculo deste critério foi obtido pela planilha pontuada apresentada na Tabela 5.15 e as respostas e referências na Tabela 5.15 .

Tabela 5.15 - Planilha pontuada para o critério impacto ambiental

\begin{tabular}{|c|c|}
\hline \multicolumn{2}{|l|}{ Impacto ambiental } \\
\hline Item & Pontuacão \\
\hline \multirow{3}{*}{ 1. Qual a intensidade do odor gerado pela alternativa? } & 0 - Baixa \\
\hline & 8.35 - Média \\
\hline & 16,7 - Alta \\
\hline \multirow{3}{*}{ 2. Qual a intensidade das vibrações e de ruídos emitidos pela alternativa? } & 0 - Baixa \\
\hline & 8.35 - Média \\
\hline & 16,7 - Alta \\
\hline \multirow{2}{*}{ 3. Na operação da alternativa é necessário o consumo de energia elétrica? } & 0 - Não \\
\hline & $16,7-\operatorname{Sim}$ \\
\hline \multirow{2}{*}{ 4. Na operação da alternativa é necessário o uso de produtos químicos? } & $0-$ Não \\
\hline & $16,7-\operatorname{Sim}$ \\
\hline \multirow{3}{*}{ 5. A alternativa causa risco de poluição do solo? } & 0 - Baixa \\
\hline & 8.35 - Média \\
\hline & 16,7 - Alta \\
\hline \multirow{3}{*}{ 6. A alternativa causa risco de poluição da água subterrânea ou superficiais? } & 0 - Baixa \\
\hline & 8.35 - Média \\
\hline & 16,7 - Alta \\
\hline
\end{tabular}

Tabela 5.16 - Valores adotados para quantificar o critério impacto ambiental

\begin{tabular}{lccccccc}
\hline \multicolumn{7}{c}{ Impacto ambiental } \\
\hline Alternativa & Odor & Ruído & $\begin{array}{c}\text { Energia } \\
\text { elétrica }\end{array}$ & $\begin{array}{c}\text { Produto } \\
\text { químico }\end{array}$ & $\begin{array}{c}\text { Poluição } \\
\text { do solo }\end{array}$ & $\begin{array}{c}\text { Poluição } \\
\text { da água }\end{array}$ & Pontuação \\
\hline A1. TS & Alta & Baixa & Não & Não & Alta & Média & 41,75 \\
A2. TS + FAn & Alta & Baixa & Não & Não & Média & Baixa & 25,05 \\
A3. TS + Wet & Alta & Baixa & Não & Não & Baixa & Baixa & 16,7 \\
A4. UASB + BAS & Alta & Média & Sim & Não & Baixa & Baixa & 41,75 \\
A5. UASB + LAC & Alta & Alta & Sim & Não & Baixa & Baixa & 50,1 \\
A6. TS + MBR & Alta & Alta & Sim & Sim & Baixa & Baixa & 66,8 \\
\hline
\end{tabular}




\subsubsection{9 - Conformidade com a Política e Legislação Ambiental}

Para aquela tecnologia que oferecer um efluente em conformidade com as legislações ambientais foi atribuída pontuação quanto maior for a associação de conformidades. Para comparação dos parâmetros das alternativas com a legislação vigente avaliaram-se duas situações específicas de acordo com o cenário considerado. Para o cenário 1 e 2 considerou-se os padrões de lançamento de efluente sanitário no corpo receptor com a Resolução 430/2011 do CONAMA e, para o cenário 3 considerou-se apenas as alternativas A4, A5 e A6 para serem avaliadas de acordo com os parâmetros de Classe 3 dos padrões de reúso da ANA (2005). Os padrões de classe 3 foram os escolhidos por ser o menos restritivo comparados as outras classes. A planilha pontuada para avaliar esse critério está apresentada na Tabela 5.17.

Tabela 5.17 - Planilha pontuada para o critério conformidade com a política e legislação ambiental

\section{Conformidade com a Política e Legislação Ambiental}

Item

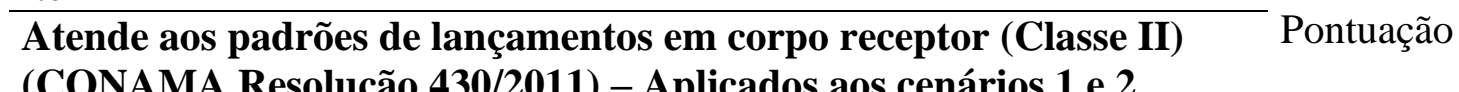

11) - Aplicados aos cenários

1. $\mathrm{DBO}_{5}(120 \mathrm{mg} / \mathrm{L}$ ou $60 \%)$

0 - Não atende

33,3 - Atende

0 - Não atende

2. Nitrogênio amoniacal (20 mg/L)

33,3 - Atende

0 - Não atende

3. SST (remoção > 20\%)

33,3 - Atende

Atende aos padrões de reúso da ANA (2005) - Classe 3: irrigação de
áreas verdes e rega dos jardins - Aplicado aos cenário 3

1. SST - Sólidos suspenos totais $(\leq 20,0 \mathrm{mg} / \mathrm{L}) \quad 0$ - Não atende

1. SST - Sólidos suspensos totais $(\leq 20,0 \mathrm{mg} / \mathrm{L})$

25 - Atende

2. Turbidez $(\leq 5,0 \mathrm{NTU})$

0 - Não atende

25 - Atende

3. $\mathrm{DBO}_{5}(\leq 20,0 \mathrm{mg} / \mathrm{L})$

0 - Não atende

25 - Atende

0 - Não atende

4. Nitrogênio amoniacal (5-30 mg/L)

25 - Atende

Na Tabela 5.18 apresentam-se os dados de alguns parâmetros de qualidade de efluente dos sistemas de tratamento de esgoto sanitário encontrados na literatura e a pontuação adotada para a avaliação desse critério. 
Tabela 5.18 - Valores adotados para quantificar o critério conformidade com a política e legislação ambiental

\begin{tabular}{ccccccc}
\hline Parâmetros & A1. TS & $\begin{array}{c}\text { A2. TS }+ \\
\text { FAn }\end{array}$ & $\begin{array}{c}\text { A3. TS }+ \\
\text { Wet }\end{array}$ & $\begin{array}{c}\text { A4. UASB } \\
\text { BAS }\end{array}$ & $\begin{array}{c}\text { A5. UASB + } \\
\text { LAC }\end{array}$ & $\begin{array}{c}\text { A6. TS + } \\
\text { MBR }\end{array}$ \\
\hline $\begin{array}{c}\mathrm{DBO}_{5}(\mathrm{mg} / \mathrm{L}) \\
\begin{array}{c}\text { Nitrogênio amoniacal } \\
(\mathrm{mg} / \mathrm{L})\end{array}\end{array}$ & 170 & $<60$ & $<20$ & 12 & $<20$ & $<10$ \\
$\begin{array}{c}\text { Turbidez (UNT) } \\
\text { SST - Sólidos }\end{array}$ & 60 & 78 & - & $<20 *$ & 16 & 3.2 \\
$\begin{array}{c}\text { suspensos totais } \\
\text { Pontuação }\end{array}$ & $<100$ & $<20$ & $<20$ & 14 & $<-15$ & $<5$ \\
Cenários 1 e 2 & 66,8 & 100 & 100 & 100 & 100 & 100 \\
Cenário 3 & - & - & - & 75 & 50 & 100 \\
\hline
\end{tabular}

*Valor não encontrado e por analogia considerando o baixo teor de SST adotou-se menor que 20. Referências: Andrade Neto et al (2000); Chernicharo et al, (2001); EPA (2002); Gonçalves et al (1998); von Sperling, (2005); Ávila (2005); Sartor (2008); Abegglen (2008); Almeida el al (2010); Bof et al., (2001) Skouteris et al., (2012a); Abbas et al. (2012); Luna et al (2013).

\subsubsection{0 - Aceitação da comunidade/família}

Este critério tem a missão de indicar a receptividade da comunidade a uma determinada tecnologia de tratamento. Este critério envolve complexidades e incertezas decorrentes dos interesses, identidades culturais, ideologias e objetivos das diferentes partes interessadas, além de experiências do passado. Uma pontuação elevada foi dada a tecnologia com maior reconhecimento público, e uma pontuação baixa foi dada a uma tecnologia que não foi compreendida ou respeitada publicamente. A planilha pontuada elaborada para avaliação desse critério está apresentada na Tabela 5.19 e as respostas na Tabela 5.20.

Tabela 5.19 - Planilha pontuada para o critério Aceitação da comunidade/chefe da família

$$
\text { Aceitação da comunidade/chefe da família }
$$

\begin{tabular}{ll}
\hline Item & Pontuação \\
\hline 1. O sistema pode ser aceito pela comunidade ou pela família? & $0-$ Não \\
& 33,3 - Sim \\
\hline 2. O sistema pode possibilitar o envolvimento da comunidade na & 0 - Não \\
manutenção e operação do sistema? & 12,5 - Parcialmente \\
& 33,3 - Sim \\
\hline \multirow{2}{*}{ 3. O sistema pode ser adaptado de acordo com as necessidades da } & 0 - Não \\
comunidade? & 12,5 - Parcialmente \\
& 33,3 - Sim \\
\hline
\end{tabular}


Tabela 5.20 - Planilha pontuada para o critério Aceitação da comunidade/família

\begin{tabular}{lcccc}
\hline \multicolumn{4}{c}{ Aceitação da comunidade/família } \\
\hline Alternativa & $\begin{array}{c}\text { Aceitabilidade } \\
\text { do sistema }\end{array}$ & $\begin{array}{c}\text { Envolve a } \\
\text { comunidade na } \\
\text { O\&M }\end{array}$ & $\begin{array}{c}\text { Pode ser } \\
\text { adaptado ou } \\
\text { expandido }\end{array}$ & Pontuação \\
\hline A1. TS & Sim & Sim & Sim & 100 \\
A2. TS + FAn & Sim & Sim & Sim & 100 \\
A3. TS + Wet & Sim & Sim & Sim & 100 \\
A4. UASB + BAS & Sim & Parcialmente & Parcial & 66,7 \\
A5. UASB + LAC & Sim & Não & Parcial & 50 \\
A6. TS + MBR & Sim & Não & Não & 33,3 \\
\hline
\end{tabular}

\subsection{3 - Avaliação das Alternativas e da Metodologia}

Os resultados do preenchimento das planilhas ponderadas e das planilhas pontuadas foram apresentados no Capítulo 5, e por meio deles constituiu-se a matriz de avaliação que está apresentada na Tabela 5.21. Dados os diferentes cenários, os valores adotados para o critério referente à conformidade com a política e legislação ambiental variaram conforme a aplicação.

Tabela 5.21 - Matriz de avaliação das alternativas de acordo com cada critério

\begin{tabular}{|c|c|c|c|c|c|c|c|}
\hline \multicolumn{8}{|c|}{ Pay-off Matrix } \\
\hline \multirow{2}{*}{ Dimensão } & \multirow{2}{*}{ Critério } & \multicolumn{6}{|c|}{ Alternativas } \\
\hline & & $\mathrm{A} 1$ & $\mathrm{~A} 2$ & $\mathrm{~A} 3$ & A4 & A5 & A6 \\
\hline \multirow{5}{*}{ Técnica } & $\mathrm{C} 1$ & 0 & 0 & 0 & 50 & 75 & 100 \\
\hline & $\mathrm{C} 2$ & 0 & 3 & 100 & 14 & 26 & 3 \\
\hline & $\mathrm{C} 3$ & 40 & 100 & 40 & 40 & 20 & 0 \\
\hline & $\mathrm{C} 4$ & 100 & 87,5 & 87,5 & 50 & 50 & 37,5 \\
\hline & $\mathrm{C} 5$ & 0 & 0 & 25,05 & 41,75 & 50 & 100 \\
\hline \multirow{2}{*}{ Econômica } & C6 & 0 & 13 & 26 & 59 & 92 & 100 \\
\hline & $\mathrm{C} 7$ & 0 & 0 & 25,05 & 50 & 75,15 & 100 \\
\hline \multirow{3}{*}{ Ambiental } & $\mathrm{C} 8$ & 41,75 & 25,05 & 16,7 & 41,75 & 50,1 & 66,8 \\
\hline & $\mathrm{C} 9^{1}$ & 66,6 & 100 & 100 & 100 & 100 & 100 \\
\hline & $\mathrm{C} 9^{2}$ & - & - & - & 75 & 50 & 100 \\
\hline Social & $\mathrm{C} 10$ & 100 & 100 & 100 & 66,7 & 50 & 33,3 \\
\hline
\end{tabular}


Nos próximos tópicos estão apresentados os resultados das alternativas para análise multicritério e multiobjetivo com a aplicação dos métodos TOPSIS e ELECTRE III. As alternativas estão posicionadas quanto à ordem de classificação no ranking. De modo que os resultados da posição das alternativas do método ELECTRE III está apresentado na coluna 2, e do método TOPSIS nas demais colunas juntamente com os valores encontrados para os coeficientes de similaridade com $\mathrm{p}=1, \mathrm{p}=2$ e $\mathrm{p}=\infty$.

Os valores dos limiares para o método ELECTRE III de indiferença (q), preferência (p) e veto(v) podem ser constantes ou variar ao longo da escala. Deve-se notar que não existem verdadeiros valores para os limiares. Portanto, os valores escolhidos para atribuir aos limiares são os que melhor se adaptam para expressar o caráter imperfeito do conhecimento (Figueira et al, 2005). O limite de veto não foi utilizado pois em todos os critérios estão aplicados na mesma escala, sendo que, diferença entre as opções. Os desempenhos dos critérios não apresentam grande discrepância, por isso, desconsiderou o veto nesta avaliação.

Neste trabalho, escolheram-se os limiares de preferências (p) com $25 \%$ do valor médio dos critérios definidos como valores de referências e adotou-se uma relação de p/q=2,5. Na Tabela 5.22 apresenta os valores adotados para representar a indiferença e a preferência de cada critério.

Tabela 5.22 - Limiares de preferência e de indirença adotados para a simulação do método ELECTRE III.

\begin{tabular}{ccc}
\hline Critérios & $\mathrm{q}$ & $\mathrm{p}$ \\
\hline C1 & 3,8 & 9,4 \\
C2 & 4,7 & 11,7 \\
C3 & 4,0 & 10,0 \\
C4 & 6,9 & 17,2 \\
C5 & 3,6 & 9,0 \\
C6 & 4,8 & 12,1 \\
C7 & 4,2 & 10,4 \\
C8 & 4,0 & 10,1 \\
C9 & 9,4 & 23,6 \\
C10 & 7,5 & 18,8 \\
\hline
\end{tabular}




\subsubsection{1 - Avaliação dos resultados no Cenário 1}

Para este cenário, os resultados apresentados na Tabela 5.23, dada a não exigência ao considerar os critérios ambientais e dar enfoque aos critérios referentes ao funcionamento das tecnologias, indicam que a melhor alternativa a ser aplicada nesta situação seriam as alternativas A1 - Tanque séptico e a A2 - Tanque séptico seguido de filtro anaeróbio, por serem tecnologias relativamente simples e de fácil implantação. Já a tecnologia que pior se adequaria ao Cenário 1 se adotada para esta situação é a A6 - Tanque séptico seguido por MBR, devido a sua complexidade, alto custo e necessidade frequente de manutenção. Percebe-se uma similaridade nos resultados obtidos pelo método ELECTRE III com o do TOPSIS para $p=\infty$.

Tabela 5.23 - Resultados da simulação nos métodos ELECTRE III e TOPSIS para o Cenário 1

\begin{tabular}{|c|c|c|c|c|}
\hline Cenário 1 & ELECTRE-III & & TOPSIS & \\
\hline Ranking & Alt. & $\begin{array}{c}\text { Alt. } \\
\mathrm{C}_{\mathrm{k}}{ }^{*}(\mathrm{p}=1)\end{array}$ & $\begin{array}{c}\text { Alt. } \\
\mathrm{C}_{\mathrm{k}}{ }^{*}(\mathrm{p}=2)\end{array}$ & $\begin{array}{c}\text { Alt. } \\
\mathrm{C}_{\mathrm{k}}^{*}(\mathrm{p}=\infty)\end{array}$ \\
\hline $1^{\circ}$ & $\mathrm{A} 1 \mathrm{e} \mathrm{A} 2$ & A2 & A2 & A1 e A2 \\
\hline $2^{o}$ & A3 & A1 & A3 & A3 \\
\hline $3^{\circ}$ & A4 & A3 & A1 & A4 \\
\hline $4^{\circ}$ & A5 & A4 & A4 & A5 \\
\hline $5^{\circ}$ & A6 & A5 & A5 & A6 \\
\hline $6^{\circ}$ & & A6 & A6 & \\
\hline
\end{tabular}

\subsubsection{2 - Avaliação dos resultados no Cenário 2}

No Cenário 2 há uma restrição maior quanto à confiabilidade do sistema de tratamento, os possíveis impactos que a tecnologia possa causar ao meio ambiente e à permanência do efluente dentro dos padrões de lançamento que devem ser alcançados pela Resolução 430/2011 do CONAMA. Na Tabela 5.24 mostra-se que a alternativa A1 fica na pior posição no ranking, para o parâmetro $\infty$, dada pelo desvio de maior importância, evidenciando que essa tecnologia não se aplica a locais mais restritivos e sugerindo um refinamento do seu efluente final complementado com pós-tratamento, como no caso das alternativas A2 e A3 (tanque séptico seguido de filtro anaeróbio e seguido de wetland), que foram as melhores classificadas, e, portanto, mais adequada para esta situação. Isto sugere que essas duas alternativas atendem melhor aos requisitos ambientais e é tecnicamente e economicamente viável. Porém, para o caso da alternativa A3 (sistema com plantas), se o 
local tiver limitação de área, a solução que deverá ser adotada precisa atender o requisito de disponibilidade de área para instalação, no caso a alternativa A2 é a melhor solução. Enquanto que a alternativa A6 mostra-se novamente como a tecnologia menos adequada para ser implantada nesse Cenário 2.

Tabela 5.24 - Resultados da simulação nos métodos ELECTRE III e TOPSIS para o Cenário 2

\begin{tabular}{|c|c|c|c|c|}
\hline Cenário 2 & ELECTRE-III & & TOPSIS & \\
\hline Ranking & Alt. & $\begin{array}{c}\text { Alt. } \\
\mathrm{C}_{\mathrm{k}}^{*}(\mathrm{p}=1)\end{array}$ & $\begin{array}{c}\text { Alt. } \\
\mathrm{C}_{\mathrm{k}}^{*}(\mathrm{p}=2)\end{array}$ & $\begin{array}{c}\text { Alt. } \\
\mathrm{C}_{\mathrm{k}}^{*}(\mathrm{p}=\infty)\end{array}$ \\
\hline $1^{o}$ & $\mathrm{~A} 1, \mathrm{~A} 2$ e $\mathrm{A} 3$ & A2 & $\mathrm{A} 2$ e $\mathrm{A} 3$ & $\mathrm{~A} 2$ e $\mathrm{A} 3$ \\
\hline $2^{o}$ & A4 & A3 & A4 & A 4 e A5 \\
\hline $3^{\circ}$ & A5 & A1 & A5 & A1 e A6 \\
\hline $4^{\circ}$ & A6 & A4 & A1 & \\
\hline $5^{\circ}$ & & A5 & A6 & \\
\hline $6^{\circ}$ & & A6 & & \\
\hline
\end{tabular}

\subsubsection{3 - Avaliação dos resultados no Cenário 3}

Os valores propostos para os padrões de reúso de água inviabilizam quase todos os sistemas de tratamento quando se opta pelo reúso de água mais restrito, exceto para o tratamento com reator biológico com membrana (MBR). Baseado nisso, para o cenário 3, fez-se uma pré-triagem das alternativas, para que fossem avaliadas apenas as que atendessem aos padrões de qualidade. Chegou-se à conclusão de que nem todas estavam em conformidade com os principais parâmetros. Com isso, relaxaram-se um pouco os valores dos padrões exigidos para o reúso de água na consideração das alternativas, adicionando as tecnologias que melhor podem se adequar para alcançar os níveis adequados para o reúso de água de Classe 3, com adaptações no tratamento.

As alternativas escolhidas para serem avaliadas nesta etapa foram as seguintes: (A4) UASB seguido de filtro biológico aerado; (A5) UASB seguido por lodos ativados; e (A6) Tanque séptico acompanhado do MBR. Para atender à exigência do Cenário 3, considerouse que todas essas alternativas teriam ao final a desinfecção do efluente tratado, como recomendado pela NBR 13969/1997. 
Os padrões adotados foram estabelecidos pela Agência Nacional de Águas (ANA, 2005) para o reúso de água para irrigação de áreas verdes e rega de jardins, já apresentados anteriormente no tópico 3.1. Os resultados para avaliação das tecnologias de tratamentos para esse cenário estão apresentados na Tabela 5.25

Tabela 5.25 - Resultados da simulação nos métodos ELECTRE III e TOPSIS para o Cenário 3

\begin{tabular}{ccccc}
\hline Cenário 3 & ELECTRE-III & \multicolumn{3}{c}{ TOPSIS } \\
\hline Ranking & Alt. & Alt. $_{\mathrm{k}}{ }^{*}(\mathrm{p}=1)$ & $\begin{array}{c}\text { Alt. } \\
\mathrm{C}_{\mathrm{k}}{ }^{*}(\mathrm{p}=2)\end{array}$ & $\mathrm{C}_{\mathrm{k}}{ }^{*}(\mathrm{p}=\infty)$ \\
\hline $1^{\text {o }}$ & A4 & A4 & $\mathrm{A} 4$ & A6 \\
$2^{\text {o }}$ & A5 e A6 & A5 & A6 & A4 \\
$3^{\text {o }}$ & & A6 & A5 & A5 \\
\hline $\mathrm{C}_{\mathrm{k}}{ }^{*}$ - coeficiente de similaridade. Alt. - alternativa. A1. TS; A2. TS+FAn; A3. TS+Wet; A4. UASB+BAS;
\end{tabular}
A5. UASB+LAC; A6. TS+MBR

É notório que a alternativa A6 somente no método TOPSIS $(p=\infty)$ ficou em primeiro lugar no ranking em decorrência desse parâmetro refletir a influência do maior desvio, mesmo sendo considerada a alternativa ideal voltada à aplicação para o reúso de água por ser a única que alcança os padrões exigidos pelo critério de conformidade com a legislação ambiental. Ao passo que a A4 - Tanque séptico seguido por biofiltro aerado submerso respondeu como a opção ótima para este cenário. Já a A5 - UASB seguido de lodos ativados não é recomendável para ser aplicada nesta situação.

\subsubsection{4 - Análise de sensibilidade}

A análise de sensibilidade foi realizada por meio de variação dos pesos atribuídos a cada critério, permitindo, assim, verificar quais seriam as alterações no resultado final caso as suas preferências variassem.

As prioridades finais das alternativas são altamente dependentes dos pesos ligados aos critérios principais. Assim, a análise de sensibilidade deve ser realizada para observar o impacto de pesos variados sobre os resultados. Se a classificação não muda, os resultados são considerados robustos, e em caso contrário, são sensíveis (Ouyang et al. 2015). Se o ranking é altamente sensível a pequenas alterações nos pesos, uma revisão cuidadosa dos pesos deve ser proposta. Além disso, os critérios de decisão adicionais devem ser envolvidos como um ponto do ranking altamente sensível a uma potencial discriminação fraca da série de critérios. 
A ordenação das alternativas de acordo com a classificação da melhor (primeira posição) ou pior (última posição), para adoção dos valores dos pesos iguais tanto para todos os critérios (Tabela 5.26) como para as dimensões (Tabela 5.27), mostraram pequenas variações. No entanto, essas variações não foram consideradas altamente sensíveis, mostrando que a variação aconteceu conforme o esperado.

Tabela 5.26 - Resultados da simulação nos métodos ELECTRE III e TOPSIS com aplicação de pesos iguais para cada critério

\begin{tabular}{|c|c|c|c|c|}
\hline \multirow{2}{*}{ Ranking } & \multirow{2}{*}{$\frac{\text { ELECTRE III }}{\text { Alt. }}$} & \multicolumn{3}{|c|}{ TOPSIS } \\
\hline & & Alt. $\mathrm{C}_{\mathrm{k}}{ }^{*}(\mathrm{p}=1)$ & Alt. $C_{k}^{*}(p=2)$ & Alt. $C_{k}^{*}(p=\infty)$ \\
\hline $\mathbf{1}^{\mathbf{o}}$ & $\mathrm{A} 1$ e $\mathrm{A} 2$ & A2 & $\mathrm{A} 2$ & A4 \\
\hline $2^{\circ}$ & A3 & A1 & A3 & A5 \\
\hline $3^{\mathbf{o}}$ & A4 & A3 & A1 & $\mathrm{A} 1, \mathrm{~A} 2, \mathrm{~A} 3 \mathrm{e} \mathrm{A} 6$ \\
\hline $4^{\circ}$ & A5 & A4 & A4 & \\
\hline $5^{\circ}$ & A6 & A5 & A5 & \\
\hline $6^{0}$ & & A6 & A6 & \\
\hline
\end{tabular}

Tabela 5.27 - Resultados da simulação nos métodos ELECTRE III e TOPSIS com aplicação de pesos iguais para as dimensões

\begin{tabular}{|c|c|c|c|c|}
\hline \multirow{2}{*}{ Ranking } & \multirow{2}{*}{$\begin{array}{c}\text { ELECTRE III } \\
\text { Alt. }\end{array}$} & \multicolumn{3}{|c|}{ TOPSIS } \\
\hline & & Alt. $C_{k}^{*}(p=1)$ & Alt. $\mathrm{C}_{\mathrm{k}}^{*}(\mathrm{p}=2)$ & Alt. $C_{k}^{*}(p=\infty)$ \\
\hline $1^{\mathrm{o}}$ & $\mathrm{A} 2$ & $\mathrm{~A} 2$ & $\mathrm{~A} 2$ & $\mathrm{~A} 2 \mathrm{e} \mathrm{A} 3$ \\
\hline $2^{\circ}$ & $\mathrm{A} 1$ & A3 & A3 & A1 \\
\hline $3^{\circ}$ & A3 & A1 & A1 & A4 \\
\hline $4^{\circ}$ & A4 & A4 & A4 & A5 \\
\hline $5^{\circ}$ & A5 & A5 & A5 & A6 \\
\hline $6^{\circ}$ & A6 & A6 & A6 & \\
\hline
\end{tabular}

$\mathrm{C}_{\mathrm{k}}{ }^{*}$ - coeficiente de similaridade. Alt. - alternativa. A1. TS; A2. TS+FAn; A3. TS+Wet; A4. UASB+BAS; A5. UASB+LAC; A6. TS+MBR

$\mathrm{Na}$ abordagem das quatro dimensões, os valores encontrados na Tabela 5.28, Tabela 5.29, Tabela 5.30 e Tabela 5.31 referem-se aos valores maiores dados aos critérios técnicos, econômicos, ambientais e sociais, respectivamente. O ranking mostrou-se sensível somente quando houve grandes alterações dos pesos em relação aos critérios por dimensões. 
Tabela 5.28 - Resultados da simulação nos métodos ELECTRE III e TOPSIS com aplicação de pesos dobrados para os critérios técnicos

\begin{tabular}{|c|c|c|c|c|}
\hline \multirow[b]{2}{*}{ Ranking } & \multirow{2}{*}{$\begin{array}{c}\text { ELECTRE III } \\
\text { Alt. }\end{array}$} & \multicolumn{3}{|c|}{ TOPSIS } \\
\hline & & $\begin{array}{c}\text { Alt. } \\
\mathrm{C}_{\mathrm{k}}^{*}(\mathrm{p}=1)\end{array}$ & $\begin{array}{c}\text { Alt. } \\
\mathrm{C}_{\mathrm{k}}^{*}(\mathrm{p}=2)\end{array}$ & $\begin{array}{c}\text { Alt. } \\
\mathrm{C}_{\mathrm{k}}{ }^{*}(\mathrm{p}=\infty)\end{array}$ \\
\hline $\mathbf{1}^{\mathbf{o}}$ & $\mathrm{A} 1 \mathrm{e} \mathrm{A} 2$ & A1 & $\mathrm{A} 2$ & A1 \\
\hline $2^{\circ}$ & A3 & $\mathrm{A} 2$ & A3 & A4 \\
\hline $3^{\circ}$ & A4 & $\mathrm{A} 3$ & A1 & $\mathrm{A} 2, \mathrm{~A} 3, \mathrm{~A} 5, \mathrm{~A} 6$ \\
\hline $4^{\circ}$ & A5 & A4 & A4 & \\
\hline $5^{\circ}$ & A6 & A5 & A5 & \\
\hline $6^{0}$ & & A6 & A6 & \\
\hline
\end{tabular}

Tabela 5.29 - Resultados da simulação nos métodos ELECTRE III e TOPSIS com aplicação de pesos dobrados para os critérios econômicos

\begin{tabular}{|c|c|c|c|c|}
\hline \multirow[b]{2}{*}{ Ranking } & \multirow{2}{*}{$\begin{array}{c}\text { ELECTRE III } \\
\text { Alt. }\end{array}$} & \multicolumn{3}{|c|}{ TOPSIS } \\
\hline & & $\begin{array}{c}\text { Alt. } \\
\mathrm{C}_{\mathrm{k}}^{*}(\mathrm{p}=1)\end{array}$ & $\begin{array}{c}\text { Alt. } \\
\mathrm{C}_{\mathrm{k}}{ }^{*}(\mathrm{p}=2) \\
\end{array}$ & $\begin{array}{c}\text { Alt. } \\
\mathrm{C}_{\mathrm{k}}^{*}(\mathrm{p}=\infty)\end{array}$ \\
\hline $1^{\mathrm{o}}$ & $\mathrm{A} 1$ e $\mathrm{A} 2$ & $\mathrm{~A} 2$ & $\mathrm{~A} 2$ & A 1 e $\mathrm{A} 2$ \\
\hline $2^{o}$ & A3 & A1 & A3 & A3 \\
\hline $3^{\circ}$ & A4 & $\mathrm{A} 3$ & A1 & A4 \\
\hline $4^{\circ}$ & A5 & A4 & A4 & A5 \\
\hline $5^{\circ}$ & A6 & A5 & A5 & A6 \\
\hline $6^{\circ}$ & & A6 & A6 & \\
\hline
\end{tabular}

$\mathrm{C}_{\mathrm{k}}{ }^{*}$ - coeficiente de similaridade. Alt. - alternativa. A1. TS; A2. TS+FAn; A3. TS+Wet; A4. UASB+BAS; A5. UASB+LAC; A6. TS+MBR

Tabela 5.30 - Resultados da simulação nos métodos ELECTRE III e TOPSIS com aplicação de pesos dobrados para os critérios ambientais

\begin{tabular}{|c|c|c|c|c|}
\hline \multirow[b]{2}{*}{ Ranking } & \multirow{2}{*}{$\begin{array}{c}\text { ELECTRE III } \\
\text { Alt. }\end{array}$} & \multicolumn{3}{|c|}{ TOPSIS } \\
\hline & & $\begin{array}{c}\text { Alt. } \\
\mathrm{C}_{\mathrm{k}}{ }^{*}(\mathrm{p}=1) \\
\end{array}$ & $\begin{array}{c}\text { Alt. } \\
\mathrm{C}_{\mathrm{k}}{ }^{*}(\mathrm{p}=2)\end{array}$ & $\begin{array}{c}\text { Alt. } \\
\mathrm{C}_{\mathrm{k}}{ }^{*}(\mathrm{p}=\infty) \\
\end{array}$ \\
\hline $1^{\mathrm{o}}$ & $\mathrm{A} 1, \mathrm{~A} 2$ e $\mathrm{A} 3$ & $\mathrm{~A} 2$ & $\mathrm{~A} 3$ & $\mathrm{~A} 2$ e $\mathrm{A} 3$ \\
\hline $2^{\circ}$ & A4 & A3 & A2 & A4 \\
\hline $3^{\circ}$ & A5 & A1 & A4 & A5 \\
\hline $4^{\circ}$ & A6 & A4 & A5 & A6 \\
\hline $5^{\circ}$ & & A5 & A6 & A1 \\
\hline $6^{\circ}$ & & A6 & $\mathrm{A} 1$ & \\
\hline
\end{tabular}

$\mathrm{C}_{\mathrm{k}}{ }^{*}$ - coeficiente de similaridade. Alt. - alternativa. 
Tabela 5.31 - Resultados da simulação nos métodos ELECTRE III e TOPSIS com aplicação de pesos dobrados para os critérios sociais

\begin{tabular}{|c|c|c|c|c|}
\hline \multirow[b]{2}{*}{ Ranking } & \multirow{2}{*}{$\frac{\text { ELECTRE III }}{\text { Alt. }}$} & \multicolumn{3}{|c|}{ TOPSIS } \\
\hline & & $\begin{array}{c}\text { Alt. } \\
\mathrm{C}_{\mathrm{k}}^{*}(\mathrm{p}=1)\end{array}$ & $\begin{array}{c}\text { Alt. } \\
\mathrm{C}_{\mathrm{k}}^{*}(\mathrm{p}=2)\end{array}$ & $\begin{array}{c}\text { Alt. } \\
\mathrm{C}_{\mathrm{k}}^{*}(\mathrm{p}=\infty)\end{array}$ \\
\hline $1^{\circ}$ & $\mathrm{A} 1 \mathrm{e} \mathrm{A} 2$ & A 2 & $\mathrm{~A} 2$ & $\mathrm{~A} 1, \mathrm{~A} 2 \mathrm{e} \mathrm{A} 3$ \\
\hline $2^{\circ}$ & A3 & $\mathrm{A} 1$ & A3 & A4 \\
\hline $3^{\circ}$ & A4 & $\mathrm{A} 3$ & A1 & A5 \\
\hline $4^{\circ}$ & A5 & A4 & A4 & A6 \\
\hline $5^{\circ}$ & A6 & A5 & A5 & \\
\hline $6^{0}$ & & A6 & A6 & \\
\hline
\end{tabular}

A5. UASB+LAC; A6. TS+MBR

Para o método ELECTRE III, observou-se que a alternativa A1 manteve-se no topo do ranking, mostrando-se pouco sensível a metodologia proposta. Isso pode ser em decorrência da ausência de alguns dados que tiveram que ser determinados por analogia, os quais podem ter influenciado no resultado final.

As alternativas ideais para cada situação de aplicabilidade refletem a variabilidade dos possíveis cenários de decisão, atribuindo impacto significativo pelos pesos dos vários critérios. Entre as seis alternativas consideradas, se maior peso é conferido ao critério econômico, o tanque séptico é a opção ideal, enquanto os sistemas combinados com biofiltro aerado submerso, lodos ativados e MBR, mantém-se na posição inferior no ranking. Isto sugere que o tanque séptico é economicamente mais eficiente em comparação com outras opções. Em contraste, se maior peso foi atribuído ao critério ambiental, o tanque séptico fica como a alternativa inferior no ranking. Logo, percebe-se que, com as variações dos pesos premiando o aspecto ambiental, as melhores alternativas no ranking são a A2 tanque séptico seguido de filtro anaeróbio e a A3 UASB seguido de wetland.

Estes resultados apresentaram sensibilidade considerada compatível com a análise feita normalmente por profissionais do setor. Por isso, não foram realizadas modificações na metodologia inicialmente proposta. 


\section{6 - CONCLUSÕES E RECOMENDAÇÕES}

Esta pesquisa permitiu descrever e registrar aspectos da tecnologia do processo de biorreator com membrana (MBR) voltados para a sua aplicação aos sistemas descentralizados de esgotos, tais como a sua concepção e dimensionamento, requisitos de operação e de manutenção, suas vantagens e desvantagens, permitindo obter as principais conclusões para propor um sistema unifamiliar e se aprofundar no assunto.

Foi desenvolvida uma metodologia simplificada de avaliação tecnológica de processos de tratamento de esgotos descentralizados com uma abordagem de análise de decisão multiobjetivo e multicritério, utilizando método com variável discreta e construindo o problema para obter uma solução por hierarquização. Os métodos de análise multiobjetivo selecionados e utilizados foram o ELETRE III e o TOPSIS. Na análise tecnológica proposta, por motivo de simplicidade, adotaram-se apenas algumas das dimensões da Tecnologia normalmente consideradas, e somente os critérios possíveis de mensuração rápida e simples dessas dimensões. Essa proposta metodológica de avaliação foi testada por um processo de análise de sensibilidade, no qual foram variados os valores dos pesos de cada dimensão e de cada critério.

A metodologia de avaliação tecnológica desenvolvida foi então processada para três cenários muito comuns e possíveis de existirem sob as condições brasileiras, incluindo-se as mais remotas regiões do País. Para o Cenário 1, considerou-se que o efluente poderia ser infiltrado no terreno, e as melhores alternativas a serem aplicadas nesta situação seriam as alternativas A1 (Tanque séptico) e a A2 (Tanque séptico seguido de filtro anaeróbio), por serem tecnologias simples, com baixo custo e de fácil implantação. No Cenário 2, para atender a confiabilidade desejável para o sistema de tratamento e a permanência do efluente dentro dos padrões de lançamento estabelecidos pela Resolução 430/2011 do CONAMA, as alternativas A2 e A3 (tanque séptico seguido de filtro anaeróbio e tanque séptico seguido de wetland), são as mais adequadas para este cenário, por atenderem aos requisitos ambientais e serem tecnicamente e economicamente viáveis. A alternativa A6 (Tanque séptico seguido por MBR) é a ideal para o Cenário 3, por ser a única que atende aos padrões de reúso. No entanto, a alternativa ótima para este cenário 3 seria a A4 Tanque séptico seguido por biofiltro aerado submerso. 
O MBR por ser uma tecnologia considerada complexa e com altos custos de implantação e manutenção se mostrou adequado para ser instalado apenas em locais que sofrem com a escassez hídrica e necessitam de utilizar o efluente tratado de esgoto sanitário.

Entretanto, alguns aspectos da implantação da tecnologia MBR que podem ser considerados relevantes para sua adoção em sistemas descentralizados de esgotos no Brasil não foram levados em consideração pela metodologia de avaliação tecnológica desenvolvida no presente trabalho. Isso sugere automaticamente que a metodologia poderá sofrer ajustes mais refinados, para incluir algumas dimensões da tecnologia não consideradas no momento, e, por óbvio, critérios mais precisos de avaliação. Portanto, sugere-se rever as planilhas pontuadas e ponderadas.

Por exemplo, uma questão importante não capturada pela metodologia proposta é o domínio pela comunidade da tecnologia, a sua "apropriação" pelo País. Sabe-se e é notório que o Brasil não domina a tecnologia de fabricação das membranas, o que torna a adoção da tecnologia MBR um fator de grande dependência pela importação de membranas e equipamentos para funcionamento dos módulos de membranas. Então, para que a metodologia capturasse esse fator, seria necessário que a ela fosse incorporada a dimensão da política tecnológica.

A possibilidade ou não de se realizar o reúso de água parece ser o grande divisor entre a adoção ou não da tecnologia MBR. Se se continuar a considerar padrões tão restritivos de qualidade da água para reúso, então, pelo valor alcançado para Sólidos Suspensos Totais e Turbidez no efluente das alternativas de tratamento de esgoto normalmente consideradas, somente a tecnologia MBR tem condições de atender a esses critérios de exigência. Espera-se que o Brasil adote uma legislação para reúso de água que seja realística, e, portanto, permita que outras alternativas de processos biológicos de tratamento de esgotos que não a MBR possam ser levadas em consideração nos cenários com reúso de água.

Por outro lado, sugere-se que na metodologia proposta sejam inseridos outros métodos multiobjetivo e multicritério e que seja promovida a consulta a atores e especialistas para atribuir pesos e avaliar os critérios utilizados para a avaliação tecnológica. E, ainda, uma sugestão para aprimoramento do processo de análise tecnológica realizado é a adoção de outra problemática decisória, que é a de alocação, onde se teria que criar classes de 
adequação da tecnologia (adequada, inadequada) e cada alternativa tecnológica seria classificada em uma dessas classes. Nesse caso, bastaria trocar os métodos de análise multiobjetivo aqui utilizados por outros que permitam o procedimento de alocação (como, por exemplo, o próprio TOPSIS modificado, ou o ELECTRE-TRI).

Os custos para a implantação e operação do MBR, bem como a comparação com outros processos, como Lodos Ativados, podem ser tópicos de estudo para uma análise de custo mais aprofundada quando aplicados a sistema unifamiliar ou descentralizado.

Finalmente, é importante ressaltar que os custos mais altos de implantação e de manutenção da tecnologia MBR jogaram importante papel na análise tecnológica realizada. Os resultados obtidos com o processamento da metodologia consideraram como dados de entrada os custos atuais registrados. Entretanto, esses custos do processo MBR estão declinando rapidamente, de tal forma que os resultados obtidos com a metodologia proposta para análise poderão ser alterados em pouco tempo. 


\section{REFERÊNCIAS BIBLIOGRÁFICAS}

Abbas, T.R. and Dixon, M.A. (2012). Applicability of MBR technology for decentralized Municipal wastewater treatment in Iraq. Regional conference on Wastewater Purification \& reuse, Crete, Greece.

Abegglen, C.K (2008). Membrane bioreactor technology for decentralized wastewater treatment and reuse. Dissertation of doctor of Sciences, Swiss Federal Institute of Technology Zurich, $150 \mathrm{p}$.

Abegglen, C.K.; Ospelta, M.; Siegrist, H. (2008). Biological nutrient removal in a smallscale MBR treating household wastewater. Water Research 42. 338 - 346.

ABNT - Associação Brasileira de Normas Técnicas. NBR 13.969 (1997). Projeto, Construção e Operação de Sistemas de Tanques Sépticos - Tratamento e Disposição dos Efluentes de Tanques Séptico. Rio de Janeiro.

ABNT - Associação Brasileira de Normas Técnicas. NBR 15527 (2007). Água de chuva Aproveitamento de coberturas em áreas urbanas para fins não potáveis - Requisitos. Rio de Janeiro.

Alaboud, T.M and Magram, S.F. (2008). A Discourse on Feasibility of the Membrane Bioreactor Technology for Wastewater Reuse in Saudi Arabia. Research Journal of Environmental Sciences 2(6):445-455

Alem Sobrinho, P. E Jordão, E. P. Pós-Tratamento de Efluentes de Reatores Anaeróbios Uma Análise Crítica. p.491-513. In: CHERNICHARO, C. A. L. (coordenador) PósTratamento de Efluentes de Reatores Anaeróbios. Belo Horizonte: Projeto PROSAB, 2001. 544p.

ANA - Agência Nacional Das Águas (2005). Conservação e Reúso da Água em Edificações. Prol Editora Gráfica: São Paulo.

Andrade Neto, C.O.; Haandel, A van ; Melo, H.N.S. (2002). O Uso Do Filtro Anaeróbio para Pós-Tratamento de Efluentes de Reatores Anaeróbios no Brasil. In: X Simpósio Luso-Brasileiro de Engenharia Sanitária E Ambiental, 2002, Braga, Portugal. Anais do X Simpósio Luso-Brasileiro de Engenharia Sanitária e Ambiental. Braga: APESB/APRH/ABES, 2002.

Arévalo, J.; Ruiz, L.M.; Parada-Albarracín, J.A.; González-Pérez, D.M.; Pérez, J.; Moreno, B.; Gómez, M.A. (2012) Wastewater reuse after treatment by MBR. Microfiltration or ultrafiltration? Desalination 299. 22-27

Ávila, R.O. (2005). Avaliação do desempenho de sistemas tanque séptico-filtro anaeróbio com diferentes tipos de meio suporte.

Aydiner, C.; Sen, U.; Koseoglu-Imer, D.U.; Dogan, E.C. (2016). Hierarchical prioritization of innovative treatment systems for sustainable dairy wastewater management. Journal of Cleaner Production 112, 4605-4617.

Battilani, A.; Steiner, M.; Andersen, M.; Back, S.N.; Lorenzen, J.; Schweitzer, A.; Dalsgaard, A.; Forslund, A.; Gola, S.; Klopmann, W.; Plauborg, F.; Andersen, M.N. (2010) Decentralised water and wastewater treatment technologies to produce functional water for irrigation. Agricultural Water Management 98. 385-402.

Belli, J.T.; Amaral, P.A.P.; Recio, M.A.L.; Vidal, C.M.S; Lapolli, F.R. (2012). Biorreator à membrana em batelada sequencial aplicado ao tratamento de esgoto. Eng. Sanit. Ambient. vol.17 no.2 Rio de Janeiro.

Belton, V. (1986) A comparison of the analytic hierarchy process and a simple multiattribute value function. European Journal of Operational Research 26. 7-21. NorthHolland. 
Benitez, M.G.; Garriga, C.S.; Ferré, R. G. (2002). Bioreactores de Membrana (MBR). Departamento de Proyectos de Ingeniería. Universitat Politécnica de Catalunya. Gespaser SA.

Boer, L.; Labro, E. Morlacchi, P. (2001) A review of methods supporting supplier selection. European Journal of Purchasing \& Supply Management 7. 75-89.

Bof, V. S.; Sant'ana, T. D. C.; Wanke, R.; Silva, G. M. ; Salim, F. P. C. ; Nardotto, J. I. ; Suzart Netto, E. ; Pegoretti, J. M. (2001). ETEs Compactas associando reatores anaeróbios e aeróbios ampliam a cobertura do saneamento no Estado do Espírito Santo. Trabalho II-0170. $21^{\text {o. }}$ Congresso Brasileiro de Engenharia Sanitária e Ambiental, Anais do, ABES, João Pessoa, PB, 16-21 de setembro de 2001.

BRASIL. Lei Federal No 9.433 (1997). Política Nacional de Recursos Hídricos: Brasília, Ministério do Meio Ambiente.

Brites, C.R.C. Abordagem multiobjetivo na seleção de sistemas de reúso de água em irrigação paisagística no Distrito Federal: 2008. Dissertação de Mestrado em Tecnologia Ambiental e Recursos Hídricos. Universidade de Brasilía.

Brostel, R.C. (2002). Formulação de modelo de avaliação de desempenho global de Estações de Tratamento de Esgotos Sanitários (ETEs). Dissertação de Mestrado, Publicação PTARH.DM - 56/02, Departamento de Engenharia Civil e Ambiental, Universidade de Brasília, Brasília, DF, 278 p.

Buarque, C. (1983) Tecnologia Apropiada: Una Politica para la Banca de Desarrollo de America Latina. Lima, Peru: ALIDE - Asociación Latinoamericana de Instituciones Financieras de Desarollo.

Buer, T. and Cumin, J. (2010). MBR module design and operation. Desalination, Vol.250(3), pp.1073-1077

Carneiro, G.A.; Barbosa, R.F.M.; Souza, M.A.A. (2001) Tecnologia apropriada em saneamento: uma nova abordagem com o emprego de análise multiobjetivo e multicritério. In: Congresso Brasileiro de Engenharia Sanitária e Ambiental, $21^{\circ}$, João Pessoa. Anais. João Pessoa: ABES.

Chapman S.; G. Leslie; I. Law. (2001). Membrane Bioreactors (MBR) for Municipal Wastewater Treatment - An Australian Perspective Stephen Chapman. Disponivel em:

$<$ http://www.sswm.info/sites/default/files/reference_attachments/CHAPMAN\%20et $\% 20$ al\%20ny\%20MBR\%20for\%20Minicipal\%20Wastewater\%20Treatment.pdf $>$.

Acessado em 18 de Janeiro de 2015.

Chernicharo, C.A.L. (2007). Reatores anaeróbios. Belo Horizonte: Departamento de Engenharia Sanitária e Ambiental - UFMG. 2 ed. 380 p.

Chernicharo, C.A.L.; Van Haandel, A.C.; Foresti, E.; Cybis, L.F. (2001). Introdução. In: Pós-tratamento de efluentes de reatores anaeróbios. Belo Horizonte: ABES PROSAB. 544p.

CNRH - Conselho Nacional de Recursos Hídricos. Resolução No. 54 (2005) - Estabelece critérios gerais para reuso de água potável.

Costanzi, R.N.; Hespanhol, I.; Asada, L.N.; Marques, A. (2005). Tratamento de efluente por reator biológico aeróbio com membrana visando o reúso de água. Revista Brasileira de Engenharia Agrícola e Ambiental, v.9, (Suplemento), p.217-220. Campina Grande, PB, DEAg/UFCG - http://www.agriambi.com.br

Côté, P., Buisson, H., Praderie, M. (1998) "Immersed Membranes Activated Sludge Process Applied to the Treatment of Municipal Wastewater", Water Science and Technology, v. 38, n. 4-5, pp. 437-442.

Côté, P.; Alam Z.; Penny, J. (2012). Hollow fiber membrane life in membrane bioreactors (MBR). Desalination 288. 145-151. 
Côté, P.; Arviv, R.; Liu, M. (2004) Comparison of membranes options for water reuse and reclamation. ZENON Environmental Inc., Canada.

Dagnino, R. P. (1978) Tecnologia Apropriada - Uma Alternativa? Dissertação de Mestrado, Departamento de Economia, Universidade de Brasília, Brasília, DF, 257p.

Dezotti, M.; SantÁnna Jr., G. L.; Bassin, J. P. (2011) Processos biológicos avançados para tratamento de efluentes e técnicas de biologia molecular para estudo da diversidade microbiana. Editora Interciência Ltda, Rio de Janeiro, Brasil, 368 p.

Di Bella, G.; Durante, F.; Torregrossa, M.; Viviani, G. (2010). Start-up with or without inoculum? Analysis of an SMBR pilot plant. Desalination 260, 79-90.

EPA. (2002). Onsite wastewater treatment systems manual. Office of Water.Office of Research and Development. EPA-625-R-00-008. Washington, DC: Government Printing Office.

EPA. United States Environmental Protection Agency - USEPA. (2007). Wastewater management fact sheet. Membrane bioreactors. Setembro. Disponível em: <http://water.epa.gov/scitech/wastetech/upload/2008_01_23_mtb_etfs_membranebioreactors.pdf $>$. Acessado em: 18/12/2014.

Felizatto, M.R.; Nery, F.C.; Rodrigues, A.S.; Silva, C.M. (2016). Water reuse for landscape irrigation and toilet flushing in Brasilia, Brazil. Good practice examples and future research needs in Safe use of wastewater in agriculture workshop. United Nations University: UNU-Flores. 24-25 Fevereiro 2016, Lima, Peru.

Figueira, J.; Mousseau, V.; Roy, B (2005).."ELECTRE methods". In J. Figueira, S. Greco, and M. Ehrgott, editors,Multiple Criteria Decision Analysis: State of the Art Surveys, pages 133-162. Springer Verlag, Boston, Dordrecht, London.

Ganoulis, J. (2011). Risk analysis of wastewater reuse in agriculture. 1st International and 4th National Congress on Recycling of Organics Wastes in Agriculture 9-10 November, Isfahan, Iran

Giacobbo, A.; Feron, G.L.; Rodrigues, M.A.S.; Bernardes, A.M.; Meneguzzi, A. (2011). Utilização de biorreator à membrana para tratamento de efluentes. HOLOS, Ano 27, Volume 1.

Gil, J.A.; Dorgeloh, E.; Van Lier, J.B.; Van Der Graaf, J.H.J.M.; Prats, D. (2012). Start-up of decentralized mbrs. Part I: The influence of operational parameters. Desalination 285. 324-335.

Gomes, L.F.A.M.; Araya, M.C.G.; Carignano, C. (2004). Tomada de decisão em cenários complexos. São Paulo, SP. Thomson, 168 p.

Goncalves, R. F.; Araújo, V. L. ; Chernicharo, C. A. L. . Association of a UASB reactor and a submerged aerated biofilter for domestic sewage treatment. Water Science and Technology, v. 38, n.8-9, p. 189-195, 1998.

Guo, X.; Liu, Z.; Chen, M.; Liu, J.; Yang, M. (2014). Decentralized wastewater treatment technologies and management in Chinese villages. Front. Environ. Sci. Eng., 8(6): 929-936

Hai, F. I. and Yamamoto, K. (2011). Membrane Biological Reactors. In P. Wilderer (Eds.), Treatise on Water Science (pp. 571-613). UK: Elsevier.

Ho, W.; Xu, X.; Dey, P.K. (2010) Multi-criteria decision making approaches for supplier evaluation and selection. European Journal of Operational Research 202, 16-24.

Hunt, C.C. Modelo Multicritério de apoio à decisão aplicada á seleção de sistema de tratamento de esgoto para pequenos municípios. 2013.118f. Dissertação (mestrado) Universidade Federal do Rio de Janeiro, Escola Politécnica e Escola de Química, Programa de Engenharia Ambiental, Rio de Janeiro, 2013.

IBGE - Instituto Brasileiro de Geografia e Estatística. Pesquisa Nacional de Saneamento Básico. Rio de Janeiro: 2010. 
IWA (2014) Activated Sludge - 100 years and Couting. Chapter 16: Membrane bioreactors. Crawford, G.V.; Judd, S.; Zsirais, T.

IWA. International Water Association. (2011). 10th Specialized Conference on Small Water and Wastewater Systems and 4th Conference on Decentralised Water and Wastewater International Network. 18the22nd April 2011, Venice, Italy.

Jordão, E. P. e Pessôa, C. A. (2009)Tratamento de esgotos domésticos. Rio de Janeiro: ABES, 4. ed.

Judd, S. (2006). The MBR book: principles and applications of membrane bioreactors in water and wastewater treatment. 1 Ed., San Diego, California, USA. Elsevier Ltda.

Judd, S. (2008). The status of membrane bioreactor technology. Trends in Biotechnology, February 2008, Vol.26(2), pp.109-116. Elsevier Ltd. doi:10.1016/j.tibtech.2007.11.005.

Judd, S. (2015). The status of industrial and municipal effluent treatment with membrane bioreactor technology. Chemical Engineering Journal.

Judd, S.; Judd, C. (2011). The MBR book: principles and applications of membrane bioreactors for water and wastewater treatment. 2 ed. Oxford: Elsevier/ButterworthHeinemann. Burlington, MA. 519 p.

Kelemenis, A. e Askounis, D. (2010) A new TOPSIS-based multi-criteria approach to personnel selection. Expert Systems with Applications 37, 4999-5008

Kligerman, D.C. (1995) Esgotamento Sanitário: de Alternativa Tecnológica a Tecnologias Apropriadas - Uma Análise Técnica, Econômica e Social. Dissertação de mestrado do curso de Planejamento Urbano da Universidade Federal do Rio de Janeiro, Rio de Janeiro, 154p.

Krzeminski, P.; van der Graaf, J.H; van Lier, J.B. (2012). Specific energy consumption of membrane bioreactor (MBR) for sewage treatment, Water Sci. Technol. 65. 380.

Libralato, G.; Ghirardini, A.V.; Avezzù, F. (2012). To centralize ou to decentralize: An overview of the most recent trends in wastewater treatment management. Journal of Environmental Management 94. 61e68.

Luna, M.L.D.; Sousa, J.T.; Lima, V.L.A.; Alves, A.S.; Pearson, H.W. (2013). Póstratamento de efluente de tanque séptico utilizando filtros intermitentes de areia operando em condições tropicais. Scientia Plena 9, 093102.

Maton, L.; Psarras, G.; Kasapakis, G.; Chartzoulakis, K.; Lorenzen, J.R.; Andersen, M.; Bak, S.N.; Boesen, M.; Pedersen, S.M.; Kloppmann, W. (2010) Assessing the net benefits of using wastewater treated with a membrane bioreactor for irrigating vegetables in Crete. Agricultural Water Management, Vol.98(3), pp.458-464.

Mendonça, E.C. (2009). Metodologia para avaliação de desempenho de sistemas de drenagem urbana. Dissertação de Mestrado em Tecnologia Ambiental e recursos Hídricos, Departamento de Engenharia Civil e Ambiental, universidade de Brasília, $\mathrm{DF}, 171 \mathrm{p}$.

Mendoza, G.A. e Martins, H. (2006) Multi-criteria decision analysis in natural resource management. Forest Ecology and Management 230, 1-22.

Metcalf e Eddy. (1991). Wastewater engineering: treatment, disposal and reuse. $3^{\mathrm{a}}$ Edição. McGraw-Hill Book Company, New York, EUA. 1334p.

Metcalf e Eddy. (2003). Wastewater engineering e Treatment and reuse. $4^{\mathrm{a}}$ Edição. McGraw-Hill Book Company, New York, EUA.

Metcalf e Eddy. (2007). Water Reuse: Issues, Technologies, and Applications. $5^{\text {a }}$ Edição. McGraw-Hill Book Company, New York, EUA.

Molinos-Senante, M.; Garrido-Baserba, M.; Reif, R; Hernández-Sancho, F.; Poch, M. (2012) Assessment of wastewater treatment plant design for small communities: 
Environmental and economic aspects. Science of the Total Environment, 427-4281118.

Neder, K.D.; Carneiro, G. A.; Queiroz, T.R.; Souza, M.A.A. (2002). Selection of natural treatment processes for algae removal from stabilisation pond effluents in Brasília, using multicriterion methods. Water Science and Technology 46 (4-5), 347-354.

Neoh, C.H.; Noor, Z.Z.; Mutamim, N.S.A.; Lim, C.K. (2016) Green technology in wastewater treatment technologies: Integration of membrane bioreactor with various wastewater treatment systems. Chemical Engineering Journal 283. 582-594.

Oakley, S.M.; Gold, A.J; Oczkowski, A.J. (2016) Nitrogen control through decentralized wastewater treatment: Process performance and alternative management strategies. Ecological Engineering 36, 1520-1531.

Oliveira, M.T.C.S. e Moraes, L.R.S. (2005). A tecnologia apropriada e o sistema condominial de esgoto sanitário: uma revisão conceitual. $23^{\circ}$ Congresso Brasileiro de Engenharia Sanitária e Ambiental,1-19, Campo Grande/MS.

Ouyang, X.; Guo, F.; Shan, D. Yu, H.; Wang, 7. (2015). Development of the integrated fuzzy analytical hierarchy process with multidimensional scaling in selection of natural wastewater treatment alternatives. Ecological Engineering 74 (2015) 438-447

Pearce, G.K. (2008). UF/MF pre-treatment to RO in seawater and wastewater reuse applications: a comparison of energy costs. Desalination 222, 66-73

Phillips, K. (2015) Membrane system boosts water reuse Filtration and Separation, Vol.52(3), pp.40,42-40,43. Disponivel em: <http://www.filtsep.com/view/42310/membrane-system-boosts-water-reuse/>. Acessado em 25 de agosto de 2015.

Poh, K.L. (1998) A knowledge-based guidance system for multi-attribute decision making. Anijicial Intelligence in Engineering 12, 315-326.

PROSAB (1999). Tratamento de esgotos sanitários por processo anaeróbio e disposição controlada no solo. Rio de Janeiro: ABES. José Roberto Campos.

Rosseto, R.; Pagotto Jr, R. Santos, M.A.; Gasperi, R.L.P.; Andrade, J.P.M. (2014). Aspectos técnicos e operacionais da EPAR Capivari II. Revista Online: Pollution Engineering, Disponível em: <http://www.revistape.com.br/artigo-tecnico/aspectostecnicos-e-operacionais-da-epar-capivari-ii/2206>. Acessado em 20 de dezembro de 2014.

Roy, B. (1985). Méthodologie Multicritère d'Aide à la Decision, Economica, Paris, 423p.

Roy, B. (1991). The outranking approach and the foundations of electre methods. Theory and Decision. 31: 49-73, Kluwer Academic Publishers.

Sadr, S.M.K.; Onder, T. Saroj, D.; Ouki, S. (2013). Appraisal of membrane processes for technology selection in centralized wastewater reuse scenarios. Sustain. Environ. Res., 23(2), 69-78

Sadr, S.M.K.; Saroj, D.P. ; Kouchaki, S.; Ilemobade, A.A.; Ouki, S.K. (2015). A group decision-making tool for the application of membrane technologies in different water reuse scenarios. Journal of Environmental Management $15697 \mathrm{e} 108$.

Santasmasas, C.; Rovira, M.; Clarens, F.; Valderrama, C. (2013) Grey water reclamation by decentralizes MBR prototype. Resources, Conservation and Recycling 72102 107.

São Paulo. Lei Estadual No 13276 (2002). Torna obrigatória a execução de reservatório para as águas coletadas por coberturas e pavimentos nos lotes edificados ou não, que tenham área impermeabilizada superior a $500,00 \mathrm{~m}^{2}$

Sartor, M.; Kaschek, M.; Mavrov, V. (2008). Feasibility study for evaluating the client application of membrane bioreactor (MBR) technology for decentralised municipal wastewater treatment in Vietnam. Science Direct. Desalination 224 172-177. 
Schneider, R.P. e Tsutiya, M.T. (2001). Membranas Filtrantes para o Tratamento de Água, Esgoto e Água de Reúso. ABES-Associação Brasileira de Engenharia Sanitária e Ambiental, São Paulo, Brasil.

Sistema Nacional de Informações sobre Saneamento - SNIS. (2014) Disponível em: <http://www.snis.gov.br/diagnostico-agua-e-esgotos>. Acessado em 17 de abril de 2016.

Skouteris, G.; Arnot, T.C.; Feki , F.; Jraou, M.; Sayadi, S. (2012a). Operation of a submerged aerobic membrane bioreactor for decentralised municipal wastewater treatment in North Africa. Water Practice \& Technology Vol 7. N 3. doi:10.2166/wpt.2012.055.

Skouteris, G.; Hermosilla, D.; López, P.; Negro, C.; Blanco, Á. (2012b). Anaerobic membrane bioreactors for wastewater treatment: A review. Chemical Engineering Journal, Vol.198-199, pp.138-148.

Souza, M. A. A. (1992) "Methodology for Selection of Wastewater Treatment Processes". PhD. Thesis. Birmingham, UK: School of Civil Engineering, The University of Birmingham.

Souza, M. A. A., Carneiro, G. A., Lopes Júnior, R. P. E Cordeiro Netto, O. M. (2001) Análise Tecnológica de Alternativas para Pós-tratamento de Efluentes de Reatores Anaeróbios. Trabalho II-088. 21 ${ }^{\text {o. }}$ Congresso Brasileiro de Engenharia Sanitária e Ambiental, Anais do, ABES, João Pessoa, PB, 16-21 de setembro de 2001 (meio digital).

Souza, M.A.A. (2014). Notas de aula da disciplina análise de sistemas ambientais, Programa de Pós-Graduação em Tecnologia Ambiental e Recursos Hídricos, Universidade de Brasília.

Souza, M.A.A. e Foster, C.L. (1996). Metodologias para seleção de processos de tratamento de águas residuárias. Revista Engenharia Sanitária e Ambiental. Volume 2. $\mathrm{N}^{\mathrm{o}} 1$.

Subtil, E.L.; Hespanhol, I.2; Mierzwa, J.C. (2013). Biorreatores com Membranas Submersas (MBRs): alternativa promissora para o tratamento de esgotos sanitários para reuso. Rev. Ambiente \& Água. vol. 8 n. 3 Taubaté.

Tai, C. S.; Snider-Nevin, J.; Dragasevich, J.; Kempson, J. (2014). Five years operation of a decentralized membrane bioreactor package plant treating domestic wastewater. Water Practice \& Technology Vol 9 No 2. doi: 10.2166/wpt.2014.024.

Tecle, A.; Fogel, M.; E Duckstein, L. (1988) Multicriterion Selection of Wastewater Management Alternatives. Journal of Water Resources Planning and Management Division. Proceedings of ASCE, 114 (4) 383-398.

Trinh, T.; Branch, A.; Hambly, A.C; Carvajal, G.; Coleman, H.M.; Stuetz, R.M.; Drewes, J.; Le-Clech, P. Khan, S.J. (2016). Hazardous events in membrane bioreactors - Part 1: Impacts on key operational and bulk water quality parameters. Journal of Membrane Science 497, 494-503.

Vanzetto, A.S. (2012). Análise das alternativas tecnológicas de desaguamento de lodos produzidos em estações de tratamento de esgoto. Dissertação de Mestrado em Tecnologia Ambiental e recursos Hídricos, Departamento de Engenharia Civil e Ambiental, universidade de Brasília, DF, $185 \mathrm{p}$.

Verrecht, B.; Maere, T.; Benedetti, L.; Nopens, I.; Judd, S. (2010). Model-based energy optimisation of a small-scale decentralised membrane bioreactor for urban reuse. Science Direct. Water Research 44. 4047-4056.

Von Sperling, M. (1995). Introdução à qualidade das águas e ao tratamento de esgotos. Belo Horizonte: Departamento de Engenharia Sanitária e Ambiental, UFMG, v.1, $240 \mathrm{p}$. 
Von Sperling, M. (2005). Introdução à qualidade das águas e ao tratamento de esgoto, Princípios do tratamento biológico de águas residuárias. UFMG Vol.1. Belo Horizonte, Brasil, 53-116p.

Wang, J.J.; Jing, Y.Y.; Zhang, C.F; Zhao, J.H. (2009) Review on multi-criteria decision analysis aid in sustainable energy decision-making. Renewable and Sustainable Energy Reviews 13, 2263-2278.

WEF - Water Environment Federation. (2012). Membrane Bioreactors: WEF Manual of Practice $N^{o}$ 36. McGraw-Hill Professional.

Werner, M. (2009). Water and wastewater systems sustainability in remote Australia. Master of Engineering thesis, School of Civil, Mining and Enviromental Engineering Faculty of Engineering, university of Wollongong.

Willoughby, K.W. (1990) Technology Choice: A Critique of the Appropriate Technology Movement. London, UK: Intermediate Technology Publications.

Wu, L., Weiping, C., French, C., and Chang, A. (2009). Safe Application of Reclaimed Water Reuse in the Southwestern United States. University of California Extension Publication \#8357. URL: http://anrcatalog.ucdavis.edu

Yang, W.; Cicek, N.; Ilg, J. (2006) State-of-the-art of membrane bioreactors: worldwide research and commercial applications in North America. Journal of Membrane Science, V. 270, p. 201-211.

Yoon, S. H.; Kim, H. S.; Yeom, I. T. (2004). "The Optimum Operational Condition of Membrane Bioreactor (MBR): Cost Estimation of Aeration and Sludge Treatment", Water Research, v. 38, pp. 37-46.

Yoon, S.H. (2015) Membrane Bioreactor Processes: Principles and Applications. 452 p. Hoboken : CRC Press.

Zanakis, S.H.; Solomon, A.; Wishart, N.; Dublish, S. (1998) Multi-attribute decision making: A simulation comparison of select methods. European Journal of Operational Research IO7, 507-529 


\section{APÊNDICE A - DIMENSIONAMENTO}

\section{Dimensionamento da membrana}

A primeira etapa do dimensionamento constitui a concepção da membrana. A partir de estudos piloto e orientações fornecidas pelo fabricante, determinam-se: (1) a área da membrana nas condições de pico e o volume mínimo do tanque de membrana; (2) a Demanda Específica de Aeração necessária (SADm); (3) a capacidade de aeração para a limpeza da membrana; e (4) a contribuição da capacidade de aeração por meio do balanço de massa da Equação (A.1).

$$
V_{\text {m,min }}=\frac{A_{m}}{\emptyset_{\text {tanque }}}
$$

na qual:

$\mathrm{A}_{\mathrm{m}}$ : área da membrana

$\varphi$ : Densidade de empacotamento da membrana

2. Dimensionamento do sistema biológico

A segunda etapa do dimensionamento é a concepção do processo biológico, apresentada em seguida com detalhes, baseado no modelo de dimensionamento proposto por Judd (2011).

O primeiro passo é a determinação do tempo de retenção de sólidos ( $\Theta x$,aer) necessário para atingir a concentração desejada de amônia $(\mathrm{Ne})$, baseado na taxa de crescimento de bactérias nitrificantes $\left(\mu_{\mathrm{n}}\right)$ que estão apresentadas nas Equações (A.2) e (A.3).

$$
\begin{gathered}
\mu_{n}=\left(\frac{\mu_{n, m} N_{e}}{K_{n}+N_{e}}\right)\left(\frac{O D}{k_{O}+O D}\right)-K_{e, n} \quad \text { (eq. 2) } \\
\theta_{x, \text { aer }}=S F \frac{1}{\mu_{n}}
\end{gathered}
$$

Na qual:

$\mu_{\mathrm{n}, \mathrm{m}}$ : Taxa de nitrificação máxima de crescimento específico, gSSV/(gSSV d) 
$\mathrm{N}_{\mathrm{e}}$ : Amônia total, nitrogênio total ou NTK no efluente, mg/L

OD: oxigênio dissolvido

$\mathrm{K}_{\mathrm{n}}$ : Meio coeficiente de saturação para a nitrificação

$\mathrm{K}_{\mathrm{o}}$ : Meio coeficiente de saturação para o oxigênio

$\mathrm{K}_{\mathrm{e}, \mathrm{n}}$ : Coeficiente de decaimento endógeno Nitrificação, gSSV/(g SSV d)

SF: fator de segurança (adotado 1.5)

Baseado no $\Theta x$,aer, o cálculo de produção de biomassa $\left(\mathrm{M}_{\mathrm{x}, \text { bio }}\right)$ pode ser encontrado conforme a Equação (A.4). Inicialmente, usa-se uma estimativa do NOx sendo $80 \%$ de TKN para o cálculo da produção de biomassa. Calculou-se, ainda, a concentração de DBO efluente pela Equação (A.5).

$$
\begin{gathered}
M_{x, \text { bio }}=\frac{Q Y\left(S-S_{e}\right)}{1+K_{e} \theta_{x, a e r}}+\frac{f_{d} K_{e} Q Y\left(S-S_{e}\right) \theta_{x, a e r}}{1+K_{e} \theta_{x, a e r}}+\frac{Q Y_{N}\left(N O_{X}\right)}{1+K_{e, n} \theta_{x, a e r}} \\
S_{e}=\frac{k_{s}\left(1+K_{e} \theta_{x, a e r}\right)}{\theta_{x, a e r}\left(\mu_{m}-K_{e}\right)-1}
\end{gathered}
$$

Na qual:

$\mathrm{K}_{\mathrm{s}}$ : coeficiente de saturação, gDQO $/ \mathrm{m}^{3}$

$\mathrm{K}_{\mathrm{e}}$ : Coeficiente de decaimento endógeno heterotrófico, gSSV/(g SSV d)

S: DBO afluente, $\mathrm{g} / \mathrm{m}^{3}$

$\mathrm{S}_{\mathrm{e}}$ : DBO efluente, $\mathrm{g} / \mathrm{m}^{3}$

$\mathrm{f}_{\mathrm{d}}$ : Fração da biomassa que permanece como detritos celulares, geralmente $0,1-0,15$ gSSV/g substrato

Q: vazão média $\mathrm{m}^{3} / \mathrm{d}$

Y: Coeficiente de produção heterotrófico, gSSV/(gDBO)

$\mathrm{Y}_{\mathrm{N}}$ : Coeficiente de produção de nitrificação, gSSV/(gDBO)

$\mathrm{NO}_{\mathrm{x}}$ : Concentração de NTK oxidável ao nitrato, $\mathrm{g} / \mathrm{m}^{3}$

$\mu_{\mathrm{m}}$ : Taxa máxima de crescimento específico heterotróficos, gSSV/(gSSV d)

Chega-se, então, ao momento de calcular a concentração NOx com a Equação (A.6), usando o valor de $\mathrm{M}_{\mathrm{x}, \text { bio }}$ encontrado pela Equação 4 e pela concentração de TKN oxidado para forma de nitrato em $\left(\mathrm{g} \cdot \mathrm{m}^{-3}\right)$.

$$
N O_{X}=T K N-N_{e}-0.12 \frac{M_{x, b i o}}{Q}
$$

Na qual:

TKN: nitrogênio afluente, $\mathrm{g} / \mathrm{m}^{3}$ 
Após calcular concentração de NTK oxidável ao nitrato (NOx), faz-se a iteração desse novo valor encontrado com a Equação (A.4), para encontrar um novo valor de $\mathrm{M}_{\mathrm{x}, \text { bio }}$.

No próximo passo, determina-se a produção de biomassa total $\left(\mathrm{M}_{\mathrm{X}, \mathrm{TSS}}\right)$ por adição da fração não biodegradável no afluente $\mathrm{SSV}_{\mathrm{NB}}$ e $\mathrm{SST}_{\text {Inerte }}$ por meio das Equações (A.7), (A.8) e (A.9), respectivamente.

$$
\begin{gathered}
M_{X, S S T}=\frac{M_{x, b i o}}{0.85}+Q\left(S S V_{N B}+S S T_{i}\right) \\
S S V_{N B}=\left(1-\frac{D Q O_{B P}}{D Q O_{P}}\right) S S V \\
S S T i=S S T-S S V
\end{gathered}
$$

Na qual:

DQO $_{\mathrm{bp}}$ : Demanda química de oxigênio particulada total, $\mathrm{g} / \mathrm{m}^{3}$

$\mathrm{DQO}_{\mathrm{b}}$ : Demanda química de oxigênio particulada biodegradável, $\mathrm{g} / \mathrm{m}^{3}$

$\mathrm{SSV}_{\mathrm{NB}}$ : Sólidos suspensos voláteis não-biodegradáveis, $\mathrm{g} / \mathrm{m}^{3}$

$\mathrm{SST}_{\mathrm{I}}$ : Sólidos suspensos totais inertes, $\mathrm{g} / \mathrm{m}^{3}$

Usando valores adotados para o SSLM e o TRS aeróbio, o volume do tanque aeróbio pode ser calculado por meio da obtenção da massa de sólidos sendo aerada. Então, utilizando o SSLM aeróbio para converter essa massa para o volume ocupado de sólidos, obtém-se a Equação (A.10) para determinar o volume do tanque aeróbio ( $\left.\mathrm{V}_{\text {aer }}\right)$.

$$
V_{\text {aer }}=\frac{M_{X, S S T} \theta_{x, a e r}}{X_{a e r}}
$$

Na qual:

$\mathrm{X}_{\text {aer: }}$ Concentração do SSLM na zona aeróbia, $\mathrm{g} / \mathrm{m}^{3}$

A concentração do SSLM na zona anóxica $\left(\mathrm{X}_{\mathrm{anox}}\right)$ pode ser encontrada por meio da equação (A.11).

$$
X_{\text {anox }}=X_{\text {aer }}\left(\frac{r_{\text {int }}}{1+r_{\text {int }}}\right)
$$


Na qual:

$\mathrm{r}_{\text {int: }}$ taxa de recirculação interna (adimensional)

Para calcular a concentração do SSLM na zona aeróbia utiliza a Equação (A.12) a seguir.

$$
X_{a e r}=X_{m}\left(\frac{r_{m r}}{1+r_{m r}}\right)
$$

Na qual:

$\mathrm{r}_{\mathrm{mr}}$ : Razão de recirculação da membrana (adimensional)

$\mathrm{X}_{\mathrm{m}}$ : Nível do licor misto de sólidos em suspensão de no tanque de membrana, $\mathrm{g} / \mathrm{m}^{3}$

A vazão de descarte do lodo $\left(\mathrm{Q}_{\mathrm{w}}\right)$ pode ser determinada em função do volume do tanque aeróbio com o TRS aeróbio, pelo emprego da Equação (A.13) a seguir.

$$
Q_{W}=\frac{V_{a e r}}{\theta_{x, a e r}}
$$

O volume do tanque anóxico necessário deriva de um processo de iteração (processo iterativo), sujeito à restrição de que a capacidade de desnitrificação $\left(\mathrm{NO}_{\mathrm{r}}, \mathrm{KgNO}_{3}\right.$-N/d) tem que ser maior do que a carga de nitrato $\left(\mathrm{NO}_{\text {carga }}\right.$, em $\mathrm{kg}$ de $\mathrm{NO}_{3}-\mathrm{N} /$ dia $)$ inferida a partir da zona aeróbia por meio do fluxo de recirculação (Qint, em $\mathrm{m}^{3} / \mathrm{dia}$ ), calculadas pelas Equações (A.14) e (A.15), respectivamente.

$$
\begin{gathered}
N O_{r}=V_{\text {anox }} X_{b, \text { anox }} S D N R \\
N O_{\text {carga }}=Q r_{\text {int }}\left(T N K-N_{e}-0.12 \frac{M_{x, \text { bio }}}{Q}\right)
\end{gathered}
$$

Na qual:

SDNR: taxa de desnitrificação especifica, $\left(\mathrm{gNO}_{3}-\mathrm{N} / \mathrm{g}\right.$ SSVLM d)

A taxa de recirculação $\left(\mathrm{r}_{\mathrm{int}}\right)$ necessária para obter a concentração de nitrato desejada $\mathrm{NO}_{\mathrm{e}}$, é dada pela Equação (A.16).

$$
r_{\text {int }}=\frac{N O_{x}}{N O_{e}}-1
$$


Na qual:

$\mathrm{NO}_{\mathrm{e}}$ : Concentração de nitrato efluente, $\mathrm{g} / \mathrm{m}^{3}$

Em sequência, o procedimento adotado exige que se compare a capacidade de desnitrificação obtida $\left(\mathrm{NO}_{\mathrm{R}}\right)$ com a $\mathrm{NO}_{\text {carga }}$, e que se ajuste o $\mathrm{TRH}_{\text {anoxico }}$ se o valor de $\mathrm{NO}_{\mathrm{R}}$ for inadequado. A fração da biomassa ativa na zona anóxica $\left(\mathrm{X}_{\mathrm{b}, \text { anox }}\right)$ leva em conta o $\mathrm{r}_{\text {int }} \mathrm{e}$ pode ser encontrado pelo emprego da Equação (A.17) mostrada a seguir

$$
X_{b, a n o x}=\left(\frac{Q \theta_{x, a e r}}{V}\right)\left(\frac{Y\left(S-S_{e}\right)}{1+K_{e} \theta_{x, a e r}}\right)\left(\frac{r_{i n t}}{r_{\text {int }}+1}\right)
$$

Para determinar a razão alimento/micro-organismo (A/M) é necessário escolher o TRH anóxico, calculado pela Equação (A.18).

$$
A / M=\frac{Q S}{V_{\text {anox }} X_{b, \text { anox }}}
$$

Na qual:

$\mathrm{X}_{\mathrm{b}, \text { anox }}$; Biomassa ativa na zona anóxica, $\mathrm{g} / \mathrm{m}^{3}$

Para uma determinada capacidade de desnitrificação insuficiente para desnitrificar a carga de nitrato de entrada, o valor do Vanox tem de ser ajustado e o procedimento reiterado até surgir um valor para o Vanox que garanta a capacidade de desnitrificação suficiente.

A taxa de desnitrificação especifica (SDNR) baseada na taxa $\mathrm{A} / \mathrm{M}$ de $\mathrm{DQO}_{\mathrm{b}}$ pode ser encontrada empiricamente, por meio de interpolação na Figura A.1.
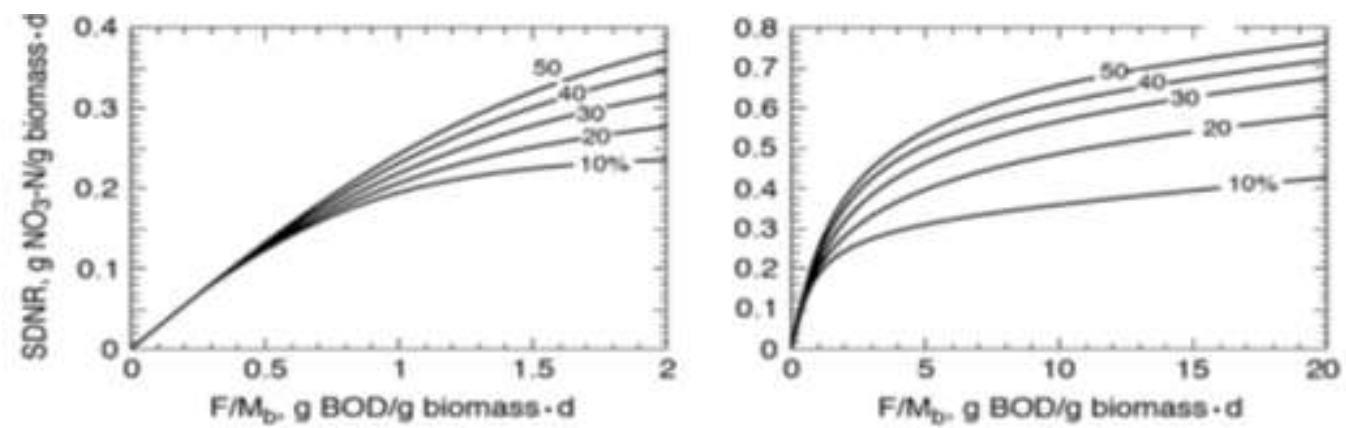

Figura A.1 - Curvas cinética de nitrificação (Judd, 2011) 
O controle do TRS em um sistema biológico aeróbio determina a taxa de degradação de substrato, a nitrificação, e a produção de lodos em excesso e a concentração da biomassa. O TRS é tipicamente baseado nos objetivos desejados para o tratamento. Contudo, algumas empresas têm indicado um requisito mínimo para o valor de TRS de 8 a 10 dias (WEF, 2012).

O TRS total do processo pode ser encontrado por meio da adição do TRS anóxico e aeróbio, e é controlado pelo descarte periódico dos sólidos (lodo) do processo, como mostrado na Equação (A.19).

$$
\theta_{x, \text { processo }}=\frac{V_{a e r} X_{a e r}+V_{a n o x} X_{a n o x}}{Q_{w} X_{a e r}}=\theta_{x, a e r}+\theta_{x, \text { anox }}
$$

Após seguir esses passos utilizando as equações mostradas, deve-se calcular a demanda de Oxigênio $\left(\mathrm{M}_{\mathrm{O}}\right)$ para o tratamento biológico pelo emprego da Equação (A.20).

$$
\begin{gathered}
M_{O}=Q\left(S-S_{e}\right)-1.42 M_{x, b i o}+4.33 Q N O_{x}-2.86 Q\left(N O_{x}-N O_{e}\right) \\
M_{O}=M_{m}+M_{b}
\end{gathered}
$$

Na qual:

$\mathrm{M}_{\mathrm{m}}$ : Oxigênio transferido pela aeração da membrana, $\mathrm{kg} / \mathrm{d}$

$\mathrm{M}_{\mathrm{b}}$ : Oxigênio necessário pela a aeração biológica, $\mathrm{kg} / \mathrm{d}$

3. Dimensionamento do Sistema de aeração

A terceira etapa do dimensionamento consiste em conceber o sistema de aeração, apresentado em seguida com detalhes.

Inicialmente, calcula-se o Fator de Correção dos sólidos suspensos $(\alpha)$ pela Equação (A.21), onde $x$ refere-se a bolhas finas ou grosseiras.

$$
\alpha=e^{-\omega_{x} X}
$$


Na qual:

$\omega:$ Fator para a bolha de aeração (adimensional)

$\mathrm{X}$ : Concentração do SSLM, g/m $\mathrm{m}^{3}$

Em seguida, deve-se determinar o fator de correção da temperatura $(\varphi)$ pela Equação (A.22).

$$
\varphi=1.024^{(T-20)}
$$

Na qual:

T: temperatura, ${ }^{\circ} \mathrm{C}$

Posteriormente, calcula-se a taxa de aeração na membrana $\left(\mathrm{Q}_{\mathrm{A}, \mathrm{m}}\right)$ pela Equação (A.23).

$$
Q_{A, m}=S A D_{m} A_{m}
$$

Na qual:

$\mathrm{SAD}_{\mathrm{m}}$ : Demanda de aeração específica em relação à área da membrana, $\mathrm{Nm} 3 /\left(\mathrm{m}^{2} \mathrm{~h}\right)$

$\mathrm{A}_{\mathrm{m}}$ : Área da membrana, $\mathrm{m}^{2}$

Após determinar a taxa necessária para aerar a membrana, encontra-se a transferência de $\mathrm{O}_{2}$ pela membrana (Mm), em $\mathrm{Kg} \mathrm{O}_{2} /$ d de acordo com a Equação (A.24).

$$
M_{m}=Q_{A, m} \rho_{A}\left(S O T E_{\text {grossa }} y_{\text {grossa }}\right) O_{A, m} \alpha \beta \varphi
$$

Na qual:

$\mathrm{Q}_{\mathrm{A}, \mathrm{m}}$ : vazão de aeração da membrana

$\rho_{\mathrm{A}}$ : Densidade do ar, $\mathrm{Kg} / \mathrm{m}^{3}$

SOTE ${ }_{\text {grossa: }}$ Padrão de eficiência de transferência de oxigênio, bolha de aeração grossa, $\% . \mathrm{m}^{-1}$

$\mathrm{Y}_{\text {grossa: }}$ Profundidade do aerador de bolha grossa, $\mathrm{m}$

$\mathrm{O}_{\mathrm{A}, \mathrm{m}}:$ Percentagem de massa do oxigénio no ar, $\%$

$\alpha$ : Relação da transferência de massa de oxigénio em suspensão com água pura (adimensional)

$\beta$ : Relação de transferência de massa de oxigénio em água salina com água pura (adimensional)

O fluxo de ar líquido para atender aos requisitos biológicos $\left(\mathrm{Q}_{\mathrm{A}, \mathrm{b}}\right), \mathrm{em} \mathrm{Nm}^{3} / \mathrm{h}$ é dado pela Equação (A.25). 


$$
Q_{A, b}=\frac{M_{O}-M_{m}}{\rho_{A}\left(S O T E_{\text {fina }} Y_{\text {fina }}\right) O_{A, m} \alpha \beta \varphi}
$$

Na qual:

MO: Oxigênio total necessário, $\mathrm{kg} / \mathrm{d}$

Mm: Oxigênio transferido pela aeração da membrana, $\mathrm{kg} / \mathrm{d}$

$\mathrm{SOTE}_{\text {fina: }}$ Padrão de eficiência de transferência de oxigênio, bolha de aeração fina, $\% / \mathrm{m}$

$\mathrm{Y}_{\text {fina }}$ : Profundidade do aerador de bolha fina, $\mathrm{m}$

$\alpha$ : Relação de transferência de massa de oxigênio no lodo com a água pura $\beta$ : Relação da transferência de massa de oxigénio dissolvido na operação com concentração de sólidos com a água pura.

4. Resultados do dimensionamento

Tabela A.1 - Dimensionamento do sistema de membrana.

\section{Dimensionamento da Membrana}

\section{Parâmetros}

Valores adotados / calculados

Q: vazão média $\left(\mathrm{m}^{3} / \mathrm{d}\right)$

Qmax: vazão de pico $\left(\mathrm{m}^{3} / \mathrm{d}\right)$

Q: vazão média ou fluxo de permeado $\left(\mathrm{m}^{3} / \mathrm{h}\right)$

Qmax: vazão de pico $\left(\mathrm{m}^{3} / \mathrm{h}\right)$

$\mathrm{J}_{\mathrm{net}} *(\mathrm{LMH})$

$\mathrm{J}_{\text {net,pico }}(\mathrm{LMH})$

Área da membrana $\left(\mathrm{m}^{2}\right)$

$\varphi$ : Densidade de empacotamento da membrana $\left(\mathrm{m}^{2} / \mathrm{m}^{3}\right)$

$\mathrm{Q}_{\mathrm{A}, \mathrm{M}}$ : vazão de aeração na membrana $\left(\mathrm{Nm}^{3} / \mathrm{h}\right)$

Volume Minimo $\left(\mathrm{m}^{3}\right)$

SADm: Demanda especifica de aeração em relação a área da membrana $\mathrm{Nm}^{3} /\left(\mathrm{m}^{2} \mathrm{~h}\right)$

SADp: Demanda especifica de aeração em relação ao vol. de permeado $\left(\mathrm{Nm}^{3} \mathrm{ar} / \mathrm{m}^{3}\right.$ permeado)

$\mathrm{X}_{\mathrm{m}}$ : Nível do licor misto de sólidos em suspensão e no tanque de membrana, $\left(\mathrm{g} / \mathrm{m}^{3}\right)$ 
Tabela A.2 - Dimensionamento do sistema biológico aeróbio

\begin{tabular}{|c|c|}
\hline \multicolumn{2}{|l|}{ Dimensionamento do Sistema Biológico } \\
\hline Parâmetros & lculados \\
\hline Q: vazão média $\left(\mathrm{m}^{3} / \mathrm{d}\right)$ & 0.8 \\
\hline $\mathrm{S}:$ DBO afluente $\left(\mathrm{g} / \mathrm{m}^{3}\right)$ & 229 \\
\hline SF: fator de segurança & 3 \\
\hline$\mu_{\mathrm{n}, \mathrm{m}}:$ Taxa de nitrificação máx de cresc específico, $\mathrm{gSSV} /(\mathrm{gSSV}$ d) & 0.75 \\
\hline $\mathrm{N}_{\mathrm{e}}$ : concentração de Amônia efluente, $\left(\mathrm{g} / \mathrm{m}^{3}\right)$ & 0.7 \\
\hline OD: oxigênio dissolvido $\left(\mathrm{g} / \mathrm{m}^{3}\right)$ & 2 \\
\hline $\mathrm{K}_{\mathrm{n}}$ : Meio coeficiente de saturação para a nitrificação & 0.74 \\
\hline $\mathrm{K}_{\mathrm{o}}$ : coeficiente de saturação para o oxigênio & 1 \\
\hline $\mathrm{K}_{\mathrm{e}, \mathrm{n}}$ : Coeficiente de decaimento endógeno Nitrificação, (gSSV/g SSV d) & 0.08 \\
\hline $\mathrm{K}_{\mathrm{s}}:$ coeficiente de saturação, $\left(\mathrm{gDQO} / \mathrm{m}^{3}\right)$ & 20 \\
\hline $\mathrm{K}_{\mathrm{e}}$ : Coeficiente de decaimento endógeno heterotrófico, gSSV/(g SSV d) & 0.12 \\
\hline$\mu_{\mathrm{m}}$ : Taxa máxima de crescimento específico heterotróficos, $(\mathrm{d}-1)$ & 6 \\
\hline $\mathrm{f}_{\mathrm{d}}$ : Fração da biomassa que permanece como detritos celulares, gSSV/g substrato & 0.15 \\
\hline Y: Coeficiente de produção heterotrófico, gSSV/(GDBO) & 0.4 \\
\hline $\mathrm{Y}_{\mathrm{N}}$ : Coeficiente de produção de nitrificação, gSSV/(GDBO) & 0.12 \\
\hline NTK: nitrogênio afluente, g.m $m^{-3}$ & 40 \\
\hline SST: Sólidos Suspensos Totais afluente $\left(\mathrm{g} / \mathrm{m}^{3}\right)$ & 151 \\
\hline SSV: Sólidos Suspensos Volateis afluente $\left(\mathrm{g} / \mathrm{m}^{3}\right)$ & 107 \\
\hline DQO: Demanda quimica de oxigenio $\left(\mathrm{g} / \mathrm{m}^{3}\right)$ & 481 \\
\hline $\mathrm{f}_{\mathrm{bp}}$ : Fração de DQO lentamente biodegradável & 0.5 \\
\hline $\mathrm{f}_{\mathrm{up}}$ : Fração de DQO particulada não biodegradável & 0.25 \\
\hline$r_{\mathrm{mr}}$ : Razão de recirculação da membrana & 4 \\
\hline$\mu$ n: taxa de crescimento especifica das bactérias nitrificantes $\left(\mathrm{d}^{-1}\right)$ & 0.16 \\
\hline TRS (Өx,aer) (dia) & 18.40 \\
\hline $\mathrm{Y}_{\text {obs }}$ : Coeficiente de produção observador (gSSV /gDBO) & 0.23 \\
\hline Px,het: Produção de biomassa (g/dia) & 41.65 \\
\hline Px,aut: Produção de biomassa (g/dia) & 0.00 \\
\hline $\mathrm{P}_{\mathrm{x}, \mathrm{bio}}:$ Produção de biomassa (KgSSV/dia) & 0.04 \\
\hline $\mathrm{S}_{\mathrm{e}}$ : DBO efluente, $\mathrm{g} \cdot \mathrm{m}^{-3}$ & 0.60 \\
\hline $\mathrm{NO}_{\mathrm{x}}$ : Concentração de NTK oxidável ao nitrato $\left(\mathrm{g} / \mathrm{m}^{3}\right)$ & 33.05 \\
\hline $\mathrm{P}_{\mathrm{X} \text {.TSS: }}$ Determinar a produção de biomassa total (Kg SST/dia) & 0.11 \\
\hline $\mathrm{SSV}_{\mathrm{NB}}$ : Sólidos suspensos voláteis não-biodegradáveis $\left(\mathrm{g} / \mathrm{m}^{3}\right)$ & 35.67 \\
\hline SSTi: Solidos suspensos totais inerte $\left(\mathrm{g} / \mathrm{m}^{3}\right)$ & 44.00 \\
\hline $\mathrm{DQO}_{\mathrm{bp}}$ : Demanda química de oxigênio particulada total $\left(\mathrm{g} / \mathrm{m}^{3}\right)$ & 240.50 \\
\hline $\mathrm{DQO}_{\mathrm{b}}$ : Demanda química de oxigênio particulada biodegradável $\left(\mathrm{g} / \mathrm{m}^{3}\right)$ & 360.75 \\
\hline $\mathrm{V}_{\text {aer: }}$ : volume do tanque aeróbio $\left(\mathrm{m}^{3}\right)$ & 0.26 \\
\hline $\mathrm{X}_{\text {aer }}$ : Concentração do SSLM na zona aeróbia $\left(\mathrm{g} / \mathrm{m}^{3}\right)$ & 8000 \\
\hline $\mathrm{X}_{\mathrm{m}}$ : Nível do licor misto de sólidos em suspensão e no tanque de membrana $\left(\mathrm{g} / \mathrm{m}^{3}\right)$ & 10000 \\
\hline $\mathrm{NO}_{\mathrm{e}}$ : Concentração de nitrato efluente $\left(\mathrm{g} / \mathrm{m}^{3}\right)$ & 10.00 \\
\hline Qw: Vazão de descarte de lodo $\left(\mathrm{m}^{3} / \mathrm{d}\right)$ & 0.014 \\
\hline $\mathrm{r}_{\text {int: }}$ taxa de recirculação interna & 2.31 \\
\hline TRH aerobio (h) & 7.78 \\
\hline
\end{tabular}


Tabela A.3 - Dimensionamento do sistema biológico anóxico

\begin{tabular}{|c|c|}
\hline \multicolumn{2}{|c|}{ Dimensionamento do Sistema Biológico } \\
\hline \multicolumn{2}{|l|}{ Zona anóxica } \\
\hline Parâmetros & Valores adotados /calculados \\
\hline $\mathrm{X}_{\text {anox }}$; Concentração de SSLM na zona anóxica, $\left(\mathrm{g} / \mathrm{m}^{3}\right)$ & 5579.63 \\
\hline Өx,anox: idade do lodo requerida para a nitrificação (d) & 9.73 \\
\hline $\mathrm{X}_{\mathrm{b}, \text { anox}} ;$ Biomassa ativa na zona anóxica, $\left(\mathrm{g} / \mathrm{m}^{3}\right)$ & 1127.71 \\
\hline $\mathrm{V}_{\text {anox }}:$ volume do tanque anóxico $\left(\mathrm{m}^{3}\right)$ & 0.197 \\
\hline $\mathrm{A} / \mathrm{M}_{\mathrm{b}}$ : relação alimento microorganismos & 0.83 \\
\hline SDNR: taxa de desnitrificação especifica, (gNo3-N/g SSLMV d) & 0.15 \\
\hline $\mathrm{NO}_{\mathrm{R}}$ : capacidade de desnitrificação $(\mathrm{Kg} / \mathrm{d})$ & 0.0339 \\
\hline $\mathrm{NO}_{\text {carga: }}$ Carga de nitrato na zona anoxica $(\mathrm{Kg} / \mathrm{d})$ & 0.0610 \\
\hline $\mathrm{M}_{\mathrm{O}}$ : Oxigênio requerido $\left(\mathrm{kg} \mathrm{O}_{2} /\right.$ dia $)$ & 0.24 \\
\hline TRH anoxico (h) & 5.90 \\
\hline Volume total do processo $\left(\mathrm{m}^{3}\right)$ & 0.456 \\
\hline Өx,processo- TRS do processo (dia) & 28.13 \\
\hline Fração do volume total do tanque anoxico & 0.43 \\
\hline TRH processo $(\mathrm{h})$ & 13.68 \\
\hline
\end{tabular}

Tabela A.4 - Dimensionamento do sistema de aeração.

\begin{tabular}{|c|c|c|}
\hline \multirow{2}{*}{ Dimensionamento do sistema de aeração } & Biológico & Membrana \\
\hline & Bolha fina & Bolha grossa \\
\hline$\alpha:$ Fator de correção dos sólidos suspensos $(\alpha)$ & 0.511 & 0.432 \\
\hline$\omega:$ Fator para a bolha de aeração & 0.084 & 0.084 \\
\hline X: Concentração do SSLM, (kg/L) & 8 & 10 \\
\hline$\varphi:$ Fator de correção da temperatura & 1.00 & 1.00 \\
\hline $\mathrm{T}:$ temperatura, ${ }^{\circ} \mathrm{C}$ & 20 & 20 \\
\hline $\mathrm{Q}_{\mathrm{A}, \mathrm{m}}:$ vazão de aeração da membrana $\left(\mathrm{Nm}^{3} / \mathrm{h}\right)$ & - & 1.091 \\
\hline \multicolumn{2}{|l|}{$\mathrm{SAD}_{\mathrm{m}}$ : Demanda de aeração específica em relação à área da } & 0.30 \\
\hline $\mathrm{A}_{\mathrm{m}}:$ Área da membrana, $\left(\mathrm{m}^{2}\right)$ & - & 3.636 \\
\hline $\mathrm{M}_{\mathrm{m}}$ : Transferência de $\mathrm{O}_{2}$ pela membrana, em Kg O $\mathrm{O}_{2} \cdot \mathrm{d}^{-1}$ & - & 0.14 \\
\hline$\rho_{\mathrm{A}}:$ Densidade do ar, $\left(\mathrm{Kg} / \mathrm{m}^{3}\right)$ & 1.2 & 1.2 \\
\hline SOTE$_{x}$ : Padrão de eficiência de transf. de $\mathrm{O}$, bolha de aeração, $\% \cdot \mathrm{m}^{-1}$ & 0.05 & 0.02 \\
\hline Yx: Profundidade do aerador de bolha grossa, $\mathrm{m}$ & 5 & 2.3 \\
\hline $\mathrm{O}_{\mathrm{A}, \mathrm{m}}:$ Percentagem de massa do oxigénio no ar,\% & 23.2 & 23.2 \\
\hline \multicolumn{3}{|l|}{$\beta$ : Correção de transferência de massa de $\mathrm{O}$ em água salina com água } \\
\hline $\mathrm{M}_{\mathrm{O}}$ : Oxigénio total necessário, $\mathrm{kg} / \mathrm{d}$ & 0.24 & - \\
\hline \multicolumn{3}{|l|}{$\mathrm{M}_{\mathrm{b}}$ : Oxigênio necessário pela aeração biológica, $\mathrm{kg} / \mathrm{d}$} \\
\hline $\begin{array}{l}\left(\mathrm{M}_{\mathrm{o}}-\mathrm{M}_{\mathrm{M}}\right) \\
\mathrm{O}_{\mathrm{b}} \text { : Fluxo de ar líquido para atender aos requisitos biológicos. }\end{array}$ & 0.11 & - \\
\hline $\begin{array}{l}\mathrm{Q}_{\mathrm{A}, \mathrm{b}}: \text { Fluxo de ar líquido para atender aos requisitos biológicos, } \\
\left(\mathrm{Nm}^{3} / \mathrm{h}\right)\end{array}$ & - & 0.032 \\
\hline t1: Temperatura de entrada do ar ${ }^{\circ} \mathrm{C}$ & \multicolumn{2}{|c|}{20} \\
\hline $\begin{array}{l}\text { P1: Pressão de entrada do ar flange de admissão do compressor } \\
\left(\mathrm{Kg} / \mathrm{cm}^{2} \text { ou bar }\right)\end{array}$ & \multicolumn{2}{|c|}{5000} \\
\hline Rh: umidade relativa do ar (\%) & \multicolumn{2}{|c|}{30} \\
\hline Pv: pressão parcial do vapor de água $\left(\mathrm{Kg} / \mathrm{cm}^{2}\right.$ ou bar) & \multicolumn{2}{|c|}{5} \\
\hline Conversão de $\mathrm{Nm}^{3} / \mathrm{h}=\mathrm{m}^{3} / \mathrm{h} .(\mathrm{Tp} / \mathrm{Tr}) .[\mathrm{Pr}-(\mathrm{Pv} \cdot \mathrm{Rh})] / \mathrm{Pp}$ & \multicolumn{2}{|c|}{4374.58} \\
\hline
\end{tabular}




\section{APÊNDICE B - LEVANTAMENTO DE CRITÉRIOS}

Tabela B.1 - Levantamento dos critérios encontrados na literatura

\begin{tabular}{|c|c|c|c|c|c|c|c|c|c|c|c|c|c|c|}
\hline $\mathrm{N}^{\mathrm{o}}$. & Critérios de avaliação & $\begin{array}{l}\text { Souza } \\
(1992)\end{array}$ & $\begin{array}{l}\text { Souza } \\
\text { et al. } \\
(2001) \\
\end{array}$ & $\begin{array}{l}\text { Carneiro } \\
\text { et al. } \\
(2001)\end{array}$ & $\begin{array}{l}\text { Brostel } \\
(2002)\end{array}$ & $\begin{array}{l}\text { Werner } \\
(2009)\end{array}$ & $\begin{array}{l}\text { Ganoulis } \\
(2011)\end{array}$ & $\begin{array}{l}\text { Sadr } \\
\text { et al. } \\
(2013) \\
\end{array}$ & $\begin{array}{l}\text { Tjandraatmadja } \\
\text { et al. }(2013)\end{array}$ & $\begin{array}{l}\text { Sadr } \\
\text { et al. } \\
(2015)\end{array}$ & $\begin{array}{l}\text { Ouyang } \\
\text { et al } \\
(2015)\end{array}$ & $\begin{array}{l}\text { Aydiner } \\
\text { et al. } \\
(2016)\end{array}$ & $\begin{array}{l}\text { Metcalf } \\
\text { e Eddy } \\
(2007)\end{array}$ & $\begin{array}{l}\text { Freq. } \\
\text { de } \\
\text { uso \% }\end{array}$ \\
\hline 1 & Custo de capital (ou implantação) & $\mathrm{x}$ & $\mathrm{x}$ & $\mathrm{x}$ & & $\mathrm{x}$ & $\mathrm{x}$ & $\mathrm{x}$ & $\mathrm{x}$ & $\mathrm{x}$ & $\mathrm{x}$ & & & 75 \\
\hline 2 & Custo de O\&M (despesas contínuas) & $\mathrm{x}$ & $\mathrm{x}$ & $\mathrm{x}$ & $\mathrm{x}$ & $\mathrm{x}$ & $\mathrm{x}$ & $\mathrm{x}$ & $\mathrm{x}$ & $\mathrm{x}$ & $\mathrm{x}$ & & $\mathrm{x}$ & 92 \\
\hline 3 & Consumo de energia & $\mathrm{x}$ & $\mathrm{x}$ & & $\mathrm{x}$ & & & & & $\mathrm{x}$ & & $\mathrm{x}$ & $\mathrm{x}$ & 50 \\
\hline 4 & Impacto Ambiental & $\mathrm{x}$ & $\mathrm{x}$ & $\mathrm{x}$ & $\mathrm{x}$ & & & & & $\mathrm{x}$ & & & & 42 \\
\hline 5 & $\begin{array}{l}\text { Aceitação da comunidade/chefe da } \\
\text { família }\end{array}$ & $\mathrm{x}$ & & $\mathrm{x}$ & & & & $\mathrm{x}$ & $\mathrm{x}$ & $\mathrm{x}$ & & & & 42 \\
\hline 6 & Adaptabilidade & & & & & & & & $\mathrm{x}$ & $\mathrm{x}$ & & & $\mathrm{x}$ & 25 \\
\hline 7 & Facilidade de construção e expansão & & $\mathrm{x}$ & & & & & & $\mathrm{x}$ & $\mathrm{x}$ & & & & 25 \\
\hline 8 & Demanda por área & $\mathrm{x}$ & $\mathrm{x}$ & $\mathrm{x}$ & & & & & & $\mathrm{x}$ & $\mathrm{x}$ & & $\mathrm{x}$ & 50 \\
\hline 9 & Nivel de complexidade & & & & & & & $\mathrm{x}$ & & $\mathrm{x}$ & & & $\mathrm{x}$ & 25 \\
\hline 10 & Confiabilidade & $\mathrm{x}$ & & $\mathrm{x}$ & $\mathrm{x}$ & $\mathrm{x}$ & & $\mathrm{x}$ & $\mathrm{x}$ & $\mathrm{x}$ & & & $\mathrm{x}$ & 67 \\
\hline 11 & Dificuldade de O\&M & $\mathrm{x}$ & & & & & & & & & & & & 8 \\
\hline 12 & $\begin{array}{l}\text { Produção de resíduos sólidos/mínimo de } \\
\text { resíduos/gestão de RS }\end{array}$ & & & & $\mathrm{x}$ & $\mathrm{x}$ & & & & & & & & 17 \\
\hline 13 & Dificuldade de cond.de resíduos sólidos & $\mathrm{x}$ & & & & & & & & & & & & 8 \\
\hline 14 & $\begin{array}{l}\text { Exigência de equipamento } \\
\text { importado/pacote completo }\end{array}$ & $\mathrm{x}$ & & & & $\mathrm{x}$ & & & & & & & & 17 \\
\hline 15 & Quantidade de pessoal para O\&M & $\mathrm{x}$ & & & & $\mathrm{x}$ & & & & & & & & 17 \\
\hline 16 & Aplicabilidade do processo & $\mathrm{x}$ & & & & & & & & & & & $\mathrm{x}$ & 17 \\
\hline 17 & Qualidade da agua residuária bruta & $\mathrm{x}$ & & & & & & & & & & & & 8 \\
\hline 18 & Fatores climáticos/efeitos sazonais & $\mathrm{x}$ & & & & & & & $\mathrm{x}$ & & $\mathrm{x}$ & & $\mathrm{x}$ & 33 \\
\hline 19 & Desempenho do processo & $\mathrm{x}$ & & & & & & & & & & & $\mathrm{x}$ & 17 \\
\hline 20 & Compatibilidade com outros processos & $\mathrm{x}$ & & & & & & & & & & & $\mathrm{x}$ & 17 \\
\hline 21 & Necessidade de pós-tratamento & $\mathrm{x}$ & & & & & & & & & & & & 8 \\
\hline 22 & Sustentabilidade financeira & $\mathrm{x}$ & & & & & & & & & & $\mathrm{x}$ & & 17 \\
\hline 23 & Dificuldade de implantação & $\mathrm{x}$ & & & & & & & & & & & & 8 \\
\hline 24 & Quantidade de resíduos (lodo) produzidos & $\mathrm{x}$ & $\mathrm{x}$ & $\mathrm{x}$ & & & & & $\mathrm{x}$ & & & $\mathrm{x}$ & $\mathrm{x}$ & 50 \\
\hline 25 & Manejo do lodo & $\mathrm{x}$ & & & & & & & & & & & $\mathrm{x}$ & 17 \\
\hline 26 & Condições locais & $\mathrm{x}$ & & & & & & & & & & & & 8 \\
\hline 27 & Regulamentações/legislação ambiental & $\mathrm{x}$ & & & $\mathrm{x}$ & $\mathrm{x}$ & & & $\mathrm{x}$ & & & & $\mathrm{x}$ & 42 \\
\hline
\end{tabular}


Tabela B.2 - Levantamento dos critérios encontrados na literatura (continuação)

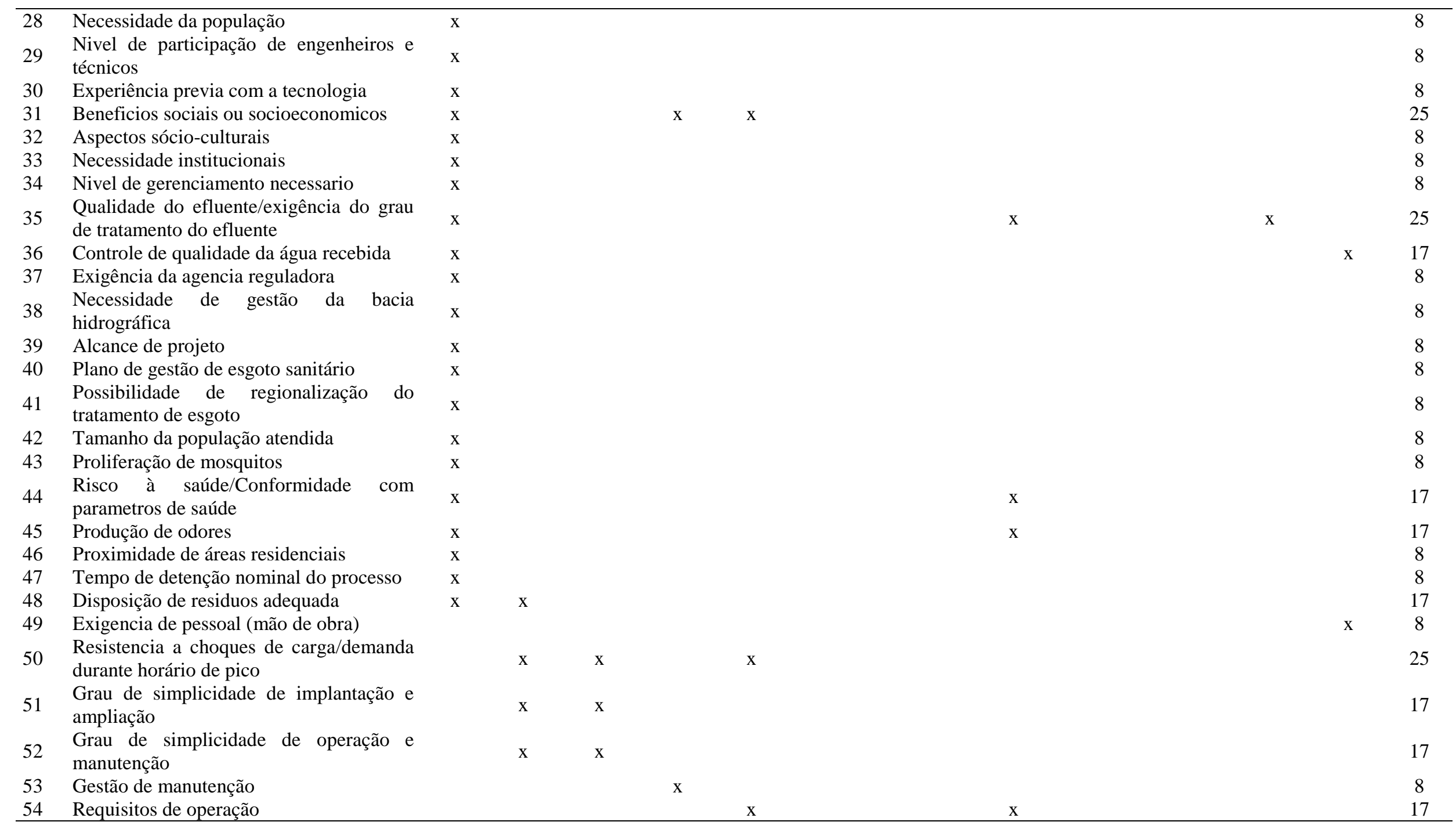


Tabela B.3 - Levantamento dos critérios encontrados na literatura (continuação)

\begin{tabular}{|c|c|c|c|c|c|c|c|c|}
\hline 55 & $\begin{array}{l}\text { Seguro para operar/segurança e saúde no } \\
\text { trabalho }\end{array}$ & & $\mathrm{x}$ & $\mathrm{x}$ & & & & 17 \\
\hline 56 & Eficiência ambiental & & & $\mathrm{x}$ & & & & 8 \\
\hline 57 & $\begin{array}{l}\text { Sistema de monitoramento e controle } \\
\text { operacional (remoto) }\end{array}$ & & $\mathrm{x}$ & & $\mathrm{x}$ & & & 17 \\
\hline 58 & Eficiência do processo & & $\mathrm{x}$ & & & & & 8 \\
\hline 59 & Especificidade da ETE & & $\mathrm{x}$ & & & & & 8 \\
\hline 60 & $\begin{array}{l}\text { Gestão de recursos humanos/Exigência } \\
\text { em capacitação de recursos humanos }\end{array}$ & & $\mathrm{x}$ & & & & & 8 \\
\hline 61 & Gestão de informação & & $\mathrm{x}$ & & & & & 8 \\
\hline 62 & Gestão organizacional & & $\mathrm{x}$ & & & & & 8 \\
\hline 63 & Viabilidade financeira & & $\mathrm{x}$ & & & & & 8 \\
\hline 64 & Gestão ambiental e sustentável & & $\mathrm{x}$ & & & & & 8 \\
\hline 65 & Participação social & & $\mathrm{x}$ & & & & & 8 \\
\hline 66 & Efic.na remoção de matéria orgânica & $\mathrm{x}$ & & & & & & 8 \\
\hline 67 & $\begin{array}{l}\text { Efic. na remoção de nitrogênio/N no } \\
\text { efluente }\end{array}$ & $\mathrm{x}$ & & & $\mathrm{x}$ & $\mathrm{x}$ & & 25 \\
\hline 68 & Efic. na remoção de fósforo & $\mathrm{x}$ & & & & $\mathrm{x}$ & & 17 \\
\hline 69 & $\begin{array}{l}\text { Efic. na remoção de organismos } \\
\text { patogênicos }\end{array}$ & $\mathrm{x}$ & & & & $\mathrm{x}$ & & 17 \\
\hline 70 & Faixa de vazões aplicaveis & & & & & & $\mathrm{x}$ & 8 \\
\hline 71 & Variação de vazões aplicaveis & & & & & & $\mathrm{x}$ & 8 \\
\hline 72 & $\begin{array}{l}\text { Constituintes inibitórios que não são } \\
\text { afetados }\end{array}$ & & & & & & $\mathrm{x}$ & 8 \\
\hline 73 & $\begin{array}{l}\text { Dimensionamento com base na cinética } \\
\text { de reação/carga de massa }\end{array}$ & & & & & & $\mathrm{x}$ & 8 \\
\hline 74 & $\begin{array}{l}\text { Dimensionamento com base nas taxas de } \\
\text { transferências de massa/ carga de massa }\end{array}$ & & & & & & $\mathrm{x}$ & 8 \\
\hline 75 & Requerimentos químicos & & & & & & $\mathrm{x}$ & 8 \\
\hline 76 & $\begin{array}{l}\text { Requerimento de outros recursos/ } \\
\text { requisitos externo }\end{array}$ & & & $\mathrm{x}$ & & $\mathrm{x}$ & $\mathrm{x}$ & 25 \\
\hline 77 & $\begin{array}{l}\text { Necessidade } \\
\text { complementares }\end{array}$ & & & & & & $\mathrm{X}$ & 8 \\
\hline 78 & Análise de ciclo de vida & & & & & & $\mathrm{x}$ & 8 \\
\hline 79 & Uso líquido da água & & & & $\mathrm{x}$ & & & 8 \\
\hline
\end{tabular}


Tabela B.4 - Levantamento dos critérios encontrados na literatura (continuação)

\begin{tabular}{|c|c|c|c|c|c|c|c|c|c|c|c|c|c|c|}
\hline 80 & Volume de água residuária produzida & & & & & & & & $\mathrm{x}$ & & & & & 8 \\
\hline 81 & Eutrofização por fósforo & & & & & & & & $\mathrm{x}$ & & & & & 8 \\
\hline 82 & gases de efeito estufa produzido & & & & & & & & $\mathrm{x}$ & & & & & 8 \\
\hline 83 & Oxidação fotoquímica & & & & & & & & $\mathrm{x}$ & & & & & 8 \\
\hline 84 & Substancias cancerigenas & & & & & & & & $\mathrm{x}$ & & & & & 8 \\
\hline 85 & Combustiveis fósseis & & & & & & & & $\mathrm{x}$ & & & & & 8 \\
\hline 86 & $\begin{array}{l}\text { Uso de recursos minerais e combustiveis } \\
\text { fosseis/Consumo de recursos naturais }\end{array}$ & & & & & & & & $\mathrm{x}$ & & & $\mathrm{x}$ & & 17 \\
\hline 87 & Capacidade de tratamento & & & & & & & & $\mathrm{x}$ & & & & & 8 \\
\hline 88 & Ruído & & & & & & & & $\mathrm{x}$ & & & & & 8 \\
\hline 89 & Interferência nas atividades domésticas & & & & & & & & $\mathrm{x}$ & & & & & 8 \\
\hline 90 & Desempenho de recuperação de água & & & & & & & & & & & $\mathrm{x}$ & & 8 \\
\hline 91 & $\begin{array}{l}\text { Desempenho de recuperação do soro do } \\
\text { leite }\end{array}$ & & & & & & & & & & & $\mathrm{x}$ & & 8 \\
\hline 92 & Acessibilidade inicial & & & & & & & & & & & $\mathrm{x}$ & & 8 \\
\hline 93 & Beneficio do investimento & & & & & & & & & & & $\mathrm{x}$ & & 8 \\
\hline 94 & Retorno do investimento & & & & & & & & & & & $\mathrm{x}$ & & 8 \\
\hline 95 & Economia de água & & & & & & & & & & & $\mathrm{x}$ & & 8 \\
\hline 96 & Variação da qualidade da DBO & & & & & & & & & & $\mathrm{x}$ & & & 8 \\
\hline 97 & Variação da qualidade da DQO & & & & & & & & & & $\mathrm{x}$ & & & 8 \\
\hline 98 & Variação da qualidade dos SS & & & & & & & & & & $\mathrm{x}$ & & & 8 \\
\hline 99 & Risco hidrológico & & & & & & & & & & $\mathrm{x}$ & & & 8 \\
\hline 100 & Manutenção & & & & & & & & & & $\mathrm{x}$ & & & 8 \\
\hline 101 & Disponibilidade de espaço aberto & & & & & & & & & & $\mathrm{x}$ & & & 8 \\
\hline 102 & Custo do terreno & & & & & & $\mathrm{x}$ & & & & & & & 8 \\
\hline 103 & Recreação & & & & & & $\mathrm{x}$ & & & & & & & 8 \\
\hline 104 & Pescaria & & & & & & $\mathrm{x}$ & & & & & & & 8 \\
\hline 105 & Natação & & & & & & $\mathrm{x}$ & & & & & & & 8 \\
\hline 106 & Saúde humana & & & & & & $\mathrm{x}$ & & & & & & & 8 \\
\hline 107 & Planta resposta & & & & & & $\mathrm{x}$ & & & & & & & 8 \\
\hline 108 & Utilização preferencial de materiais locais & & $\mathrm{x}$ & & & & & & & & & & & 8 \\
\hline 109 & Nível de rejeição do público & & $\mathrm{x}$ & & & & & & & & & & & 8 \\
\hline 110 & Conf. no fornecimento de energia & & $\mathrm{x}$ & & & & & & & & & & & 8 \\
\hline \multicolumn{2}{|c|}{ Quantidade total de critérios } & 44 & 18 & 10 & 18 & 13 & 8 & 5 & 26 & 10 & 14 & 11 & 24 & \\
\hline
\end{tabular}

